\title{
Adolescent sexual health communication with parents and peers and the associated parenting practices in Dar es Salaam Tanzania
}

Citation for published version (APA):

Kajula, L. J. (2017). Adolescent sexual health communication with parents and peers and the associated parenting practices in Dar es Salaam Tanzania: parent-adolescent dynamics in times of HIVIAIDS. [Doctoral Thesis, Maastricht University]. Datawyse / Universitaire Pers Maastricht. https://doi.org/10.26481/dis.20171130lk

Document status and date:

Published: 01/01/2017

DOI:

10.26481/dis.20171130lk

Document Version:

Publisher's PDF, also known as Version of record

Please check the document version of this publication:

- A submitted manuscript is the version of the article upon submission and before peer-review. There can be important differences between the submitted version and the official published version of record.

People interested in the research are advised to contact the author for the final version of the publication, or visit the DOI to the publisher's website.

- The final author version and the galley proof are versions of the publication after peer review.

- The final published version features the final layout of the paper including the volume, issue and page numbers.

Link to publication

\footnotetext{
General rights rights.

- You may freely distribute the URL identifying the publication in the public portal. please follow below link for the End User Agreement:

www.umlib.nl/taverne-license

Take down policy

If you believe that this document breaches copyright please contact us at:

repository@maastrichtuniversity.nl

providing details and we will investigate your claim.
}

Copyright and moral rights for the publications made accessible in the public portal are retained by the authors and/or other copyright owners and it is a condition of accessing publications that users recognise and abide by the legal requirements associated with these

- Users may download and print one copy of any publication from the public portal for the purpose of private study or research.

- You may not further distribute the material or use it for any profit-making activity or commercial gain

If the publication is distributed under the terms of Article $25 \mathrm{fa}$ of the Dutch Copyright Act, indicated by the "Taverne" license above, 


\section{Adolescent Sexual Health}

Communication with Parents and Peers

and the Associated Parenting Practices

in Dar es Salaam, Tanzania

Parent-Adolescent Dynamics in Times of HIV/AIDS

Lusajo Kajula

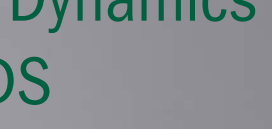




\title{
Adolescent Sexual Health Communication with Parents and Peers and the Associated Parenting Practices in Dar es Salaam, Tanzania
}

\author{
Parent-Adolescent Dynamics in Times of HIV/AIDS
}

Dissertation

\begin{abstract}
To obtain the degree of
Doctor At the Maastricht Univerisity

Under authority of the Rector Magnificus, Prof. dr. Rianne M. Letschert.

In accordance with the decision of the Board of Deans

To be defended in public on $30^{\text {th }}$ November, 2017 at 16:00 hours
\end{abstract}

By

Lusajo Joel Kajula 
Supervisor:

Prof. dr. H. de Vries

Co-Supervisor:

Prof. dr. S. F. Kaaya

Assessment Committee:

Prof. dr. B. van der Borne (Chairman)

Dr. R. Crutzen

Prof. dr. G. J. Kok

Prof. dr. L. Lechner

Dr. T. Vollink 


\section{Acknowledgment}

I would like to extend my utmost gratitude to the European Union which provided financial support for the PREPARE study (7th Framework Program, HEALTH 2009, Contract Number 241945). I would also like to extend my appreciation to the Tanzania Committee for Science and Technology (COSTECH) for financial support to me.

To my supervisor Prof. Hein de Vries, Professor in health communication at the department of health promotion at Maastricht University - the Netherlands - I extend much appreciation for support and guidance throughout this process. I am also immensely thankful to my co-supervisor Prof. Sylvia Florence Kaaya, Professor in Psychiatry at the department of Psychiatry and Mental Health, Muhimbili University of Health and Allied Sciences (MUHAS) Tanzania, for the supervision and continuous support. Thank you for making this journey easier.

There are not enough words of appreciation for thousands of participants who gave their time valuable to sit through interviews that enabled collection of data for this study. Your time and contributions are appreciated.

I am also grateful of the support from my co-authors who provided valuable input and broadened my knowledge - Dr. Sander Matthijs Eggers, Dr. Elia Mmbaga, Prof. Leif Aarø, and Prof. Nancy Darling, thank you!

The amazing support I got from the retired MUHAS VC. Prof. E.E Kaaya and the current MUHAS VC Prof. Appolinary Kamuhabwa cannot be explained. You were a light in a dark tunnel. Ahsanteni sana. I am also much grateful to the former and current Heads of department at the department of Psychiatry and Mental Health - Drs. Khalifa Mrumbi and Samuel Likindikoki for providing me with protected time when I needed it. My mentor, colleague and sister Jessie Mbwambo, you are always appreciated.

My visits to the beautiful city of Maastricht were made more enjoyable with friendship and warmth from different individuals including Patricia von Schenckendorff, Leon Kolenburg, Marja Vissers, Dr. Joyce Wetzels, Dr. Aziza Mukhayer and Mrs. Monique from Gronsveld, Maastricht who was like a second mother to me.

To my parents Judith and Joel Kajula; thank you for your unconditional love, I love you both very much. I am blessed with loving and supportive siblings; my sister Mrs. Hobokela Jackson and my brothers Imani and Kwijula Kajula, thank you for supporting my family when I was away.

To my beloved children Upendo Sophia and Amani Ibrahim, poleni for missing me when I had to be away to work on this endeavor, I love you so much. My beloved husband Khalid Maonga, you are my continuous gift in life. You are the best husband I could ever 
have wished for; I can never thank you enough. Indeed, you have affirmed my belief that love is a verb.

All the glory that may come as a result of this work goes to the Almighty God. 


\section{Table of Contents}

Acknowledgment

$\begin{array}{llr}\text { Chapter ONE Introduction } & 9\end{array}$

$\begin{array}{ll}\text { Abstract } & 10\end{array}$

Background 12

$\begin{array}{ll}\text { Project overview } & 19\end{array}$

$\begin{array}{ll}\text { Outline of the dissertation } & 20\end{array}$

References 23

Chapter TWO A review of studies of parent-child communication about sexuality and HIV/AIDS in sub-Saharan Africa 27

Abstract 28

$\begin{array}{lr}\text { Introduction } & 29\end{array}$

Methods 30

Results $\quad 31$

Discussion 43

$\begin{array}{ll}\text { Conclusions } & 47\end{array}$

References $\quad 58$

Chapter THREE Dynamics of parent-adolescent communication on sexual health and HIV/AIDS in Tanzania 61

Abstract $\quad 62$

Introduction $\quad 63$

Methods $\quad 63$

Results $\quad 65$

$\begin{array}{ll}\text { Discussion } & 68\end{array}$

$\begin{array}{ll}\text { Limitations } & 70\end{array}$

$\begin{array}{ll}\text { Conclusions } & 70\end{array}$

$\begin{array}{ll}\text { References } & 71\end{array}$

Chapter FOUR Parenting practices and styles associated with adolescent sexual health in Dar es Salaam, Tanzania 73

$\begin{array}{ll}\text { Abstract } & 74\end{array}$

$\begin{array}{ll}\text { Introduction } & 75\end{array}$

$\begin{array}{ll}\text { Methods } & 75\end{array}$

$\begin{array}{ll}\text { Results } & 77\end{array}$

Discussion $\quad 81$

Limitations $\quad 81$ 
Conclusions

References

Chapter FIVE Factors Associated with Adolescent Sexual Health Communication with Parents and Peers in Dar es Salaam, Tanzania 85

Abstract

Introduction

Methods

Measures

Results

Discussion

Limitations of the study

Key messages

References

Chapter SIX Sexual Health Communication Among Adolescents, Peers and Parents in Dar es Salaam Tanzania:

A Cluster Randomized Controlled Trial 99

Abstract

Background

Methodology

Results

Discussion

Conclusion

References

General discussion

Summary

Valorisation addendum

Curriculum Vitae

List of publications 
Chapter

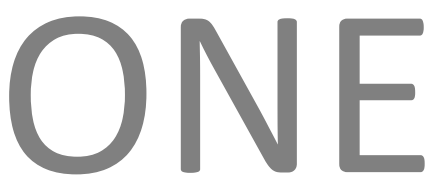

Introduction 


\section{ABSTRACT}

Tanzanian adolescents, like their peers across sub-Saharan Africa, face a grim adulthood due to their vulnerability to HIV/AIDS, which is worsened by poor preventive strategies, including irregular and incorrect condom use as well as early onset of sexual activity. Parents hold an immensely important position in influencing adolescent sexual health choices. Parenting practices, including sexual health communication are associated with positive health outcomes for adolescents including a delay in sexual debut, increased condom use and less concurrent sexual partners. An in-depth and extensive exploration of the parent-adolescent relationship, especially as it relates to adolescent sexual decision-making is important, specifically at this moment in time when the high proportion of new HIV infections, for this age group in the Tanzanian context is a cause for concern. Monitoring, preventive actions and punishment for misconduct are commonly reported as parental responses to the challenges they face in sexual health socialization of adolescent children. Fear-filled, ambiguous messages from parents decrease parentadolescent connectedness. Adolescents are more likely to engage more in sexual health communication with peers than parents. There is paucity of research on parenting practices associated with sexual health in the Tanzanian context. This thesis aims to fill this gap by providing new knowledge for preventive programs targeting adolescents to increase their effectiveness by including parenting strategies.

The motivation to carry out this study was a personal journey for me that started in my teens. I am a second born of four, with my sister as the eldest by four years. When I reached puberty in the late 1980s, the human immunodeficiency virus (HIV) and acquired immunodeficiency syndrome (AIDS) were just starting to be known. There was such a shroud of mystery surrounding HIV/AIDS. It was considered to be a highly infectious disease, and in Tanzania it was nicknamed with so many slang and Swahili words (such as: "Juliana" [the label on imported clothes fashionable in the late 1980's among prosperous businessmen and women, some of whom acquired HIV], "miwaya" [live electric wires] that mostly implied immediate death after being infected with HIV and "Kufa kilo mbili" [dying weighing two kilograms] which was associated with the extreme weight loss that was a result of AIDS).

On reaching puberty, neither my parents nor at school was I ever informed prior or after about it and the associated physical or emotional changes. All that I knew about puberty was from my school friends, who also seemed not to be very sure about it. Although my mother was a teacher and quite gentle, I did not even think about asking her - we just never had such intimate conversations. Also, while our father constantly had "meetings" with us, the topics we discussed were such as "Charity begins at home", which focused on being kind to others, on other occasions about the importance of putting school above romantic associations etc. I do not remember any discussions about early pregnancy, sexually transmitted infections (STIs) or HIV. 
In my late teens, when the HIV prevalence was increasing and HIV/AIDS was highly stigmatised, much of the formal public health messages were fear invoking such as "UKIMWI UNAUA!" (AIDS KILLS!). Preventive messages such as condom use were seldom mentioned. I first saw a condom when I was in my early twenties in the mid-90s. By then, many had died from HIV/AIDS in Tanzania and across much of sub-Saharan Africa (SSA). With increased awareness when I was in college, thoughts about the risk I was in regarding HIV infection prompted me to wonder about adolescents' vulnerability to early pregnancy, STIs, and specifically HIV. I wondered about what parental roles were for adolescent's sexual health socialisation, and reasons that may make parents and specifically African parents including mine, reluctant to communicate to their adolescent children about sexual health. Seeking better understanding on these reasons and wanting to help parents and adolescents, was what guided me in the choice of my MPhil thesis and also for my PhD. 


\section{BACKGROUND}

"If I had sex and got pregnant everything will be destroyed. My parents will ask me "Where did you get this pregnancy?" They will insult me and chase me away. My father chased my sister who got pregnant ..." Girl, 14 years old

\section{Adolescent sexual health in Tanzania}

In sub-Saharan Africa, adolescent sexual health statistics provide reason for serious concern. More than half of those newly infected with HIV/AIDS worldwide are currently between 15-24 years old, a significant number being resident in SSA (UNAIDS, 2010). Adolescents' vulnerability to HIV/AIDS increases due to a number of factors such as their scant knowledge of prevention strategies for HIV infection, irregular and incorrect condom use, as well as early onset of sexual activity. While 5.1\% of Tanzanians aged 2449 years are living with HIV, the prevalence for those aged 15-24 years is almost half that of all those that are infected at 2\% (TACAIDS, 2013). Based on a survey carried out in 2010, about 20\% of the population is aged $15-24$ years, while new HIV infections facing this demographic group is almost three quarters of all new infections in the country (National Bureau of Statistics, 2013). According to TACAIDS (2013), 10\% of boys and 9\% of girls have had sex before age 15 in Tanzania.

Studies on adolescent HIV preventive programmes have proved to be more effective if they targeted sexually inexperienced youth (Ross, Dick \& Ferguson, 2010; MatickaTyndale, Wildish \& Gichuru, 2007). In Tanzania adults (both parents and teachers) are reported to be reluctant to divulge sexual health information. Sub-Saharan Africa and Tanzania in particular, has historically held a taboo regarding adolescent sexuality discussion with parents (Mbugua, 2007; Amuyunzu-Nyamongo, Biddlecom, Ouedraogo \&Woog, 2005). Formerly in Tanzania, extended family members such as aunts and grandparents had major roles in cross-generation sexual socialisation, which mainly focused on marital roles and did not focus on sexual health (Fuglesang, 1997). Increase in urbanisation in Tanzania has created a context for some families where meetings with extended family are sporadic, hindering the previously held traditions related to cross-generation sexual socialisation (Fuglesang, 1997). Furthermore, adolescents spend more time more time in school than in the past, and marry at a later age, lengthening the period of exposure to sexual health risks (Garenne, 2004; Mensch, Singh \& Casterline, 2005). As such, parents have a bigger role to play in adolescent sexual health socialisation for young adolescents so as to reduce early sex initiation. Information about the roles of parents and peers concerning sexual education, however, is scarce in Tanzania and this absence constituted an important reason for conducting studies in this thesis to describe the influence of both parents and peers on sexual health education among Tanzanian adolescents. 
Peer influence studies have shown that peer relationships can lead to increased engagement in risky behaviours (Zimring, 1998; Brown \& Larson, 2009) including a variety of problem behaviours such as unprotected sex and illicit substance use (which also increases risks of unprotected sex) (Arnett, 1992). It has previously been established that adolescents more than adults are likely to engage in risky behaviours (Arnett, 1992). Further, adolescents are also reported to make decisions under conditions of emotional arousal while being easily influenced by peers that are also prone to risk taking behaviour (Gardner \& Steinberg, 2005). As forty per cent of new HIV infections in Tanzania occur among 16-24-year-olds (ICF International, 2013), studying the role of peer influence on adolescent sexual behaviour in Tanzania is important. This thesis hopes to inform development of parenting strategies and skill building in resisting peer influence with the aim of strengthening adolescent sexual health.

\section{Tanzania: An epidemiological profile}

The studies included in this thesis were carried out in the commercial capital of Tanzania, Dar es Salaam. The United Republic of Tanzania is located in East Africa and was formed by the unification of Tanganyika and Zanzibar. It covers the total area of 945, 234 square kilometres of which 886, 040 is land. Tanzania is known for its vast wilderness areas that include the plains of Serengeti that is populated by the "big five" game (Elephant, Lion, Leopard, Buffalo, Rhino), and Kilimanjaro, home to Africa's highest mountain. The country borders the Indian Ocean to the east, Kenya and Uganda to the north, Rwanda, Burundi and the Democratic Republic of Congo to the west; while Zambia and Malawi are to the south-west of Tanzania and Mozambique is to the south.

According to the 2012 Population and Housing Census results, Tanzania has a population of 44,928,923 of which 43,625,354 reside in the Tanzania Mainland and 1,303,569 in Zanzibar (National Bureau of Statistics, 2013). Tanzania is populated by 99\% native Africans, consisting of more than 130 tribes. Asians, European and Arab natives make the remaining $1 \%$. The official languages in Tanzania are Swahili and English; English being the official primary language of commerce, administration and higher education.

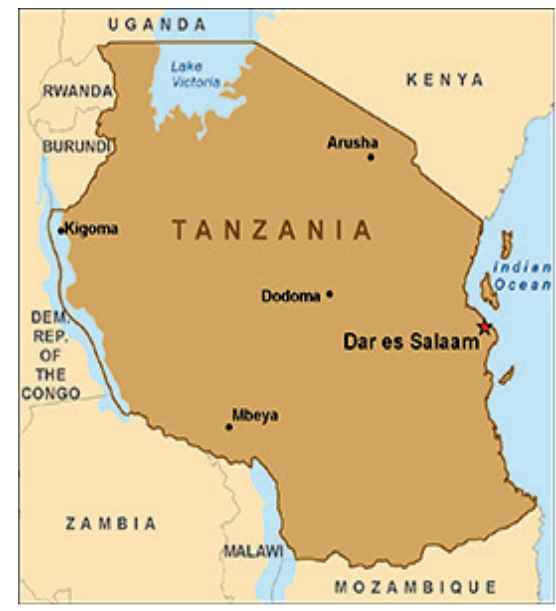

Figure 1: Map of Tanzania 


\section{Parental influences}

Parental influences on health behaviour of adolescents, including sexual behaviour have been documented widely (Viner et al., 2012; Wight, Williamson \& Henderson, 2006; Borawski, levers-Landis, Lovegreen \& Trapl, 2003; Romer et al., 1999). Parent-child practices including sexual health communication are suggested to be strong determinants of adolescent sexual decision-making and choices (Blake et al., 2001). Findings suggest parenting is important in influencing adolescent sexual health norms (Miller, Forehand \& Kotchick, 1999; Hoque \& Ghuman, 2012). Studies from the western countries have documented several parenting behaviours that predict positive sexual health outcomes for adolescents including sexual health communication and parental monitoring (Barber, Stolz \& Olsen, 2005; Wight, Williamson \& Henderson, 2005; Borawski, levers-Landis, Lovegreen \& Trapl, 2003). Research in Africa has also shown that sexual health communication with parents and other family members contribute to healthy adolescent sexual practices (Bastien, Kajula \& Muhwezi, 2011; Adu-Mireku, 2003; Maticka-Tyndale \& Tenkorang 2010). Evidence suggests that open sexual health communication with parents, especially mothers, is likely to reduce underage pregnancy for girls (Biddlecom, Awusabo-Asare \& Bankole 2009). The relationship between parenting practices such as sexual health communication on adolescent development is important in understanding and improving adolescent sexual and reproductive health. Insights into different parenting processes during adolescence may be beneficial for prevention programs working to improve adolescent sexual health.

Research analysing how parents communicate about sexual health with their children in Tanzania is lacking, whereas this knowledge is needed to understand the role of parents on adolescent sexual health socialisation and also which actions may be needed to further improve parental sexual communications with their children. Moreover, HIV prevention efforts will be more effective among adolescents when parents and the larger community are involved (Kawai et al., 2008; Namisi et al., 2015). This lack of knowledge constituted the rationale for conducting the studies outlined in Chapters 2 and 3.

\section{Peer influence on adolescent sexual behaviour}

Adolescent sexual decision-making in western as well as in African countries are influenced by peer behaviours and norms (Andrews, Tildesley, Hops \& Li, 2002; Li, Barrera, Hops \& Fisher, 2002). In a review of studies, WHO (2004) reported that having friends who were sexually active was considered a risk factor for sexual debut for adolescent boys and girls in all ten (10) studies that were reviewed while having discussed sexual reproductive health issues with peers was considered a risk factor for sexual debut in two out of three studies. 
In Tanzania, several studies have described how young people communicate with their peers about sex (Dilger, 2003; Mmbaga, 2012). Youth in Tanzania are also reported to be adapting sexual behaviours such as concurrency and condom use from peers (Yamanis, Fisher, Moody \& Kajula, 2015; Rweyemamu \& Fuglesang, 2008; Sommer, Likindikoki \& Kaaya, 2015). Boer and Mashamba in a study conducted in South Africa (2007) reported that subjective norms were the most predictive constructs for intention to use a condom for adolescents. Further, studies have previously reported on the role of peer norms as sometimes increasing the possibility for adolescent risky behaviour (Gardner \& Steinberg, 2005) or protective as when peers encourage condom use (Sheeran, Abraham \& Orbel, 1999; Dilorio et al., 2001). In another study in South Africa, adolescents reported had mixed views about peer influence on condom use when some suggested that their lack of condom use was partly due to peer influence and others reported that they were able to challenge negative peer influence (MacPhail \& Campbell, 2001). However, not much is known about peer sexual health communication compared to parent-adolescent sexual health communication and associated parenting practices in Tanzania. Based on the likely risk factors associated with peer influence on adolescent sexual health, findings from this thesis will inform appropriate peer and parenting interventions.

\section{Theoretical frameworks}

Early studies on the HIV pandemic mostly focused on individualistic transmission prevention approaches based on theoretical frameworks such as the Health Belief Model and the Social Learning Theory (Aggleton, 1996). The assumption was that if young people could only develop appropriate knowledge and skills, they would change their behaviour and adopt healthier sexual practices. Such approaches are currently criticised for failing to take into account contextual, and other proximal factors including parenting practices that may influence young people's decision-making, choices, and behaviours concerning sexual health issues (Rivers \& Aggleton, 1999). To better understand adolescent sexual health communication with parents and peers, the current dissertation combines perspectives from parenting constructs with the Integrated Model for Motivational and Behavioural Change (the I-Change Model), as this model addresses not only proximal but also more distal factors related to - for instance - social factors, such as parenting styles and practices.

The I-Change Model that originated from the Attitude-Social Influence Self-efficacy model resulted from the Theory of Reasoned Action -Ajzen \& Fishbein, 1988). These Social Learning Theories, have however been seen to focus on individual level factors explaining behaviour, with less consideration on the interactive relationship of behaviour in its social, cultural, and economic dimensions (Aggleton, 1996). The I-Change Model utilises traditional health behaviour theories, which emphasise the role of behavioural intentions (Fishbein \& Ajzen, 1977; Prochaska, DiClemente, Norcross, 1992; Ban- 
dura, 1986; Fishbein \& Ajzen, 2011). These traditional theories work on the assumption that intention is the most proximal determinant of behaviour and that changing intentions is vital to enable desired behaviours to occur (Armitage \& Conner, 2000). As such, a person's motivation or intention to achieve a particular behaviour determines their behavioural outcomes. Ranges of actions are suggested to constitute intentions; from not contemplating behaviour change to contemplation and eventually to change of behaviour. de Vries, Mesters, Van de Steeg \& Honing, (2005) suggest that a person's motivation is determined by attitudes, social influences and self-efficacy. Based on this study, sexual health communication can be predicted based on motivation factors or cognitions including attitude (pros and cons of sexual health communication), perceived social influences on sexual health communication (peer norms, behaviour and influence) as well as self-efficacy expectations (personal estimations of ability to engage in sexual health communication).

According to the I-Change Model, however, behavior cannot only be explained by these proximal variables, as the latter are determined by preceding factors and information factors. Distal or predisposing variables (the social, cultural and economic variables) are also important in adolescent sexual health communication with parents and peers (van de Wulp, Hoving \& de Vries, 2013). Such predisposing factors include parenting practices as they relate to sexual health communication (Darling \& Steinberg, 1993). Parenting practices such as support, monitoring and communication are suggested to be important in predicting adolescent sexual health (Harakeh, Scholte, Vermulst, de Vries \& Engels, 2004; Darling \& Steinberg, 1993). The I-Change Model has also been used to assess the relation of parenting styles and practices on smoking on the development of smoking related beliefs in their children (Huver, Engels, Vermulst \& de Vries 2007; Huver et al., 2006). However such knowledge is scarce concerning the association of parental sexual health communication on one hand and perceptions of sexual health behaviors on the other hand. Hence, in order to provide a first assessment we conducted a cross-sectional study (see Chapter 5) assessing whether differences in sexual health communication between parents and adolescents are also associated with differences in these perceptions, such as myths, knowledge, social norms, self-efficacy, action planning and intentions concerning condom use and delayed sex.

Further, the I-Change Model has been used to explain a variety of other health behaviours, including, HIV transmission protective behaviours, such as condom use (Eggers et al., 2014), and child abuse (Goebels, Nicholson, Walsh \& de Vries, 2008). This model was used to guide intervention development and evaluation of the international and multi-site school-based HIV prevention PREPARE project, and also served as the guiding principle for the research model used in chapters five and six assessing the effects of the PREPARE PROJECT (Aaro et al., 2014). 


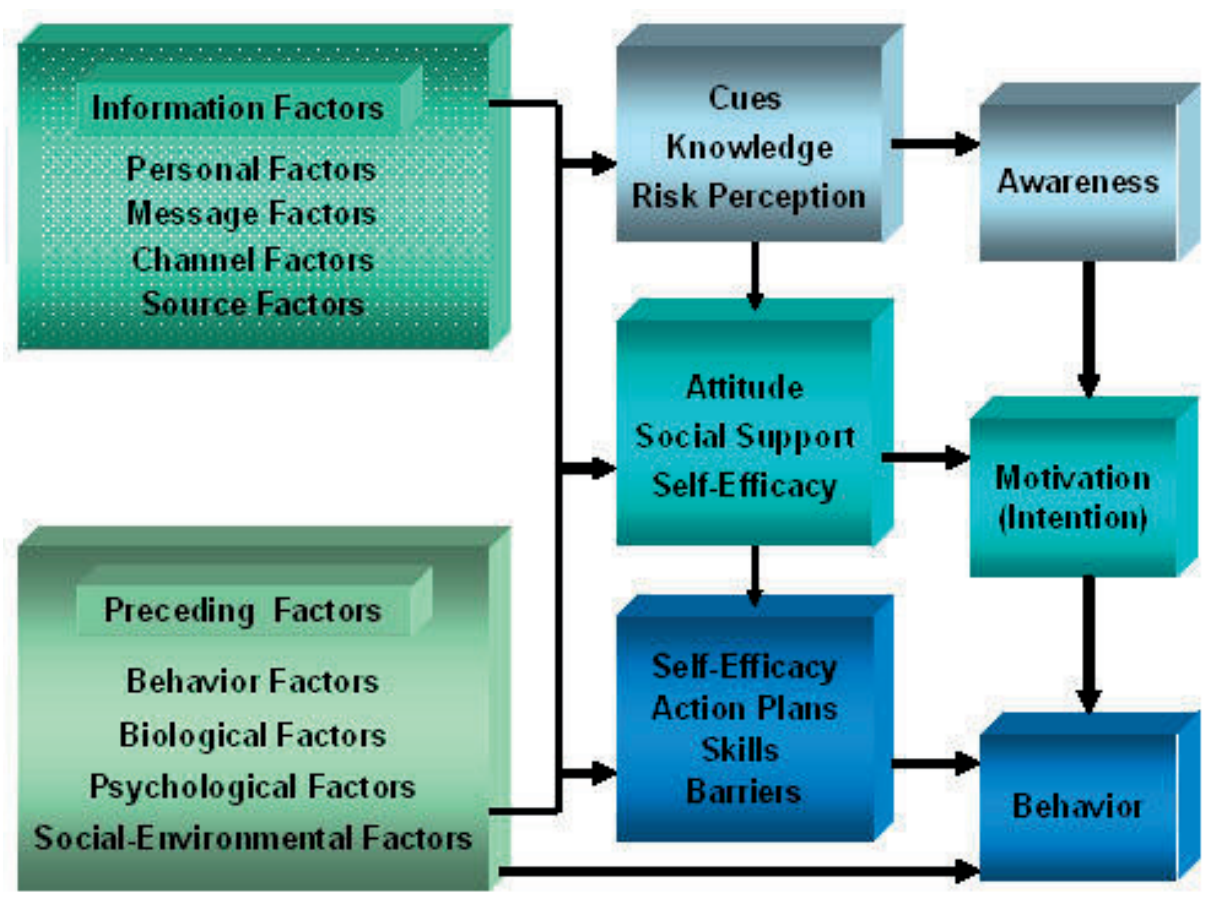

Figure 2: The I- Change model, de Vries (2008)

As shown in figure 2, the I-Change Model considers a person's behaviour to be a result of their intentions, self-efficacy as well as contextual factors (such as the parental practice of sexual health communication). In understanding parental-adolescent sexual health communication as a predictor of delay in sex initiation and consistent condom use for adolescents who have initiated sex, it is imperative to understand its influence on motivation. This study thus utilises the I-Change Model to investigate the effects of the PREPARE intervention on peer and parent sexual health communication, delayed sex initiation and condom use at last sex. Few school-based interventions have been developed and evaluated using socio cognitive theories and to the best of our knowledge effects of interventions on peer and parent sexual health communication are yet to be explored in Tanzania using, in particular the I-Change model. The I-Change Model has been used in Africa in studies concerning smoking (Swart et al., 2006), and condom use and intimate partner violence (IPV) (Eggers et al., 2014). The model has also been used to better understand parenting styles and practices in the context of smoking (Huver, Engels \& de Vries, 2006; Otten, Engels \& van den Eijnden, 2007), but not for understanding sexual health communication in the East African context including Tanzania. 


\section{Theoretical perspective on parenting}

Parental influence in the development of their children's social competence has been of interest to developmental psychologists for long. One major approach to this area is the study of "parenting styles" (Baumrind, 1972; 2005). Parenting has been defined as complex activities that include specific behaviours that work individually and together to influence child outcomes (Darling, 1999). Maccoby and Martin (1983) established two important dimensions of parenting: responsiveness and demandingness, which were further broken down into a typology of four parenting styles namely indulgent, uninvolved, authoritarian and uninvolved. Baumrind (1972) suggests that authoritative parents demand of the child, while being responsive to the child's needs. Authoritative parents monitor and impart clear standards for their child's conduct and their children are suggested to be proficient in educational and social spheres (Darling, 1999). Authoritarian parents however are reported to be highly demanding and directive while lacking responsiveness to the child's needs. Conformity and obedience is valued above open communication with the child (Baumrind, 1991). Further, an indulgent or permissive parent is responsive to the child's needs, permissive and non-directive but not demanding of the child Baumrind (1991). While these children are reported to have adept social abilities and a good self-esteem they demonstrate behavioural and scholastic problems (Darling, 1999). Indifferent, uninvolved, neglectful or disengaged is the fourth style of parenting (Baumrind, 1991). These parents are reported to not oversee their children's behaviour or support their interests and the children have been found to be incompetent in all measures (1999).

\begin{tabular}{lll}
\hline & Demandingness & \\
\cline { 2 - 3 } Responsiveness & High & Low \\
\hline High & Authoritative & Indulgent/Permissive \\
Low & Authoritarian & Neglectful/Indifferent \\
\hline
\end{tabular}

Figure 3: A scheme of classifying parenting types (Maccoby \& Martin, 1983)

While this study utilises parenting practices and types to understand parent adolescent sexual health communication, other parenting constructs such as parental psychological and behavioural control have been utilised to understand parent - adolescent sexual health communication (Schaefer, 1965a; 1965b; Barber, 1996; Steinberg, Lamborn, Dornbusch, \& Darling, 1992). Parental psychological control is described as manipulation and exploitation of the parent-child bond in several different ways including inducing guilt, withdrawing affection, uttering negative expressions and criticisms to induce shame or express disappointment (Barber, 1996); specifying on previous parental control perspectives put forward by Schaefer and others. Parental behavioural control is suggested to include demands for the child to behave according to prevailing family or social norms (ibid). Parenting processes on the other hand including several practices such as communication and monitoring are also explored by some studies that suggest 
these processes are different for boys and girls (Jacobson \& Crockett, 2000; Stattin \& Kerr, 2000). Some parental practices such as limit setting are reported to decline as adolescents grow older (Barber, Maughan \& Olsen, 2005). Given the emphasis of the studies presented here on improving sexual health information and preventive practices in young persons, our emphasis was on the parenting process of parent-adolescent sexual health communication.

Worldwide, several scholars have also described the application of parent-child communication to understand other adolescent behaviours such as smoking (Huver, Engles \& de Vries, 2006), alcohol use (Engels et al., 1999) and nutrition (Golan \& Crow, 2004). In the Tanzanian, context there has been limited focus of the effects of parentchild sexual health communication practices on adolescent behaviour; however, some initial attempts to characterise these practices reported; for example, work by Wamoyi et al., (2010), indicates presence of cultural and reported knowledge barriers to parentadolescent sexual health communications on the part of parents. Furthermore, schoolbased adolescents in Tanzania report higher preference for parental communications on HIV/AIDS, sexual abstinence and condom, and higher parental silence on these matters than South African counterparts (Namisi et al., 2009). As communication about sexual health may be influenced to a large extent by the parenting practices of parents, the studies reported in this study extend on previous work in SSA (Bastien, Kajula \& Muhwezi, 2011) and add value on the little known on the character and influences of this parenting practice on their adolescent offspring.

\section{PROJECT OVERVIEW}

The main aim of this research is to examine parenting practices associated with sexual health communication between adolescents aged 12-14, their peers and parents in Tanzania.

\section{Research questions}

Four main questions were central to this study:

1. What is the nature of parent-adolescent sexual health communication in Tanzania?

2. What is the nature of peer sexual health communication in Tanzania?

3. What are the parenting practices associated with sexual health in Tanzania?

4. How can we effectively promote delayed and safer sex? 


\section{Characteristics of the project}

The research questions above are treated in five studies as elaborated below and presented in detail in chapters 2-6. All studies use data collected during the PREPARE (Promoting sexual and reproductive health among adolescents in southern and eastern Africa) study in four African sites: Tanzania, Uganda, South Africa -Cape Town and Limpopo- (Aarø et al., 2014). Data was collected for the first time in 2012 for standard 5 \& 6 students in primary schools in Dar es Salaam, Tanzania. Follow up was conducted after 6 and 12 months. For this dissertation, only findings from Tanzanian adolescents are included.

Table 1 Characteristics of the five studies described in the current dissertation

\begin{tabular}{llllll}
\hline & Study 1 & Study 2 & Study 3 & Study 4 & Study 5 \\
\hline Chapters & 2 & 3 & 4 & 5 & 6 \\
Research question & 1,4 & 1 & 3 & 1,2 & $1,2,4$ \\
Data collection & 2011 & 2012 & 2012 & 2012 & $2012-2013$ \\
Sample size & 23 & 134 & 24 & 5,099 & 5,099 \\
\hline
\end{tabular}

\section{OUTLINE OF THE DISSERTATION}

This dissertation will provide an overview of studies conducted in order to understand adolescent sexual health and prevent risky sexual behaviour for adolescents.

Chapter 2 describes a systematic review of the literature concerning parental/caregiver and child communication on sexuality \& HIV/AIDS in sub-Saharan Africa. All authors of this chapter identified and shared peer reviewed literature published between 1980 and 2011. These included sexual health communication studies that focused on frequency, style, content, tone of discussion, preferences and associations with barriers to sexuality communication. The author of this dissertation contributed to the identification, reading and independent review of articles, consensus on type of summary to be presented and synthesis as well as reviewing and contributing to drafts of the chapter. The review helped to improve understanding of previous research conducted in SSA on sexual health communication with parents. From the review, few studies looked at parenting practices or socio-cognitive variables associated with sexual health communication or adolescent sexual behaviour. The review also pointed to the need for skills-based sexual health programs to improve sexual health communication with adolescents. Our study took some cues from the review and improved our intervention including focusing on skill based sexual health activities for peers and teachers as well including both parents in the qualitative interviews.

In chapter 3 a study in which we qualitatively explored sexual health communication between adolescents and their parents is presented. Since parent- adolescent commu- 
nication is identified as one of the potential protective factors for adolescent sexual health, we further explored similarities and differences in views and perceptions between adolescents and parents. The inductive approach was used to analyse the findings, a process that involved several steps from reading, coding, reducing and interpreting data (Ulin, Robinson \& Tolley, 2005). While these qualitative findings are not generalisable due to the small sample size (Denzin \& Lincoln, 2000), they do provide consistent trends in the nature of parent-adolescent sexual health communication in the study context.

\section{Interview scheme: Sexual health communication}

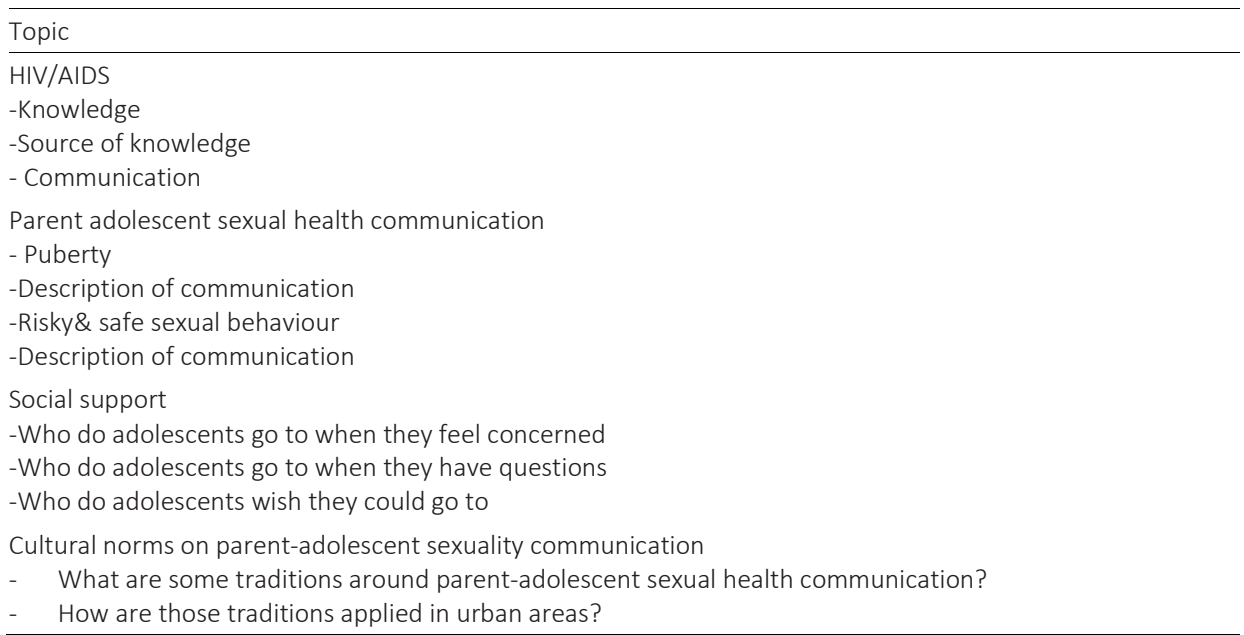

In chapter 4 we describe the parenting practices associated with adolescent sexual health in Tanzania. Parental rules and regulations, parental monitoring, parental punitive strategies and parental responsibilities were examined qualitatively. Parent-child relationships and parenting practices specifically are strong determinants of adolescent sexual health choices. The analytical approach for this chapter was inductive; the nature of the study determined the use of this method, since it allowed for interviews to be read and re-read, then data to be coded using NVivo, reduced into themes and then to be interpreted (Ulin, Robinson \& Tolley, 2005). To ensure validity of the qualitative findings, the study utilised triangulation of methods (Denzin \& Lincoln, 2000). First; two interviewers conducted the interviews, secondly; interviews were carried out in multiple locations, third multiple coders were engaged. A team of five researchers that included the main author conducted coding. The team divided the transcripts amongst themselves and then read and coded. They then discussed the codes and themes and arrived at the condensed themes. The inter-coder reliability was calculated using the Excel program. 


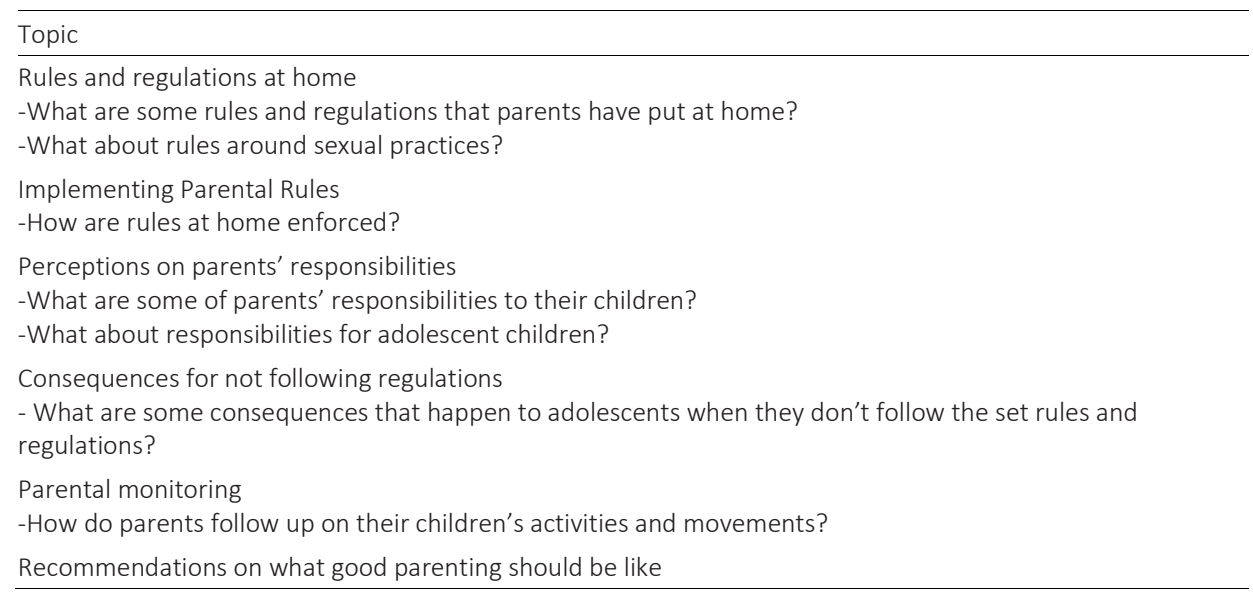

In chapter 5, findings from the first two qualitative studies showing the nature and characteristics of parent-adolescent sexual health communication and parenting practices, were instrumental in shaping the questions for subsequent quantitative studies that determined the extent of reported parent-adolescent and peer sexual health communication. The latter was included given reports of peer-to-peer sexual health communications. Socio-demographic, sexual health knowledge, psychosocial and behavioural factors were explored. Potential socio-demographic confounders including age, gender and food security were examined. Open, unambiguous parent-adolescent sexual health communication has been indicated as possible protective means in mediating the negative effects of peer influence.

Chapter 6 describes the effectiveness of the PREPARE intervention in Dar es Salaam on adolescent sexual health communication with their peers and parents. Relationships and interactions that occur within social networks are considered critical in understanding sexual behaviour and associated risk factors.

Lastly, in chapter 7 the main findings from all the 5 studies are summarised and discussed. Implications and suggestions for future interventions on adolescent sexual heath and parenting are also made. 


\section{REFERENCES}

Aarø, L. E., Mathews, C., Kaaya, S., Katahoire, A. R., Onya, H., et al.,. (2014). Promoting sexual and reproductive health among adolescents in southern and eastern Africa (PREPARE): project design and conceptual framework. BMC Public Health, 14(1), 1.

Adu-Mireku, S. (2003). Family communication about HIV/AIDS and sexual behaviour among senior secondary school students in Accra, Ghana. African Health Sciences, 3(1), 7-14.

Aggleton, P. (1996). Global priorities for HIV/AIDS intervention research. International Journal of STD and AIDS, 7, 13-6.

Ajzen, I., \& Fishbein, M. (1977). Attitude-behavior relations: A theoretical analysis and review of empirical research. Psychological bulletin, 84(5), 888.

Ajzen, I., \& Fishbein, M. (1988). Theory of reasoned action-Theory of planned behavior. University of South Florida.

Amuyunzu-Nyamongo, M., Tendo-Wambua, L., Babishangire, B., Nyagero, J., Yitbarek, N., et al., (1999). Barriers to behaviour change as a response to STD including HIV/AIDS: the East African experience. Resistances to Behavioural Change to Reduce HIV/AIDS. Health Transition Centre, Australian National University, Canberra, 1-11.

Amuyunzu-Nyamongo, M., Biddlecom, A. E., Ouedraogo, C., \& Woog, V. (2005). Qualitative evidence on adolescents' views of sexual and reproductive health in Sub-Saharan Africa. Occasional Report, 16.

Andrews, J. A., Tildesley, E., Hops, H., \& Li, F. (2002). The influence of peers on young adult substance use. Health psychology, 21(4), 349.

Armitage, C. J., \& Conner, M. (2000). Social cognition models and health behaviour: A structured review. Psychology and health, 15(2), 173-189.

Arnett, J. (1992). Reckless behavior in adolescence: A developmental perspective. Developmental review, 12(4), 339-373.

Bandura, A. (1986). Social foundations of thought and action: A social cognitive theory. Prentice-Hall, Inc.

Barber, B. K. (1996). Parental psychological control: Revisiting a neglected construct. Child development, 67(6), 3296-3319.

Barber, B. K., Maughan, S. L., \& Olsen, J. A. (2005). Patterns of parenting across adolescence. New directions for child and adolescent development,2005(108), 5-16.

Barber, B., Stolz, H., Olsen, J., Collins, W., \& Burchinal, M. (2005). Parental Support, Psychological Control, and Behavioral Control: Assessing Relevance across Time, Culture, and Method.Monographs of the Society for Research in Child Development, 70(4), I-147. Retrieved from http://www.jstor.org/stable/3701442

Bastien, S., Kajula, L. J., \& Muhwezi, W. W. (2011). A review of studies of parent-child communication about sexuality and HIV/AIDS in sub-Saharan Africa. Reproductive health, 8(1), 1.

Baumrind, D. (1972). An exploratory study of socialization effects on black children: Some black-white comparisons. Child Development, 261-267.

Baumrind, D. (1991). The influence of parenting style on adolescent competence and substance use. The Journal of Early Adolescence, 11(1), 56-95.

Baumrind, D. (2005). Patterns of parental authority and adolescent autonomy. New directions for child and adolescent development, 2005(108), 61-69.

Biddlecom, A., Awusabo-Asare, K., \& Bankole, A. (2009). Role of parents in adolescent sexual activity and contraceptive use in four African countries. International perspectives on sexual and reproductive health, 72-81.

Boer, H., \& Tshilidzi Mashamba, M. (2007). Gender power imbalance and differential psychosocial correlates of intended condom use among male and female adolescents from Venda, South Africa. British journal of health psychology, 12(1), 51-63.

Borawski, E. A., levers-Landis, C. E., Lovegreen, L. D., \& Trapl, E. S. (2003). Parental monitoring, negotiated unsupervised time, and parental trust: The role of perceived parenting practices in adolescent health risk behaviors.Journal of Adolescent Health, 33(2), 60-70. 
Brown, B. B., \& Larson, J. (2009). Peer relationships in adolescence. Handbook of adolescent psychology.

Darling, N. (1999). Parenting Style and Its Correlates. ERIC Digest.

Denzin, N. K., \& Lincoln, Y. (2000). Qualitative research. Thousand Oaks ua, 413-427.

de Vries, H., Mudde, A., Leijs, I., Charlton, A., Vartiainen, E., Buijs, G., ... \& Prins, T. (2003). The European Smoking prevention Framework Approach (EFSA): an example of integral prevention. Health Education Research,18(5), 611-626.

de Vries, H., Mesters, I., Van de Steeg, H., \& Honing, C. (2005). The general public's information needs and perceptions regarding hereditary cancer: an application of the Integrated Change Model. Patient education and counseling, 56(2), 154-165.

de Vries, H., Kremers, S. P. J., Smeets, T., Brug, J., \& Eijmael, K. (2008). The effectiveness of tailored feedback and action plans in an intervention addressing multiple health behaviors. American Journal of Health Promotion,22(6), 417-425.

de Vries, H. D., Kremers, S., Smeets, T., \& Reubsaet, A. (2008). Clustering of diet, physical activity and smoking and a general willingness to change.Psychology and Health, 23(3), 265-278. Dilger, H. (2003). Sexuality, AIDS, and the lures of modernity: reflexivity and morality among young people in rural Tanzania. Medical Anthropology, 22(1), 23-52.

Diiorio, C., Dudley, W. N., Kelly, M., Soet, J. E., Mbwara, J., \& Potter, J. S. (2001). Social cognitive correlates of sexual experience and condom use among 13-through 15-year-old adolescents. Journal of Adolescent Health, 29(3), 208-216.

Eggers, S. M., Aarø, L. E., Bos, A. E., Mathews, C., \& de Vries, H. (2014). Predicting condom use in South Africa: a test of two integrative models. AIDS and Behavior, 18(1), 135-145.

Elfeddali, I., Bolman, C., Candel, M. J., Wiers, R. W., \& De Vries, H. (2012). The role of self-efficacy, recovery self-efficacy, and preparatory planning in predicting short-term smoking relapse. British journal of health psychology,17(1), 185-201.

Engels, R. C., Knibbe, R. A., Vries, H. D., Drop, M. J., \& Breukelen, G. J. (1999). Influences of Parental and Best Friends' Smoking and Drinking on Adolescent Use: A Longitudinal Study1. Journal of Applied Social Psychology, 29(2), 337-361.

Fishbein, M., \& Ajzen, I. (1975). Belief, attitude, intention, and behavior: An introduction to theory and research. Reading, MA: Addison-Wesley.

Fishbein, M., \& Ajzen, I. (2011). Predicting and changing behavior: The reasoned action approach. Taylor \& Francis.

Fuglesang, M. (1997). Lessons for life-Past and present modes of sexuality education in Tanzanian society. Social Science \& Medicine, 44(8), 1245-1254.

Gardner, M., \& Steinberg, L. (2005). Peer influence on risk taking, risk preference, and risky decision making in adolescence and adulthood: an experimental study. Developmental psychology, 41(4), 625.

Garenne, M. (2004). Age at marriage and modernisation in sub-Saharan Africa. Southern African Journal of Demography, 9(2), 59-79.

Goebbels, A. F. G., Nicholson, J. M., Walsh, K., \& De Vries, H. (2008). Teachers' reporting of suspected child abuse and neglect: behaviour and determinants. Health education research, 23(6), 941-951.

Golan, M., \& Crow, S. (2004). Parents are key players in the prevention and treatment of weight-related problems. Nutrition reviews, 62(1), 39-50

Hoque, M., \& Ghuman, S. (2012). Do parents still matter regarding adolescents' alcohol drinking? Experience from South Africa. International journal of environmental research and public health, 9(1), 110-122.

Huver, R. M., Engels, R. C., Vermulst, A. A., \& de Vries, H. (2007). Is parenting style a context for smokingspecific parenting practices?. Drug and Alcohol Dependence, 89(2), 116-125.

Huver, R. M., Engels, R. C., \& de Vries, H. (2006). Are anti-smoking parenting practices related to adolescent smoking cognitions and behavior? Health Education Research, 21(1), 66-77.

ICF International. (2013). Tanzania HIV/AIDS and malaria indicator survey.

Jacobson, K. C., \& Crockett, L. J. (2000). Parental monitoring and adolescent adjustment: An ecological perspective. Journal of research on adolescence,10(1), 65-97. 
Kawai, K., Kaaya, S. F., Kajula, L., Mbwambo, J., Kilonzo, G. P., \& Fawzi, W. W. (2008). Parents' and teachers' communication about HIV and sex in relation to the timing of sexual initiation among young adolescents in Tanzania. Scandinavian Journal of Public Health, 36(8), 879-888.

Li, F., Barrera Jr, M., Hops, H., \& Fisher, K. J. (2002). The longitudinal influence of peers on the development of alcohol use in late adolescence: A growth mixture analysis. Journal of behavioral medicine, 25(3), 293315.

Maccoby, E. E., \& Martin, J. A. (1983). Socialization in the context of the family: Parent-child interaction. Handbook of child psychology: formerly Carmichael's Manual of child psychology/Paul H. Mussen, editor.

MacPhail, C., \& Campbell, C. (2001). 'I think condoms are good but, aai, I hate those things':: condom use among adolescents and young people in a Southern African township. Social science \& medicine, 52(11), 1613-1627.

Maticka-Tyndale, E., Wildish, J., \& Gichuru, M. (2007). Quasi-experimental evaluation of a national primary school HIV intervention in Kenya. Evaluation and program planning, 30(2), 172-186.

Maticka-Tyndale, E., \& Tenkorang, E. Y. (2010). A multi-level model of condom use among male and female upper primary school students in Nyanza, Kenya. Social science \& medicine, 71(3), 616-625.

Mbugua, N. (2007). Factors inhibiting educated mothers in Kenya from giving meaningful sex-education to their daughters. Social Science \& Medicine,64(5), 1079-1089.

Mensch, B. S., Singh, S., \& Casterline, J. B. (2005). Trends in the timing of first marriage among men and women in the developing world. The changing transitions to adulthood in developing countries: Selected studies, 118-71.

Miller, K. S., Forehand, R., \& Kotchick, B. A. (1999). Adolescent sexual behavior in two ethnic minority samples: The role of family variables. Journal of Marriage and the Family, 85-98.

Namisi, F., Aarø, L. E., Kaaya, S., Kajula, L. J., Kilonzo, G. P., Onya, H., ... \& Mathews, C. (2015). Adolescents' Communication with Parents, Other Adult Family Members and Teachers on Sexuality: Effects of SchoolBased Interventions in South Africa and Tanzania. AIDS and Behavior, 19(12), 2162-2176.

Otten, R., Engels, R. C., \& van den Eijnden, R. J. (2007). The relative contributions of parenting practices in smoking behavior of adolescents with and without asthma. Nicotine \& tobacco research, 9(1), 109-118

Prochaska, J. O., DiClemente, C. C., \& Norcross, J. C. (1992). In search of how people change: applications to addictive behaviors. American psychologist, 47(9), 1102.

Rivers, K., \& Aggleton, P. (1999). Adolescent sexuality, gender and the HIV epidemic. HIV and Development Programme.

Romer, D., Stanton, B., Galbraith, J., Feigelman, S., Black, M. M., \& Li, X. (1999). Parental influence on adolescent sexual behavior in high-poverty settings. Archives of pediatrics \& adolescent medicine, 153(10), 1055-1062.

Ross, D. A., Dick, B., \& Ferguson, J. (2010). Preventing HIV/AIDS in young people: a systematic review of the evidence from developing countries. UNAIDS Inter-agency Task Team on Young People; 2006. WHO Technical Report Series, 938.

Schaefer, E. S. (1965). Children's reports of parental behavior: An inventory. Child development, 413-424.

Schaefer, E. S. (1965). A configurational analysis of children's reports of parent behavior. Journal of consulting psychology, 29(6), 552.

Schulz, D. N., Kremers, S. P., \& de Vries, H. (2012). Are the stages of change relevant for the development and implementation of a web-based tailored alcohol intervention? A cross-sectional study. BMC public health, 12(1), 1.

Sheeran, P., Abraham, C., \& Orbell, S. (1999). Psychosocial correlates of heterosexual condom use: a metaanalysis. Psychological bulletin, 125(1), 90.

Stattin, H., \& Kerr, M. (2000). Parental monitoring: A reinterpretation. Child development, 71(4), 1072-1085.

Steinberg, L., Lamborn, S. D., Dornbusch, S. M., \& Darling, N. (1992). Impact of parenting practices on adolescent achievement: Authoritative parenting, school involvement, and encouragement to succeed. Child development,63(5), 1266-1281. 


\section{Chapter one}

Swart, D., Panday, S., Reddy, S. P., Bergström, E., \& de Vries, H. (2006). Access point analysis: what do adolescents in South Africa say about tobacco control programmes?. Health education research, 21(3), 393406.

Tanzania Commission for AIDS (TACAIDS), National Bureau of Statistics. Tanzania in figures 2012. Dar es Salaam: National Bureau of Statistics, 2013

Tanzania, H. I. V. "AIDS and malaria indicator survey 2011-12." Dar es Salaam: Tanzania Commission for AIDS (2013).

Ulin, P. R., Robinson, E. T., \& Tolley, E. E. (2005). Qualitative methods in public health. San Francisco, CA: JosseyBass.

UNAIDS report on the global AIDS epidemic 2010. WHO Publications, 2011.

Wight, D., Williamson, L., \& Henderson, M. (2006). Parental influences on young people's sexual behaviour: a longitudinal analysis. Journal of adolescence, 29(4), 473-494.

World Health Organization (WHO)"Risk and protective factors affecting adolescent reproductive health in developing countries." 2004.

van der Wulp, N. Y., Hoving, C., \& de Vries, H. (2013). A qualitative investigation of alcohol use advice during pregnancy: Experiences of Dutch midwives, pregnant women and their partners. Midwifery, 29(11), e89e98.

Viner, R. M., Ozer, E. M., Denny, S., Marmot, M., Resnick, M., Fatusi, A., \& Currie, C. (2012). Adolescence and the social determinants of health. The lancet, 379(9826), 1641-1652.

Zimring, F. E. (1998). The youth violence epidemic: Myth or reality. Wake Forest L. Rev., 33, 727. 


\title{
Chapter
}

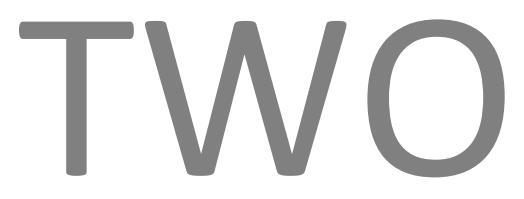

\author{
A review of studies of parent-child \\ communication about sexuality and HIV/AIDS \\ in sub-Saharan Africa
}

This chapter has been published as Bastien, S., Kajula, L. J., \& Muhwezi, W. W. (2011). A review of studies of parent-child communication about sexuality and HIV/AIDS in subSaharan Africa. Reproductive health, 8(1), 1. 


\section{ABSTRACT}

Parent-child sexuality communication has been identified as a protective factor for adolescent sexual and reproductive health, including HIV infection. The available literature on this topic in sub-Saharan Africa is increasing; however a systematic review of studies has not been conducted. This article reviews the literature in the area of parental or caregiver and child communication about sexuality and HIV/AIDS in sub-Saharan Africa. A review of peer reviewed literature published between 1980 and April 2011 was conducted. Communication process studies investigating the frequency, content, style, tone of discussions, preferences, as well as associations with and barriers to sexuality communication are reviewed. In addition, studies which examine behavioural associations with parent-child sexuality communication, and intervention studies to improve parent-child sexuality communication are examined. The findings from process studies suggest wide variation in terms of frequency of discussions, with a range of sociodemographic and other factors associated with sexuality communication. Overall, findings demonstrate that discussions tend to be authoritarian and uni-directional, characterized by vague warnings rather than direct, open discussion. Moreover, parents and young people report a number of barriers to open dialogue, including lack of knowledge and skills, as well as cultural norms and taboos. Findings are less clear when it comes to associations between parental communication and adolescent sexual activity and contraception use. However, nascent indications from intervention research suggest positive findings with increases in frequency and comfort of discussions, among other outcomes. Gaps in the research are identified and discussed with implications for future studies. 


\section{INTRODUCTION}

Improving the sexual and reproductive health of young people is a global priority. Interventions which aim to promote healthy sexual behaviour typically aim to delay sexual debut, decrease the number of sexual partners and increase condom use. In spite of concerns that sexuality education may contribute to early sexual experimentation among young people, this is not supported by evidence (Kirby, Obasi \& Laris, 2006). On the contrary, findings from studies conducted in developing countries suggest that sexuality education has the potential to positively impact knowledge, attitudes, norms and intentions, although sexual behavior change has been more limited (Kaaya et al., 2002; Paul-Ebhohimhen, Poobalan \& van Teijlingen, 2008).

Adolescent sexual decision-making and behavior are influenced by myriad factors at the individual level as well as peer, family, community and societal levels. Parents in particular play a substantial role in the gender and sexual socialization of their children. Discussing topics related to sexuality has been associated with a range of important psychosocial attributes including increased knowledge, better interpersonal communication skills, including sexual negotiation skills, and self-efficacy (Wight, Williamson \& Henderson, 2006; Peltzer, 2010; DiClemente et al., 2001; Noar, Carlyle \&Cole, 2006; Halpern-Felsher et al., 2004). Communication about sexuality between parents or caregivers and offspring has also been identified as a protective factor for a range of sexual behaviours, including a delayed sexual debut, particular for females (Markham et al., 2010).

Studies focusing on parent-child communication have focused on a range of processes that may influence effectiveness in decreasing sexual risk behavior among young people such as frequency of discussions and perceptions of quality and comfort of communication (Feldman \& Rosenthal, 2000; Rosenthal \& Shirley, 1999). The timing of communication is also of importance and is most likely to be effective prior to sexual debut to reinforce protective factors, but may also facilitate behavior change in those already sexually active (Downing et al., 2011). The content of the message and how it is transmitted have also been identified as being particularly important (Miller et al., 1998). Some studies have investigated the perceptions of young people or parents separately, whilst other studies have sought to examine differences in self-reports (Feldman \& Rosenthal, 2000; Miller et al., 1998; Rosenthal, Feldman \& Edwards, 1998; Lefkowitz, Boone, Sigman \& Kit-fong, 2002; Jaccard, Dittus \& Gordon, 1998). Growing up in a single parent household and other parental characteristics such as level of education and socio-economic status have also been explored to determine how these factors affect both communication processes and behavioural outcomes (Miller, Forehand \& Kotchick, 1999; Davis \& Friel, 2001). However, the vast majority of these studies have been conducted in North America, Europe and Australia.

Whilst programs and the literature on parent or caregiver-child sexuality communication in developing countries and sub-Saharan Africa (SSA) are limited, they are in- 
creasing (WHO, 2007). This is due both to more ecological understandings of social and contextual influences on young people's sexual behavior and the need to develop more comprehensive HIV/AIDS prevention programs that include social level influences.

The role of parents in the sexual and reproductive health of adolescents in subSaharan Africa has been studied as part of broader efforts to understand sexual socialization and sexual agency (Kinsman, Nyanzi \& Pool, 2000; Lesch \& Kruger, 2005), to determine the impact of growing up in a single or double parent household on sexual transition and sexual behavior (Ngom, Magadi \& Owuor, 2003; Tambashe \& Shapiro, 1996; Rwenge, 2000; Dimbuene \& Defo, 2011) and to determine the influence of parental characteristics on sexual behavior (Odimegwu, Solanke \& Adedokun, 2002), including social resources or parental investment (Camlin \& Snow, 2008).

Historically, the taboo nature of sexuality discussions between adults, in particular parents, and young people in sub-Saharan Africa has been well documented (Amuyunzu-Nyamongo, Biddlecom, Ouedraogo \& Woog, 2005; Mbugua, 2007; Paruk, Petersen, Bhana, Bell \& McKay, 2005). In several countries in sub-Saharan Africa, direct parental involvement in the sexual socialization of children in the past has been described as minimal. Rather, the extended family including grandparents and aunts were instrumental for imparting the necessary knowledge and skills relevant for sexual relationships (Fuglesang, 1997). With increased urbanization and social change processes however, the family unit and consequently adolescent socialization may be impacted.

The purpose of this article is to review the available literature on parent or caregiver-child communication about sexuality in SSA. In particular, we aim to review studies which focus on i) the process of parent-child sexuality communication; ii) behavioural outcomes associated with parent-child sexuality communication, and iii) interventions that have been evaluated to improve sexuality communication between parents and their children in SSA. Based on these findings, gaps for future research will be identified.

\section{METHODS}

We conducted a review of studies by searching the following databases as of April 29th, 2011: Education Resources Information Center (ERIC), PubMed, PsychINFO (Ovid), and Medline. A combination of search terms were used, including 'adolescent', 'youth', 'child', 'parent-child communication', 'family', 'caregiver', 'sexuality', 'sexual and reproductive health', 'HIV/AIDS', 'Africa' and 'sub-Saharan Africa'. In addition, a hand search of all articles identified was performed to locate other relevant studies. Inclusion for the review was restricted to those studies that were: a) published in a peer reviewed journal, b) published between 1980 and April 2011, c) conducted in sub-Saharan Africa, and d) based on empirical research concerning parent or caregiver communication about sexuality with children as a study aim or objective. We identified a total of 23 articles that met the inclusion criteria. The studies were reviewed and grouped accord- 
ing to whether they reported data which related to the process of sexuality communication (frequency, content, triggers, factors associated with communication, communication style and tone of discussions, preferences and barriers), which related to behavioural outcomes associated with sexuality communication (sexual debut, condom or contraceptive use) or which reported intervention data related to improving parentchild sexuality communication. These categories were subsequently used to structure the presentation of the results. Several studies presented findings that fit into both categories.

\section{RESULTS}

An overview of the studies included in this review can be found in Table 1. Studies were published in a range of international and African journals. The majority of studies (19 of 23) collected quantitative data. Of the quantitative studies, 14 were cross-sectional, while 5 were randomized controlled trials. Two of the papers in this review use data from the same randomized controlled trial, however the samples differ (Namisi et al., 2009; Kawai et al., 2008). Only 2 studies utilized purely qualitative methods, while 2 studies used mixed methods. Of the few studies which specified a theoretical framework for the research, the Theory of Triadic Influence, Ecological Systems Theory and Social Learning Theory, were described as influential.

The studies were conducted in both urban and rural areas in East, Southern and West Africa. Participants were recruited both from school settings and within the community. The majority of studies investigated young people's perceptions (17 of 23 studies) and the age range of these studies ranged from 10 to 24 years. Ten studies incorporated data from parents, either both parents or mothers only. Three studies were cross-national comparisons, two of which focused on African countries, while the other compared young people in Kenya and the United States. The findings below are organized according to the three review objectives relating to studies focused on the process of parent-child sexuality communication, studies which investigated behavioral associations with parent-child sexuality communication and interventions which have specifically sought to improve parent-child sexuality communication.

\section{Studies investigating the process of parent-child sexuality communication}

Communication process studies are those which describe the frequency and topic or content of discussions, triggers for discussion, the factors associated with sexuality communication, perceptions of the communication style and overall tone of discussions, preferences and barriers to communication. 


\section{Frequency and content of discussions}

A total of 20 of 23 studies investigated frequency of discussion about a range of topics related to HIV/AIDS and sexuality between caregivers or parents and children. Firstly, in relation to HIV/AIDS, studies relying on data collected from young people reported proportions in assessing frequency of communication about HIV/AIDS with parents ranging from $8 \%$ to $80 \%$, while other studies reported mean values (Namisi et al., 2009; Kawia et al., 2008; Adu-Mireku, 2003; Musa, Akande, Salaudeen \& Soladoye, 2008; Mathew, Shugaba \& Ogala, 2006; Bastien, Sango, Mnyika, Masatu \& Klepp, 2008; Bastien, Leshabari \& Klepp, 2009; Babalola, Tambashe \& Vondresek, 2005; Poulsen et al., 2010; Biddlecom, Awasabo-Asare \& Akinrinola, 2009). One study looked at change over time from 1992 to 2005 in the same randomly selected primary schools in two regions in Tanzania in talking about AIDS with parents (Bastien, Sango, Mnyika, Masatu \& Klepp, 2008). This study found that communication with parents about AIDS increased in 2005. However, as with several other studies in this review, this study did not differentiate between communication with mothers and fathers and due to the study design, it was not possible to explain the changes or attribute them to any specific intervention.

In addition to HIV/AIDS, studies investigated discussion of other topics related to sexuality. A multi-site study which assessed communication with parents about condoms and abstinence in addition to HIV/AIDS found communication on all topics was generally low and that silence was greatest on the topic of condoms (Namisi et al., 2009). This is consistent with findings from Nigeria that of 6 topics related to sexuality (development \& growth, pregnancy \& childbirth, preparation for adulthood, sexually transmitted diseases, contraception and abortion), contraception was least discussed (Adeyemo \& Brieger, 1994). Another study from Nigeria reported that $65 \%$ of mothers reported discussing 'sexuality issues' with their children at some point, however details on the recall time period and content of those discussions was not reported (Opara, Eke \& Akani, 2010). Also from Nigeria, one study reported that $39 \%$ of parents reported discussing sex with their child in the past year (Izugbara, 2008). Similar findings from Kenya indicate that while abstinence, unplanned pregnancy and HIV/AIDS were topics of discussion in many families, topics that were rarely discussed include the use of contraceptives and condoms. This was attributed to a number of reasons such as parental fears concerning potential side effects such as infertility, that it would contradict their intended message emphasizing abstinence and due to shyness and lack of knowledge.

This is in contrast to a study in Nigeria in which $98 \%$ of students reported discussion about condoms with a 'family member' (Musa, Akande, Salaudeen \& Soladoye, 2008). This study also found that $34 \%$ of respondents reported discussion about premarital sex with a family member. Although the study specified that the member of the family most often involved in sexuality discussions was the mother (44\%), compared to the father (29\%), the study did not make clear which family member was involved in discussions for each topic investigated. Another study which specified which family member was communicated with (but which did not specify which topic) found that the mother 
(with 33\% of female adolescents and 16\% of males) was the most frequently reported person with whom adolescents discussed sex-related matters, in contrast to the father ( $13 \%$ of females and $12 \%$ of males) (Kumi-Kyereme, Awusabo-Asare, Biddlecom \& Tanle, 2007). One study in Ghana assessed whether or not communication about avoiding or delaying sex took place in the last year and also whether they had discussed the use of modern contraceptives to prevent unintended pregnancy, with the mother or female guardian, father or male guardian, aunt, uncle or sibling and found that communication about these topics is low (Karim, Magnani, Morgan \& Bond, 2003). A study conducted in Burkina Faso, Ghana, Malawi and Uganda found that whilst the proportion of adolescents reporting having discussed sex-related matters was low (between $8 \%$ and $38 \%$ ), the proportion reporting communication about contraceptives was even lower with no more than $10 \%$ reporting such communication (with the exception of females in Uganda) (Biddlecom, Awusabo-Asare \& Akinrinola, 2009). Finally, a cross-sectional study from Nigeria found that $30 \%$ of adolescents reported seeking information about 'sexual matters' from their parents. This study also found that there was a significant relationship between source of information and sexual experience, for instance, a greater proportion of adolescents (55\%) who received sexuality information from peers were sexually experienced compared with $34 \%$ who sought information from parents and other sources $(p<0.01)$ (Amoran, Onadeko \& Adeniyi, 2005).

However, comparison across studies is difficult since questions concerning frequency of communication were posed differently in the various studies and in some papers, the formulation of the question was not reported. Two papers from a comparative study among South African and Tanzanian students measured frequency of communication by providing 4 response options ( 1 =never; 2 =hardly ever; $3=$ sometimes; $4=a$ lot; and $5=$ all the time), with 1 and 2 dichotomized to no communication or 'silence' and 3-5 coded as having communicated (Namisi et al., 2009; Kawai et al., 2008). Other studies used a similar scale, but with four points where $1=$ never and $4=$ more than four times (Bastien, Sango, Mnyika, Masatu \& Klepp, 2008; Bastien, Leshabari \& Klepp, 2009). One study used discussion about sexual abstinence with either parent in the past 12 months as a proxy measure for parent-child communication about sex (Babalola, Tambashe \& Vondrasek, 2005) while another similarly used discussion about sex or sexuality in the household with parents, guardians or 'other household members' during the last 12 months as an indicator for parent-child communication (Phetla et al., 2008). One study in Nigeria constructed a 12-point Family Life Communication Scale (FLCS), where discussion of a particular topic area could receive a maximum of 2 points if either parent had ever initiated discussion about sexuality with their adolescent, 1 point if someone other than the parent had initiated such a discussion and no points if it was never discussed (Adeyemo \& Brieger, 1994). The CHAMP intervention study in South Africa provided response options ranging from 'we talk about this a lot' to ' we never talk about this' (Bhana et al., 2004). Adopting a more open-ended approach, two other studies measures of parent-child communication which queried 'which types of people had 
talked to the adolescent about sex-related matters' and about 'the types of people or other sources from which the adolescent received information about contraceptive methods' (Biddlecom, Awusabo-Asare \& Akinrinola, 2009; Kumi-Kyereme, AwusaboAsare, Biddlecom \& Tanle, 2007). Finally, another study asked students if they had 'ever talked about HIV/AIDS with parents or other adults in the family', dichotomizing the response options to 'yes' and 'no' (Adu-Mireku, 2003), while a similar yes/no dichotomization took place in another study (Poulsen et al., 2010). The fact that several of the studies include terms such as guardians, other adults, and household members when inquiring about communication reflects the role of the extended family in the sexual socialization of young people in SSA. However, this makes it difficult to ascertain precisely who communicated with the child. These examples highlight the range of sensitivity employed in measuring frequency of discussion in the various studies.

One qualitative study sought to determine frequency of discussions, but found that it was difficult for participants to tell how often they discussed, while the few who were able to make an estimation reported a range from once in a day to once a month or several months (Wamoyi et al., 2010). These findings point to the potential for recall bias in the quantitative studies.

\section{Triggers for parent-child sexuality communication}

Only one study reviewed investigated triggers for discussions about HIV/AIDS, and it was reported that parents frequently used examples of relatives who had died of AIDS to initiate a discussion and to reiterate the severity of the disease. Other triggers for discussion reported by parents in this study were radio programs, flyers, parental perceptions of risky sexual behavior, or seeing someone they believed was HIV positive, for instance due to thinness (Wamoyi et al., 2010).

\section{Factors associated with sexuality communication}

Identifying factors associated with and predictors of sexuality communication is an important precursor to the development of programs and interventions to improve parent-child sexuality communication. A total of 12 studies reported data relating to this topic. One comparative study of parent-child communication in the United States and Kenya found that in both countries, the odds of communication about HIV/AIDS taking place were associated with parental perceptions that their child was ready to learn about sexuality, whether or not they had received information to educate their child about sex, and if they had greater sexual communication responsiveness. Sexual communication responsiveness was the skill, comfort \& confidence to communicate about sexuality (Poulsen et al., 2010). Regarding the second factor, having received information to educate their child about sex, the authors note that due to the wording of the item, it is not clear whether this particular finding relates to motivation or knowledge. 
Another study found that young people living in rural areas reported more frequent communication about HIV/AIDS with both mothers and fathers than those living in urban areas. In addition, attending school and having a higher socioeconomic status were found to be associated with more frequent communication with parents (Bastien, Leshabari \& Klepp, 2009). In a multi-site study conducted in South Africa and Tanzania, higher socio-economic status was similarly found to be significantly associated with more frequent communication with parents in both of the South African sites, but not in Tanzania (Namisi et al., 2009). Consistent with these findings, higher socio-economic status was also reported to increase frequency of parental communication in Nigeria (Adeyemo \& Brieger, 1994). This study also found that positive perceptions of the parental role and responsibility in family life education was associated with increased frequency of communication, as was greater time spent at home by parents.

In studies conducted in Nigeria and Kenya, it was found that the education level of the parents was associated with whether or not sexuality and HIV/AIDS had been discussed, with those having a higher level of education most likely to have had communication with their children (Musa, Akande, Salaudeen \& Soladoye, 2008; Poulsen et al., 2010; Adeyemo \& Brieger, 1994; Opara, Eke \& Akani, 2010). Parental marital status was also found to play a role in Kenya. In terms of religious affiliation, this was found to be a significant predictor of experiencing silence in one site in South Africa (Mankweng), with Catholics and other affiliations significantly more likely to report silence than Protestants (Namisi et al., 2009). Age was not found to be associated with communication about HIV/AIDS in one of the studies (Bastien, Leshabari \& Klepp, 2009), but this was not consistent with others studies in the review. For instance, in the multi-site study, it was found that students who communicated about HIV and sex with parents were more likely to be older in Tanzania and one of the South African sites (Mankweng), while age was not associated with silence in the Cape Town site (Namisi et al., 2009; Kawai et al., 2008). In a study conducted in Ghana, findings showed that sexuality communication is more common among older respondents than younger ones (KumiKyereme, Awusabo-Asare, Biddlecom \& Tanle, 2007). In terms of relationship status, one multi-site study found that those more likely to communicate with either parents or teachers were those who had a boy/girlfriend and who had used alcohol (Kawai et al., 2008). In addition, another study found that family size was associated with more frequent communication about sexuality with families of 5 or less more likely to discuss (Musa, Akande, Salaudeen \& Soladoye, 2008).

Gender differences were noted by most studies in terms of frequency of communication, although the findings are mixed. For instance, in Nigeria and Ghana, it was found that significantly higher proportions of female students reported family communication about sexuality than males ( $81 \%$ versus $63 \%$, and $46 \%$ versus $28 \%$ for females and males respectively in two studies conducted in Ghana; $86 \%$ versus $76 \%$ for females and males in a study from Nigeria( Adu-Mireku, 2003; Musa, Akande, Salaudeen \& Soladoye, 2008; Kumi-Kyereme, Awusabo-Asare, Biddlecom \& Tanle, 2007; Amoran, 
Onadeko \& Adeniyi, 2005). In a multi-site study conducted in South Africa and Tanzania it was found that after controlling for other socio-demographic variables in South Africa, a greater proportion of males reported silence from their parents concerning HIV/AIDS, abstinence and condoms compared to females, while the reverse was found in Tanzania where a higher proportion of females reported non-communication with parents on these issues compared to males (Namisi, et al., 2009). However, this finding is in contrast to another study which used the same population of students and which found that more girls than boys reported they communicated with parents about HIV and sex. This study however, adopted a longitudinal approach rather than using baseline data only, and restricted its analyses to virgins in the sample (Kawai, et al., 2008). This is consistent with another multi-country study conducted in Burkina Faso, Ghana, Malawi and Uganda which found that males in three countries were less likely than females to report parental communication about sex (Biddlecom, Awusabo-Asare \& Akinrinola, 2009). Several studies reported that the mother was the most frequent communicator or initiator of sexuality discussions (Musa, Akande, Salaudeen \& Soladoye, 2008; Wamoyi et al., 2010). However, it was found that mothers did not fully exploit this advantage to have more open discussions with their children; rather, they continued to communicate through the use of warnings and threats ( Musa, Akande, Salaudeen \& Soladoye, 2008; Wamoyi et al., 2010).

One of the factors associated with sexuality communication relates to timing and parental perceptions that their child has had his/her sexual debut. One study in Tanzania found that parents tended to wait until their daughters were in secondary school to initiate discussions about sexuality, due to the assumption and expectation that those still in primary school were not sexually active (Musa, Akande, Salaudeen \& Soladoye, 2008; Wamoyi at al., 2010). Consequently, there was reported to be increased secrecy in sexual relationships and also increased difficulty in accessing contraceptives for fear of being found to be sexually active. A study conducted among women in Nigeria reported that $41 \%$ believed sexuality education should commence between the ages of 6 10 years, whilst $32 \%$ favored starting discussions with children between the ages of 11 15 years (Opara, Eke \& Akani, 2010). Others however based the decision to initiate a discussion related to sexuality on observations of changes in behavior which are perceived to indicate the onset of sexual activity.

\section{Communication style and tone of discussions}

Several studies in the review suggest that one of the most substantial challenges to positive and effective parent-child sexuality communication relates to the communication style and tone of discussions. However, only 4 studies reviewed investigated this topic. As one study in Ghana found, communication often takes the form of instruction rather than dialogue. The study also found that communication is frequently gendered, for instance with advice given to sons to be careful, while warnings are given to girls to 
avoid sexual encounters with boys (Kami-Kyereme, Awusabo-Asare, Biddlecom \& Tanle, 2007). Similarly, a study of Nigerian parents found that parents preferred to be the initiators and dominators of discussions and perceived that if their child did so, it meant they were sexually active or planning to be. Parents in this study reportedly used imprecise terminology and tended to employ warnings and threats about sexuality rather than engage their child in dialogue (Izugbara, 2008). A recent ethnographic study conducted in rural Tanzania found that sexuality communication was most often unidirectional, initiated by parents and took the form of warnings or threats or sometimes gossip (Wamoyi at al., 2010). The consequences of premarital sex in particular were described as being the most specific and concrete. However, some parents reportedly aimed rather to emphasize the benefits of education and focus on a future oriented perspective in discussions. In rural South Africa, similar findings were reported concerning the style of communication which tended to be perceived as being judgmental, proscriptive, and negative towards young people's sexuality (Phetla et al., 2008). According to the respondents in this study, it was not the act of discussing sexuality with parents that young people were opposed to per se; rather, it was the style that was focused on and identified as a barrier to discussion.

Since some parents reportedly perceive discussions about sexuality between parent and child as being shameful, immoral or inappropriate given the sensitive nature of sexuality, one study conducted in Tanzania among young people aged 14-24 years and their parents reported that euphemisms were commonly employed to discuss sex rather than explicit terminology (Wamoyi at al., 2010). The ability to openly discuss sexuality was however found to be moderated by parent's level of education, similar to the finding that frequency of discussion is related to parental level of education (Wamoyi at al., 2010). In terms of quantitative data, one study reviewed asked respondents whether they felt 'free/open' in discussing topics related to sex, and what topics were covered (Phetla et al., 2008).

\section{Sexuality communication preferences}

In terms of preferences, findings from four studies reviewed which investigated this topic found that young people prefer sexuality communication to take place with the parent of the same sex. The South Africa-Tanzania (SATZ) study conducted among young people aged 11-17 years reported that overall, $44 \%$ of participants preferred to communicate with mothers about sexuality, while 15\% preferred fathers (Namisi et al., 2009). Mothers were the preferred communication partner by the majority of female adolescents in both Tanzania and South Africa. In Cape Town, 31\% preferred discussing with mothers, and $22 \%$ stated a preference for fathers, while in the other two sites, a greater proportion of males preferred discussing with fathers in comparison to mothers (47\% and 27\% in Dar es Salaam and Mankweng, respectively). Another study in Tanzania found that among in- and out-of-school males, $11 \%$ and $10 \%$ respectively selected 
fathers as a preferred partner for communicating about sexuality (Bastien, Leshabari \& Klepp, 2009). Among in- and out-of-school females, the study found that mothers were the first choice by both groups, with $44 \%$ and $37 \%$ of in- and out-of-school females reporting mothers as the preferred sexuality communicator, respectively. From a parental perspective, a study of Nigerian mothers and fathers parents found that they also preferred same sex discussions with their children (Izugbara, 2008).

In spite of these findings which tend to favor mothers as the preferred sexuality communicators, qualitative findings suggest that mothers are not always perceived in a positive light. For instance, focus group findings from young people in Ghana aged 1417 years classified mothers into four categories: those who are approachable (and in the minority), those who tended to brush off questions and suggest that such discussions should take place with someone else (such as another family member), those who reacted by shouting when sexuality discussions are initiated, and those who seemed to have difficulty maintaining confidentiality and were subsequently labeled 'gossipers' (Kumi-Kyereme, Awusabo-Asare, Biddlecom \& Tanle, 2007). In these focus group discussions, it was also found that fathers were often labeled as 'tyrants' who lacked listening skills and were prone to threaten or take action against their children's friends of the opposite sex.

\section{Barriers to sexuality communication}

In discussing barriers to open and frank communication about sexuality between caregivers and children, several studies mention that at least in the past, it was not considered normative in many African settings for such discussions to take place between parents and offspring. A total of 7 studies presented data on barriers to parent-child sexuality communication. From a parental perspective, a number of studies reported on barriers to sexuality communication. An article based on data collected in 1996 and 2003 in Kenya investigated the reason why educated mothers do not give 'meaningful' sex education to their daughters and identified a host of socio-cultural and religious barriers to sexuality communication (Mbugua, 2007). In particular, four factors hindering meaningful communication are discussed, including: 1) residual traditional barriers, 2) inhibitions due to European Christianity, 3) reliance on sex education books, and 4) reliance on school teachers. The majority of mothers interviewed for the study indicated that they themselves had not received pubertal or sex education from their own mothers and were thus inhibited to providing it to their own daughters due to residual barriers which fostered a sense of unease and avoidance concerning parent-child sexuality communication. European Christianity is also discussed as influencing the type of language used to discuss sexuality, to explain for instance why metaphors and other linguistic devices are used to avoid direct communication and precise terminology which is perceived as being 'dirty'. The third and fourth factors are interrelated and point to mothers' reliance on books and school teachers to provide sex education to 
their daughters, in spite of the fact that school teachers have undergone the same socialization process and reportedly experience the same discomfort as mothers in discussing sexuality (Mbugua, 2007).

Also from a parental perspective, a study conducted in Kenya found that $38 \%$ of parents thought that talking about sexuality encourages sex, however the study's hypothesis that parental attitudes in this regard would influence communication were not supported (Poulsen et al., 2010). The belief that discussing sexuality with children will lead to early sexual experimentation is documented by several other studies (Mathew, Shugaba \& Ogala, 2006; Izugbara, 2008; Wamoyi at al., 2010). Finally, 61\% of parents of 10-12 year old children in Kenya thought that they were too young to learn about sex ( Poulsen et al., 2010). These findings highlight a range of barriers perceived both by adults and young people to communicating about sex-related topics. Another study conducted in Nigeria found that low levels of communication were related to parental perceptions of their child's readiness or maturity, the assumption that their child would have heard about these issues elsewhere, that discussions of contraception for instance should be restricted to married people, and the often cited concern that such discussions may 'corrupt' young people or encourage early experimentation (Adeyemo \& Brieger, 1994).

Studies also investigated young people's perspectives on barriers to sexuality communication with their parents. A number of studies identified parental lack of knowledge of sexual and reproductive health as a barrier to communicating with their children. For instance, one study in Nigeria found that $64 \%$ of secondary school students perceived their mothers as lacking sufficient knowledge, while $87 \%$ thought fathers lacked knowledge (Mathew, Shugaba \& Ogala, 2006). In identifying other barriers to communication, this study found that $62.3 \%$ thought that their parents are too preoccupied to talk about sex, while $59 \%$ believed their parents would argue if they were to talk about sex. In addition, 30\% thought their mother would think they were interested in experimenting with sex if they were to talk about it, whilst $69 \%$ believed their father would get this impression.

Focus group data from Ghana show that young people are reluctant to discuss sexuality with their parents since they tend to prefer to discuss these issues with their friends, because they feel shy, and also because they may fear physical punishment for discussing sexuality (Kumi-Kyereme, Awusabo-Asare, Biddlemen \& Tanle, 2007). The fear of physical punishment or blame was even said to deter reporting to parents that unconsensual or unwanted sex had occurred. 


\section{Behavioral outcomes associated with parent-child sexuality communication}

\section{Associations with sexual intentions, behavior and contraceptive use}

The second topic we reviewed focused on studies which investigated behavioral outcomes associated with parent-child sexuality communication. We identified 6 studies which focused on abstinence and delayed sexual debut, and 3 studies which focused on contraceptive use. In terms of parental sexuality communication and odds of sexual activity, the findings from the multi-country study were inconsistent across countries. Among Malawian males and Ugandan females only, sexuality communication was associated with increased odds of having had sex in the last 12 months (Biddlecom, Awusabo-Asare \& Akinrinola, 2009). A cross-sectional study from the Ivory Coast found that parent-child communication in the last 12 months about abstinence was associated with an earlier sexual transition among boys, whereas it was associated with a delayed sexual debut or primary sexual abstinence, as well as secondary sexual abstinence (defined as abstinence in the last 6 months) and a reduction in number of sexual partners among girls (Babalola, Tambashe \& Vondrasek, 2005). A cross-sectional study in Nigeria found that those who reported having been 'instructed' by their mothers about sexual matters before puberty were more likely to have had their sexual debut than those who had not received the same instruction (Amoran, Onadeko \& Adeniyi, 2005). However, it is unclear from the data presented whether or not this was true for both boys and girls in the sample. In Ghana, one cross-sectional study found that communication about sex-related topics with fathers only was negatively associated with having had sex in the last 12 months among boys, but positively associated with sex in the last 12 months among girls (Kumi-Kyereme, Awusabo-Asare, Biddlecom \& Tanle, 2007). Other findings from cross-sectional studies in Ghana suggest mixed findings on this issue, one of which did not find a similar association (Adu-Mireku, 2003) and another which found that communication with family members about avoiding sex was associated with decreased odds of having had sex among males (Karim, Magnani, Morgan \& Bond, 2003). Finally, a study which investigated sexuality communication and timing of sexual debut in Tanzania found that while communication with teachers about HIV and sex was associated with a delayed sexual debut, parental communication was not after adjusting for age and conducting multivariate logistic regression (Kawai et al., 2008).

Based on the studies reviewed here, the relationship between sexuality communication and contraceptive use is unclear. The study conducted in 4 African countries found that parent-child sexuality communication was positively associated with contraceptive use for Ghanaian females and for Ugandan females and males (Biddlecom, AwusaboAsare \& Akinrinola, 2009). Another study conducted in Ghana found that communication about contraceptive use was associated with an increased likelihood of being sexually experienced among both sexes (Karim, Magnani, Morgan \& Bond, 2003). The study also found that the association between communication about sex and contra- 
ception and condom use was overall weak, except where it concerned consistent condom use with the last partner among males (Karim, Magnani, Morgan \& Bond, 2003). However, the same study also reported the puzzling finding that communication about contraceptives was associated with a decreased likelihood of condom use at first sex among males. Evidence from a cross-sectional study conducted in Ghana found that communication about HIV/AIDS between students and parents or other family members increased the odds of using a condom at last sexual intercourse (Adu-Mireku, 2003). Although this finding is promising, due to the wording of the question, it is not possible to determine who the communication took place with and what role gender may play in moderating this effect.

\section{Intervention studies focused on improving parent-child sexuality communication}

There are few examples of interventions with an explicit focus on promoting and improving sexuality communication between parents and offspring in sub-Saharan Africa. However, results from the four intervention studies reviewed here are promising. One recent intervention called IMAGE (Intervention with Microfinance for AIDS and Gender Equity) in rural South Africa designed to reduce levels of HIV and intimate partner violence also included a component which aimed to promote communication between adults and young people (Phetla et al., 2008). The quantitative and qualitative findings from this study indicate that women who participated in intervention activities reported significantly more frequent discussion about sexuality with children than women in the control group. Moreover, both intervention participants and young people reported that as a result of their participation, the content of the discussions became more specific and concrete about risk reduction strategies rather than vague messages or admonitions. Women who participated in the intervention felt that they had developed a skill set which enabled them to be more comfortable in discussing sexuality. Several other positive benefits were reported by intervention participants that are worth mentioning. It was reported that as women's awareness and skills grew through their participation, they began to feel a heightened sense of responsibility and obligation to share their knowledge with others in their community for the benefit of young people. Furthermore, a need for change in terms of cultural norms and expectations which impede parent-child sexuality communication was also recognized. However gender norms were more difficult to reconcile with several reporting difficulty in discussing sexuality with boys and opting for indirect strategies to convey risk reduction messages.

The quantitative data from this study also suggests positive intervention results, with an increase in the frequency and perceived comfort level of intervention participants to discuss HIV and other sex-related topics in comparison to the matched women in the control group (Phetla et al., 2008). This was the only study identified for this review which compared responses of parents and young people. The findings indicate that fewer young people reported having communicated about sexuality with parents in 
comparison to parental reports ( $51 \%$ vs. $80 \%$ ). However, as the authors note, the findings are not exactly comparable since young people were asked about communication with either parent and/or guardians, whilst mothers were asked about communication with their own and/or their friends' children. Young people residing in intervention households in this study reported higher levels of communication compared with a matched cohort in control villages; however the effect was not statistically significant when cluster analysis was applied to the data.

Another family-based HIV prevention intervention in South Africa called CHAMP (Collaborative HIV/AIDS and Adolescent Mental Health Programme) has been adapted from the United States (Paruk et al., 2005), with positive results reported among parents (Bhana et al., 2004). This intervention attempted to strengthen what it identified as key family processes which influence youth risk-taking behaviour such as parental monitoring, discipline effectiveness, and parent/caregiver and youth frequency and comfort in communicating about sensitive topics. In the South African context, the intervention consisted of a series of 10 manual-based sessions delivered to families with children between the ages of 10 and 11 years, with a qualitative process evaluation of the intervention at two year follow up of the same cohort (Paruk, Petersen \& Bhana, 2009). A wide range of topics were included in the manual such as parenting styles, monitoring of children, improving communication between parent and child on sensitive topics such as puberty, among others. The intervention was described as utilizing Freireian principles of participatory adult education and critical consciousness through small group experiential learning. In particular, an open-ended participatory cartoon narrative was used to engage families, with a workbook with assignments to take home to involve other family members.

In addition to other measures such as AIDS knowledge, social networks and stigma, the study assessed parental communication styles and topics that parents have difficulty talking about with their children. In terms of parenting communication styles, findings showed that the intervention group made a significant shift from engaging passive aggressive and manipulative communication styles to more assertive styles in relation to comparison group. The intervention group also showed significant improvement in their ability to discuss sensitive topics with their children in comparison to control group. Frequency of discussion was also reported to improve in the intervention group, for instance discussion about puberty increased from 55\% to 69\%, whilst discussion about sex which was ranked most difficult to talk about improved from $55 \%$ to $73 \%$ post intervention (Bhana et al., 2004). Findings from the qualitative follow-up evaluation of the intervention reported positive findings in terms of empowerment at the individual level (both parental and as a woman) and the collective level, enhanced perceptions of social support and social capital ( Paruk, Petersen \& Bhana, 2009).

The CHAMP intervention has also been subsequently tested and evaluated among black South Africans (Bell et al., 2008). This intervention also reported positive findings, however with greater intervention effects observed on caregivers than on youth. For 
instance, caregiver findings demonstrated significant intervention group differences in comparison to control with regard to caregiver monitoring and control of their children's whereabouts and behaviour. In addition, the intervention group reported increased frequency and comfort discussing HIV/AIDS and sexuality with their children, among other outcomes. With regard to youth, findings showed an increase in HIV knowledge in the intervention group compared to the control, as well as lower levels of stigma, with more limited effects on communication.

Finally, the Families Matter! Program, also adapted from a US to Kenyan context has recently been evaluated to assess intervention effect on parenting practices and parentchild communication (Vandenhoudt et al., 2010). The objective of the communitybased program is to improve protective parenting skills, knowledge, comfort and confidence of parents of children aged 9-12 years so that they can communicate about sexual reduction prior to the onset of sexual activity. Participatory learning strategies are utilized in a series of small group sessions delivered by trained facilitators. In the final session, children join and participate in a guided communication exercise. Evaluation of the program focused on 3 measures: parental attitudes towards sexuality education and whether children had ever asked their parent about a sex issue, parenting practices (comprised of parent-child relationship, positive reinforcement and monitoring) and parental responsiveness (conceptualized as parents' skill, comfort and confidence to communicate about sexuality with their child) (Vandenhoudt et al., 2010). Positive intervention effects at follow-up were found on all parenting measures except parents' report of the parent-child relationship, which the authors' note was already high at baseline with little room for improvement (Vandenhoudt et al., 2010). The intervention also positively impacted frequency of parent-child sexuality communication from $17 \%$ of children reporting having asked their parent a question about sexuality at baseline to $38 \%$ at 12 months follow-up, and $14 \%$ of parents reporting being asked a question about sexuality from their child at baseline, to $50 \%$ at follow-up (Vandenhoudt et al., 2010). In addition to these positive intervention effects, the study also found that the program was well received by parents who found it beneficial in terms of skill and confidence development, and also changed their overall attitude towards sexuality education including the belief that communicating about sexuality leads to early sexual experimentation.

\section{DISCUSSION}

The number of studies aiming to understand and improve parent-child sexuality communication in SSA is steadily increasing. Although this is a promising finding in itself, it is evident from this review that there is substantial variation in measurement and methods of investigating sexuality communication, effectively limiting the conclusions that can be drawn. Indeed, given the heterogeneity of the measures employed in the stud- 
ies included in this review, it is clear that there is a need to standardize communication measures so that comparisons can be made across studies.

The findings of the review demonstrate that the frequency of discussions about sexuality between parents and offspring varies markedly across contexts. Important information concerning the myriad factors associated with parent-child sexuality communication can be gleaned from the findings of this review, although the consistency in study findings suggests the need for further research on this topic. A range of sociodemographic characteristics were identified as being associated with parent-child sexuality communication by the studies, including sex, age, urban or rural residence, socioeconomic status, school attendance, parental level of education, religious affiliation and other household characteristics such as family size and marital status of the parents. Inconsistencies across studies likely point to contextual or methodological differences.

Aside from demographics, other factors which may be more amenable to change through future interventions and programs were identified. For instance, the findings from a comparative study of factors associated with parent-child communication about HIV/AIDS in the United States and Kenya identified the same three factors, suggesting robustness across contexts. In particular, the findings of this study indicate that parental perceptions of readiness of their child to learn about sexuality are highly influential, as are parental acquisition of information to assist them in educating their child, and finally, having a high level of 'sexual communication responsiveness'. Findings of several studies reiterated the importance of timeliness in sexuality discussions, of particular concern since programs and interventions have been found to be most effective when they target young people prior to their sexual debut. Thus, understanding how parents assess whether or not their child has had their sexual debut and conveying to them that discussions need to take place before they believe their child has had their sexual transition are important aspects to be considered when attempting to improve parent-child sexuality communication. Future research on outcome expectancies seems particularly important, given widespread concerns that sexuality discussions will lead to early experimentation, and interventions to address this misconception are also necessary to encouraging proactive communication.

A number of barriers to parent-child sexuality communication were also identified by the review, which should be taken into consideration in the development of interventions and programs. For instance, as mentioned above, lack of parental knowledge was reportedly a barrier, as perceived by parents and young people alike. This suggests that programmatic efforts need to target not only parental knowledge, but their selfefficacy and comfort to communicate with their children about sexuality. Skills based programs which incorporate role-plays may be one way to improve parental communication skills. In addition, since several studies in the review found that communication tends to be uni-directional, authoritarian and negative towards sexuality, role-play may assist parents in efforts to engage their children in a more dialogical, positive approach. Given the negative perceptions of parents that emerged from the qualitative studies on 
parental communication, it is clear that fostering the development of communication skills for parents is of importance. The cluster of attributes defined as 'parental responsiveness', including being skilled, comfortable and confident, may impact the quality of parent-child sexuality communication. Since quality may subsequently impact important outcomes such as knowledge, attitudes, intentions and behaviours, these interrelated issues need to be addressed more systematically in future studies.

In addition, the studies also pointed to the social and cultural norms which demarcate the boundaries surrounding sexuality communication with children in SSA which need to be addressed in efforts to promote and improve communication. Historical factors also play a role in shaping sexuality communication as one study in Kenya found, with residual traditional barriers and inhibitions related to European Christianity inhibiting open and direct communication. These findings demonstrate that efforts need to be multi-level and directed at the community level to increase awareness of the importance of parent-child sexuality communication.

In terms of the impact of communication on sexual intentions, behavior and contraceptive use, findings from this review are inconclusive and this is a topic of importance for future studies, particularly since a number of studies identified an association between parental communication about sexuality and sexual activity. Findings suggest a differential effect for boys and girls, and again, the issue of timing likely plays a key role in this regard.

There is a paucity of family-based interventions or those which target parent-child sexuality communication in SSA which have been rigorously evaluated, but the available findings are promising. The findings reviewed here suggest that if parents are given support to develop the attributes comprising 'parental responsiveness', they can and will communicate with their children about HIV/AIDS and sexuality. The interventions reviewed here demonstrate that it is possible to increase frequency of discussion about sensitive topics and improve the comfort level of parents, while also improving the content of the discussions to the extent that they are more explicit and less vague. The findings also point to the possibility of raising awareness of social and cultural norms which were hindering sexuality communication with the aim to begin to challenge these norms. However, as one particularly critical study highlighted, the theoretical, conceptual and methodological bases for advocating parent-child sexuality communication require careful examination and consideration in the development of such programs and interventions.

This review of parent-child sexuality communication in sub-Saharan Africa points to several gaps in the extant literature. Firstly, since the timing of sexuality discussions may impact the effectiveness of communication and since it has been identified as a particularly contentious issue, further research is needed to fully understand parental concerns and how these can be addressed in interventions and programs aiming to promote sexuality communication. Closely linked with timing are the issues of content and tone of discussions. As the findings in this review indicate, parents frequently favor 
indirect communication strategies and when communication is more direct it often comes in the form of warnings, admonitions and lectures. More qualitative data are needed to understand more fully how parents communicate with their children about sexuality and the strategies they employ. An additional gap identified by this review is the lack of information available about perceptions of quality of parent-child sexuality communication. Also limiting our understanding of parent-child sexuality communication, the qualitative process studies we reviewed focused primarily on mothers, leaving a major gap in our understanding of the role that fathers play in the parenting process and sexual socialization of children in sub-Saharan Africa. Further studies on this topic would be particularly useful to gain a more in-depth understanding of their role and thus determine how interventions can best strengthen their involvement. In addition, several studies in the review mention that future studies should investigate dimensions of parenting, including style, monitoring and control, attitudes, connectedness and communication, all of which may impact sexuality communication and which clearly merit further investigation. Finally, greater understanding is also needed of how social change is influencing the family unit, including the effects of increasing urbanization in Africa especially as it relates to the move to more nuclear families as opposed to living with the extended family and subsequently impacting communication. It is likely that this varies in urban and rural settings and more data are needed to understand how traditional practices and modes of sexual socialization are shifting.

There are additional limitations to consider when interpreting the findings of this review. Since we did not include studies which were not peer reviewed, we have not tapped into the grey literature on this subject, nor have we included theses and dissertations which may contribute relevant findings. In addition, although we did not identify any studies in languages other than English, there is a possibility that we may have missed studies written in other languages. In addition, in focusing on parent or caregiver-child sexuality communication, we have not reviewed studies related to issues such as parental control and monitoring, which is a topic receiving growing interest (Wamoyi et al., 2011; Wamoyi at al., 2011). Nor have we included studies which focus broadly on sexual socialization of children in African countries and studies which have more limited discussions of parental involvement. Finally, we also did not include studies which investigate other influential family members such as aunts. For instance, several studies have shown that aunt's played a key role in the sexual socialization of young girls (Kinsman, Nyanzi \& Pool, 2000; Muyinda, Nakuya, Pool \& Whitworth, 2003; Muyinda, Nakuya, Whitworth \& Pool, 2004).

It is also important to consider the methodological limitations of the studies themselves. The findings of the review are limited by the cross-sectional nature of the majority of the quantitative studies, which are limited in terms of establishing causality. In addition, several studies utilized convenience samples and therefore cannot be considered representative. Also, given the nature of self-report data, study results may have 
been biased. Finally, the fact that the majority of studies utilized only one perspective (either parent or child) may also have biased the findings of this review.

\section{CONCLUSIONS}

Whilst the number of studies investigating parent-child sexuality communication in subSaharan Africa is increasing, there is a need for future research employing both qualitative and quantitative methods which elucidates the factors influencing communication, including skills and intentions, as well as barriers and facilitators. This is particularly important given the tentative but promising findings of this review that parents will talk to their children about sexuality if given the appropriate support. 


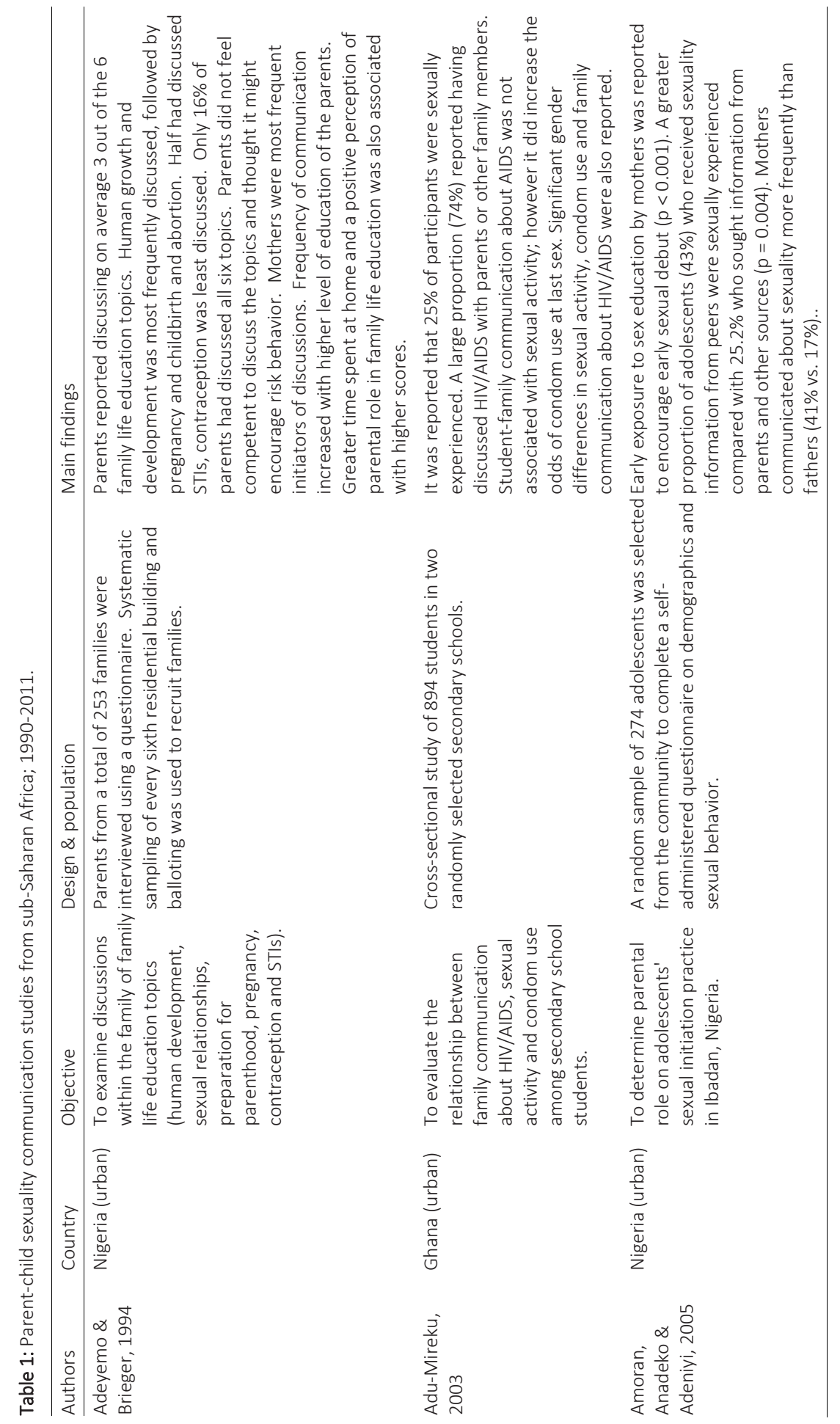




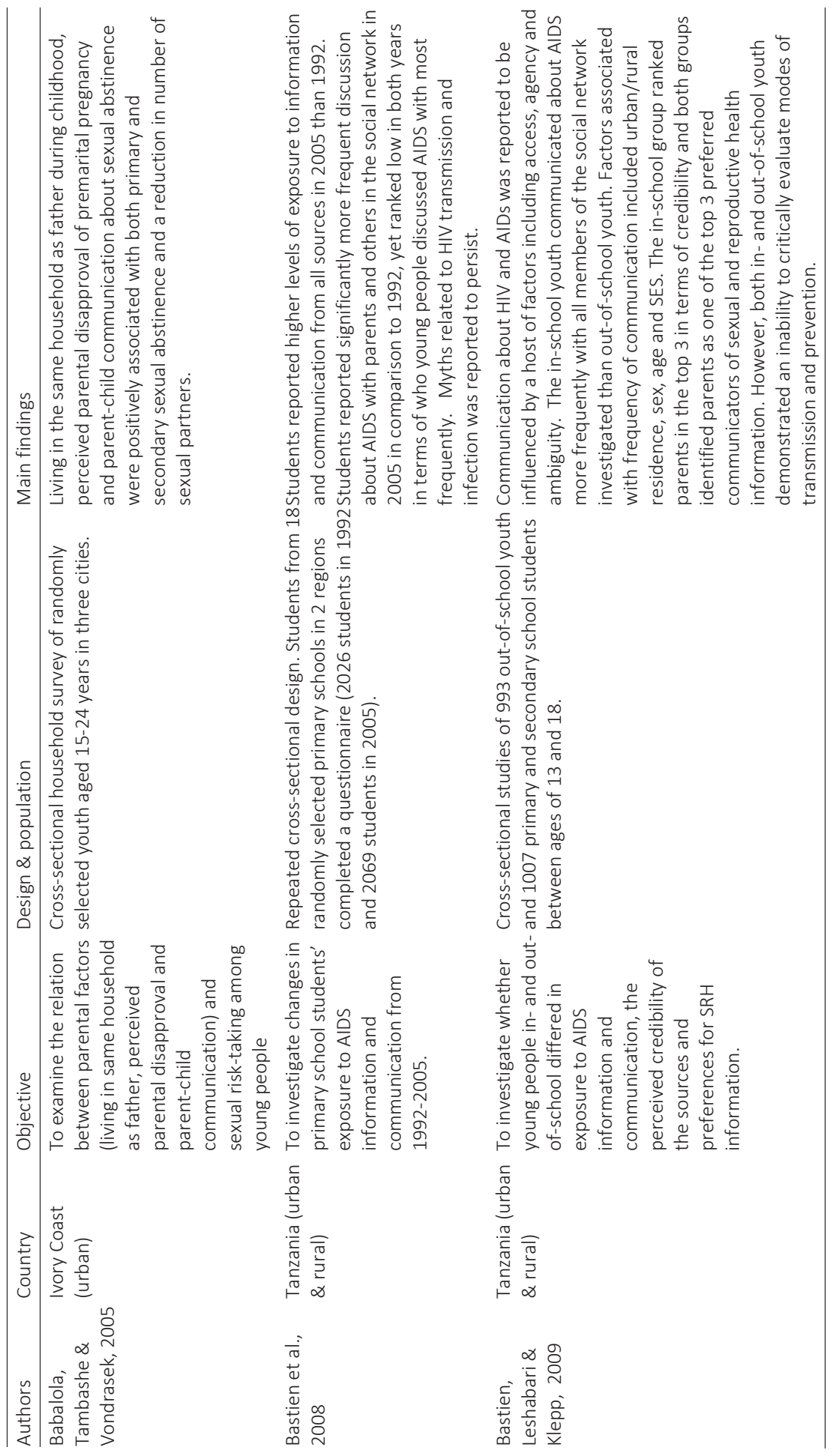




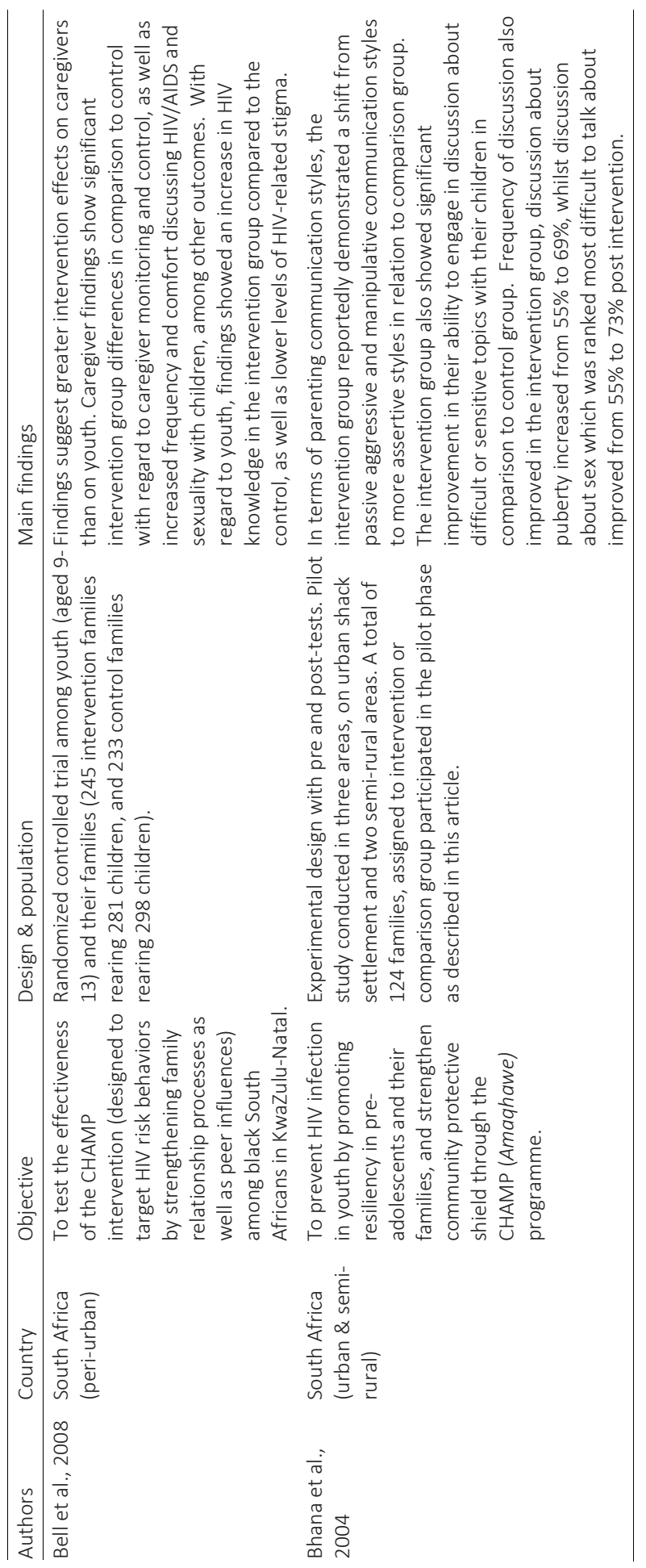




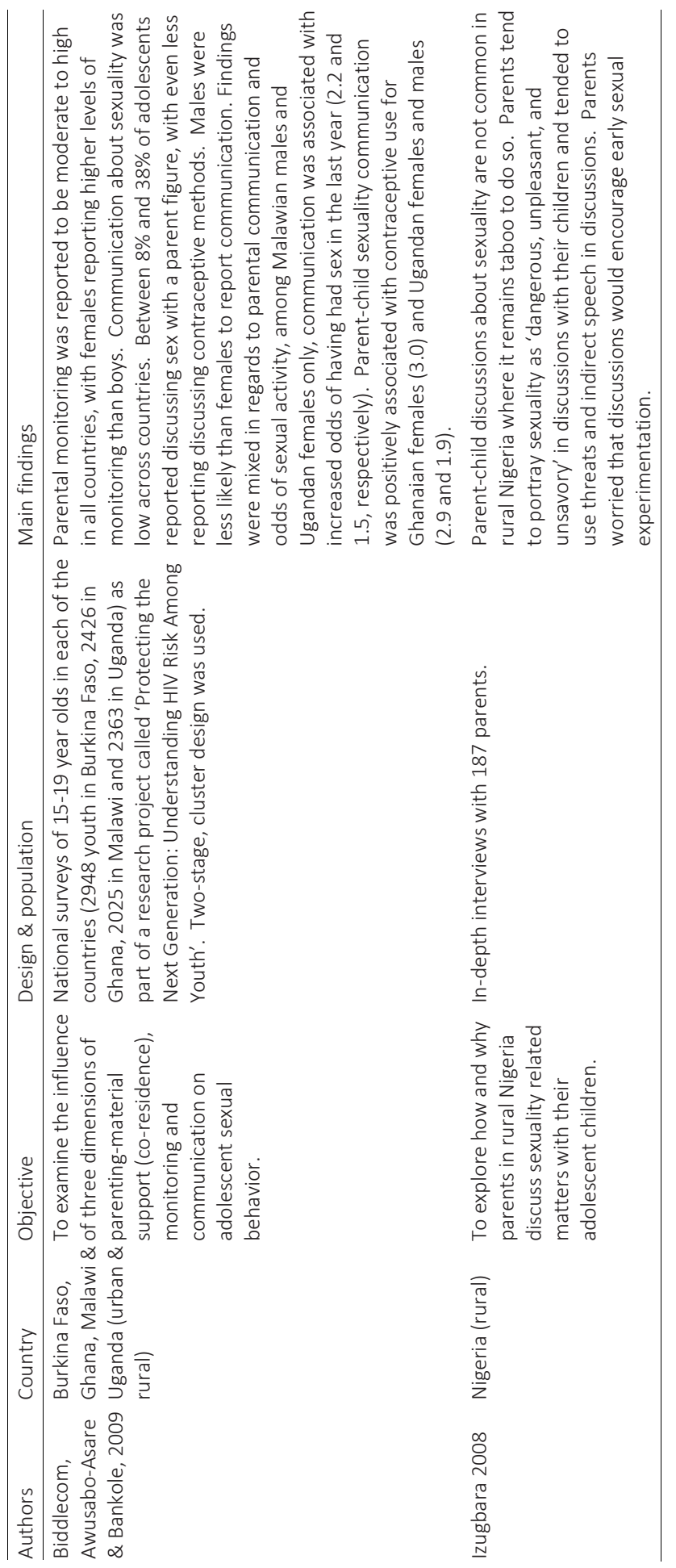




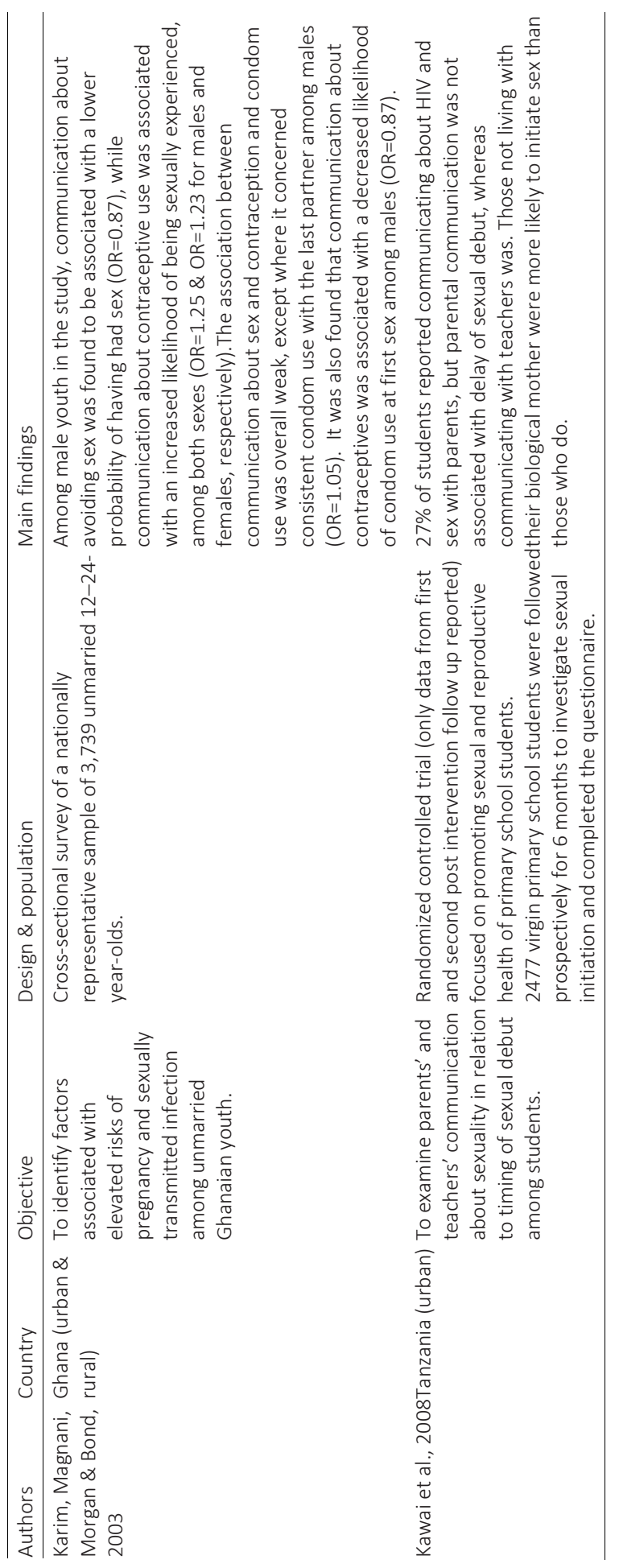




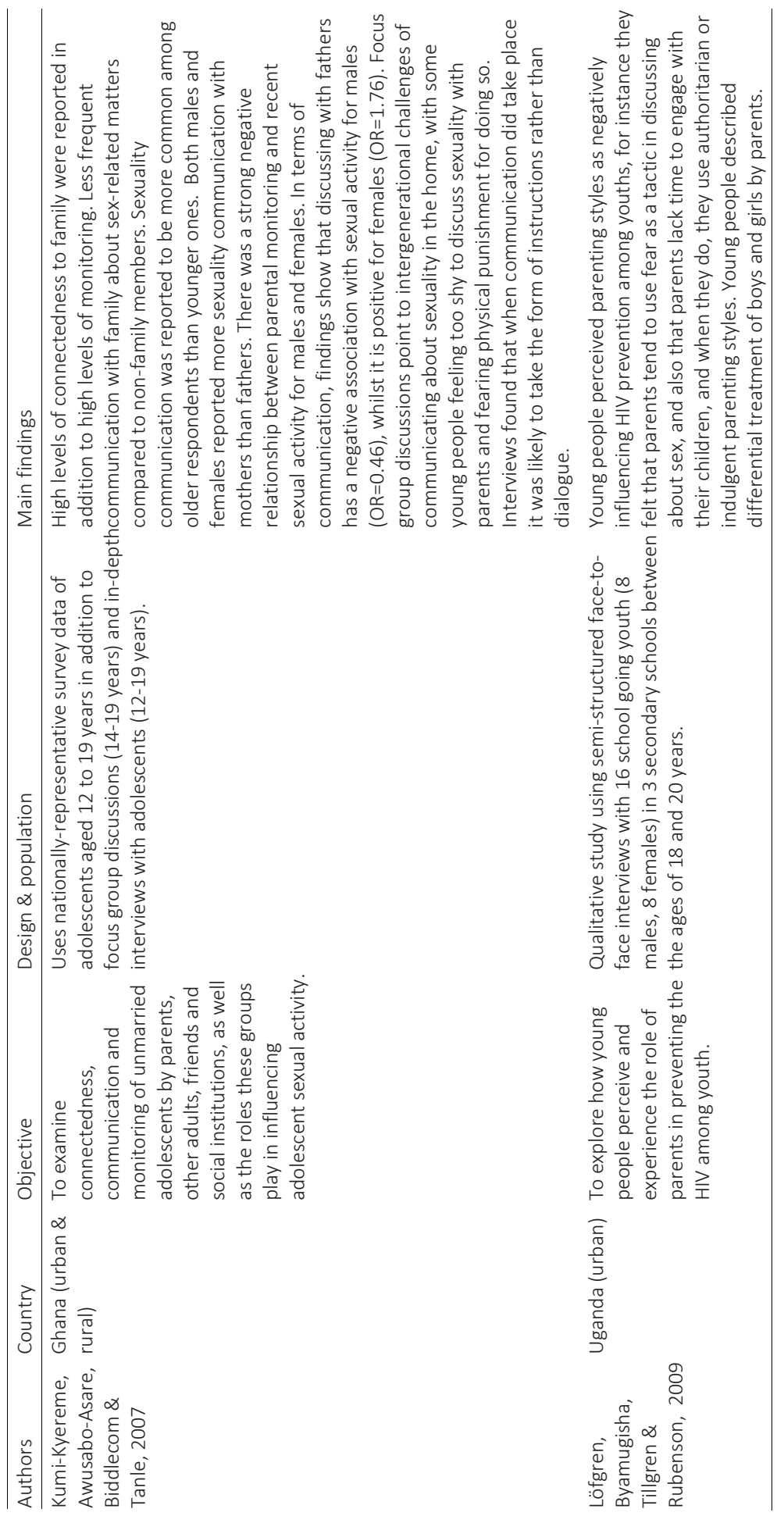




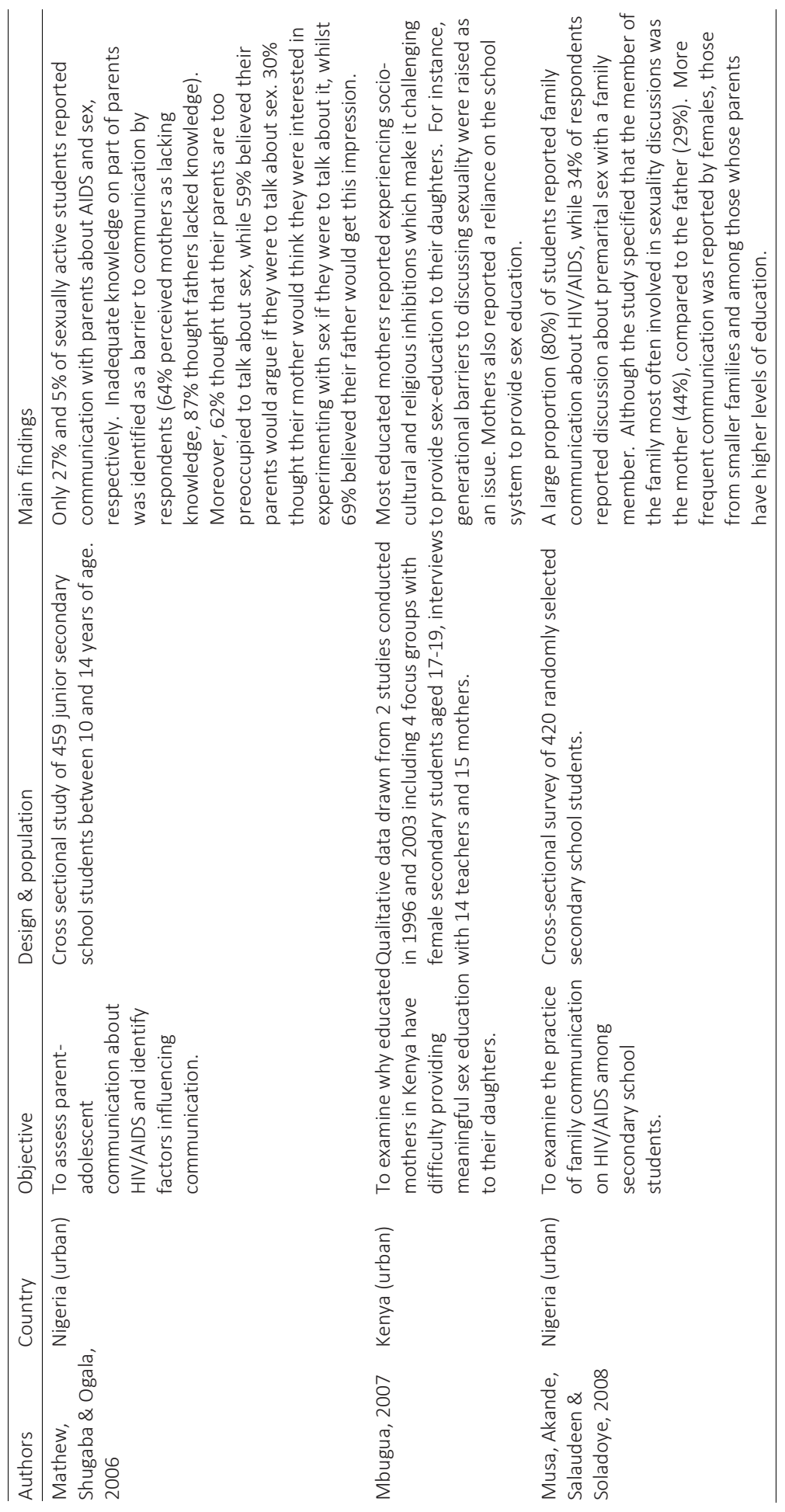




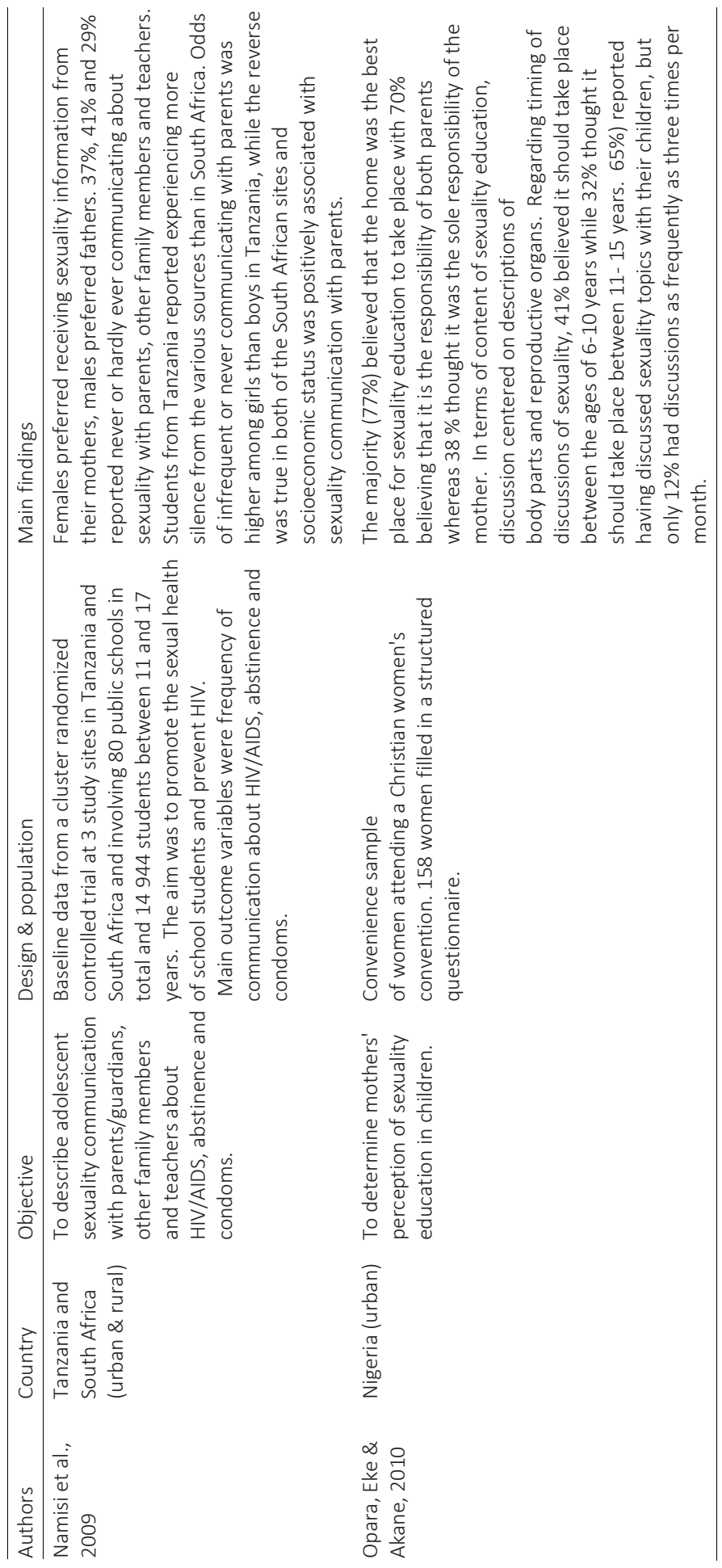




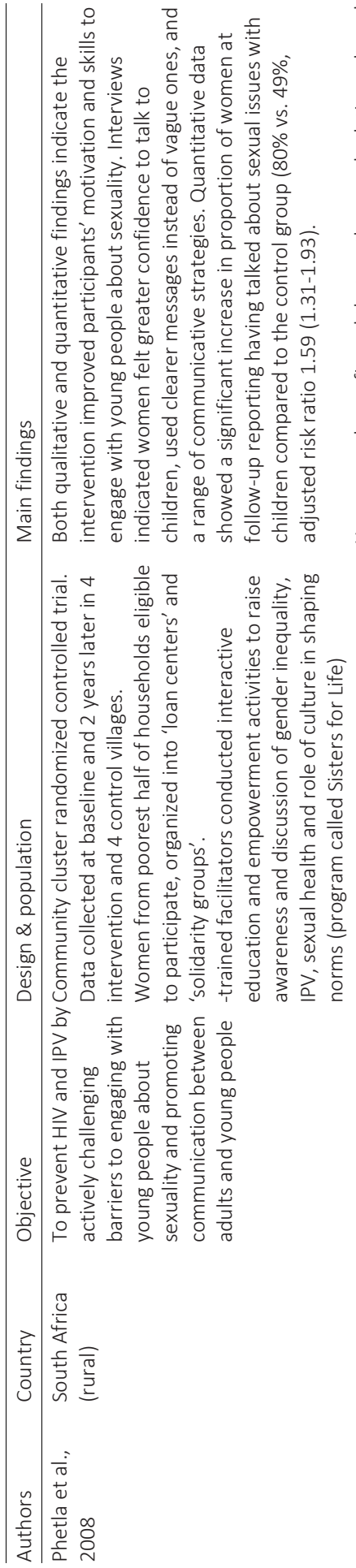

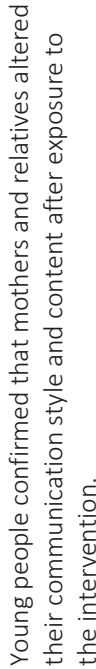

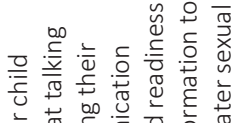

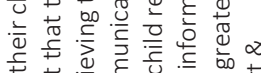

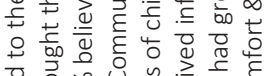

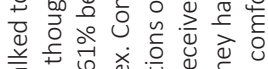

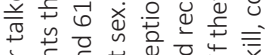

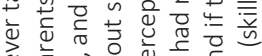

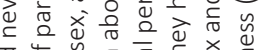

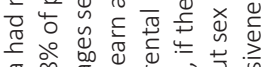

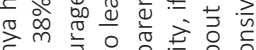

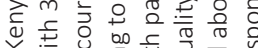

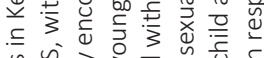

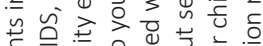

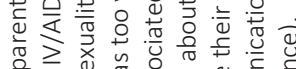

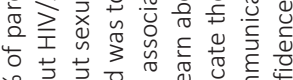

○े

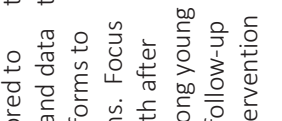

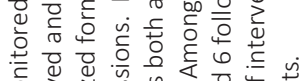

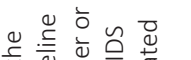

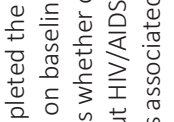

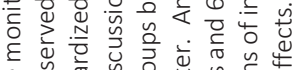

है

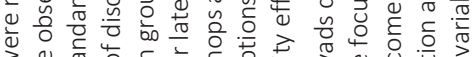

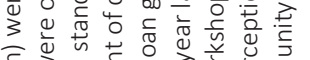

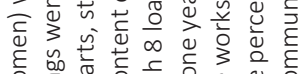

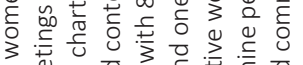

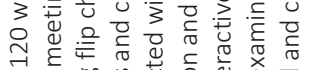

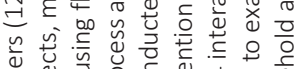

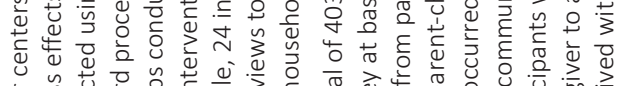

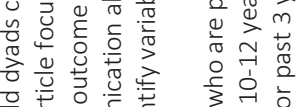

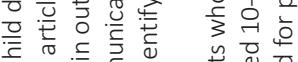

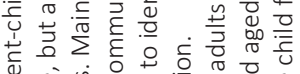

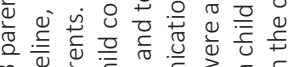

m

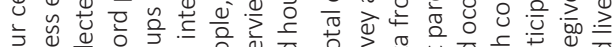

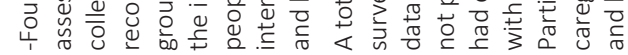

ฯ 苍 $\varepsilon$ ऽ

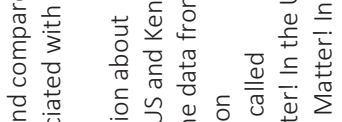

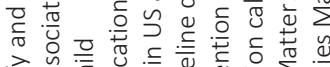

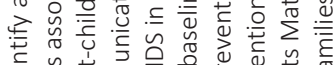

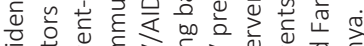

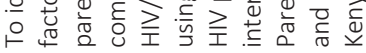

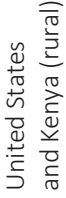

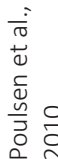




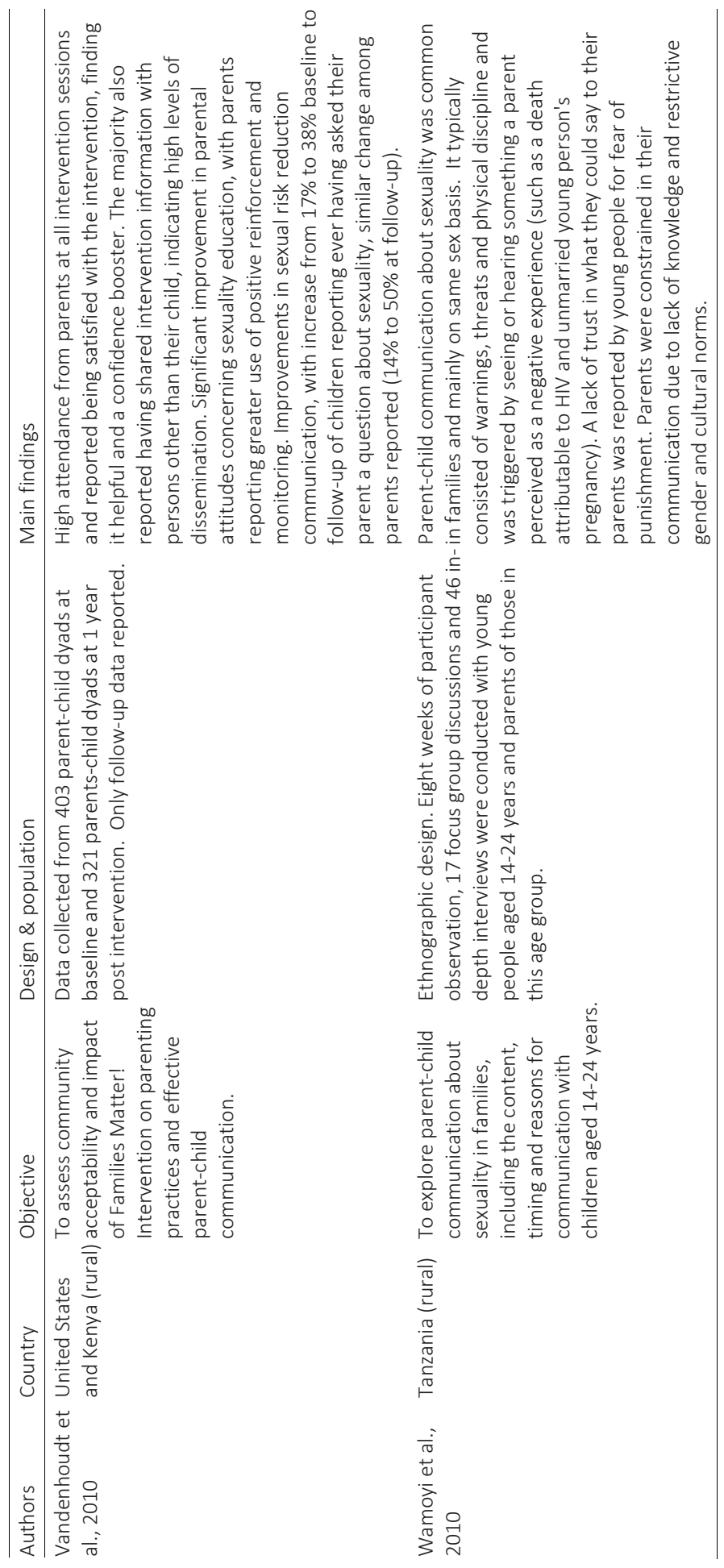




\section{REFERENCES}

Adeyemo, M. O., \& Brieger, W. R. (1994). Dissemination of family life education to adolescents by their parents in suburban ibadan, Nigeria. International quarterly of community health education, 15(3), 241-252.

Adu-Mireku, S. (2003). Family communication about HIV/AIDS and sexual behaviour among senior secondary school students in Accra, Ghana. African Health Sciences, 3(1), 7-14.

Amoran, O. E., Onadeko, M. O., \& Adeniyi, J. D. (2003). Parental influence on adolescent sexual initiation practices in Ibadan, Nigeria. International Quarterly of Community Health Education, 23(1), 73-81.

Amuyunzu-Nyamongo, M., Biddlecom, A. E., Ouedraogo, C., \& Woog, V. (2005). Qualitative evidence on adolescents' views of sexual and reproductive health in Sub-Saharan Africa. Occasional Report, 16.

Babalola, S., Tambashe, B. O., \& Vondrasek, C. (2005). Parental factors and sexual risk-taking among young people in Cote d'Ivoire. African journal of reproductive health, 49-65.

Bastien, S., Sango, W., Mnyika, K. S., Masatu, M. C., \& Klepp, K. I. (2008). Changes in exposure to information, communication and knowledge about AIDS among school children in Northern Tanzania, 1992-2005. AIDS care, 20(3), 382-387.

Bastien, S., Leshabari, M. T., \& Klepp, K. I. (2009). Exposure to information and communication about HIV/AIDS and perceived credibility of information sources among young people in northern Tanzania. African Journal of AIDS Research, 8(2), 213-222.

Bell, C. C., Bhana, A., Petersen, I., McKay, M. M., Gibbons, R., Bannon, W., \& Amatya, A. (2008). Building protective factors to offset sexually risky behaviors among black youths: a randomized control trial. Journal of the National Medical Association, 100(8), 936.

Biddlecom, A., Awusabo-Asare, K., \& Bankole, A. (2009). Role of parents in adolescent sexual activity and contraceptive use in four African countries. International perspectives on sexual and reproductive health, 72-81.

Bhana, A., Petersen, I., Mason, A., Mahintsho, Z., Bell, C., \& McKay, M. (2004). Children and youth at risk: Adaptation and pilot study of the CHAMP (Amaqhawe) programme in South Africa. African Journal of AIDS Research, 3(1), 33-41.

Camlin, C. S., \& Snow, R. C. (2008). Parental investment, club membership, and youth sexual risk behavior in Cape Town. Health Education \& Behavior, 35(4), 522-540.

Davis, E. C., \& Friel, L. V. (2001). Adolescent sexuality: Disentangling the effects of family structure and family context. Journal of Marriage and Family, 63(3), 669-681.

DiClemente, R. J., Wingood, G. M., Crosby, R., Cobb, B. K., Harrington, K., \& Davies, S. L. (2001). Parentadolescent communication and sexual risk behaviors among African American adolescent females. The Journal of pediatrics, 139(3), 407-412.

Dimbuene, Z. T., \& Defo, B. K. (2011). Risky sexual behaviour among unmarried young people in Cameroon: another look at family environment. Journal of Biosocial Science, 43(02), 129-153.

Downing, J., Jones, L., Bates, G., Sumnall, H., \& Bellis, M. A. (2011). A systematic review of parent and familybased intervention effectiveness on sexual outcomes in young people. Health education research, 26(5), 808-833.

Feldman, S. S., \& A. Rosenthal, D. (2000). The effect of communication characteristics on family members' perceptions of parents as sex educators. Journal of Research on Adolescence, 10(2), 119-150.

Fuglesang, M. (1997). Lessons for life-Past and present modes of sexuality education in Tanzanian society. Social Science \& Medicine, 44(8), 1245-1254.

Halpern-Felsher, B. L., Kropp, R. Y., Boyer, C. B., Tschann, J. M., \& Ellen, J. M. (2004). ADOLESCENTS'SELFEFFICACY TO COMMUNICATE ABOUT SEX: ITS ROLE IN CONDOM ATTITUDES, COMMITMENT, AND USE. Adolescence, 39(155), 443.

Izugbara CO. Home-based sexuality education : Nigerian parents discussing sex with their children. Youth \& Society 2008;39(4):575-600.

Jaccard, J., Dittus, P. J., \& Gordon, V. V. (1998). Parent-Adolescent Congruency in Reports of Adolescent Sexual Behavior and in Communications about Sexual Behavior. Child development, 69(1), 247-261. 
Kaaya, S. F., Flisher, A. J., Mbwambo, J. K., Schaalma, H., Aarø, L. E., \& Klepp, K. I. (2002). Review article: a review of studies of sexual behaviour of school students in sub-Saharan Africa. Scandinavian Journal of Public Health, 30(2), 148-160.

Karim, A. M., Magnani, R. J., Morgan, G. T., \& Bond, K. C. (2003). Reproductive health risk and protective factors among unmarried youth in Ghana. International family planning perspectives, 14-24.

Kawai, K., Kaaya, S. F., Kajula, L., Mbwambo, J., Kilonzo, G. P., \& Fawzi, W. W. (2008). Parents' and teachers' communication about HIV and sex in relation to the timing of sexual initiation among young adolescents in Tanzania. Scandinavian Journal of Public Health, 36(8), 879-888.

Kinsman, J., Nyanzi, S., \& Pool, R. (2000). Socializing influences and the value of sex: the experience of adolescent school girls in rural Masaka, Uganda. Culture, Health \& Sexuality, 2(2), 151-166.

Kirby, D., Obasi, A., \& Laris, B. A. (2006). The effectiveness of sex education and HIV education interventions in schools in developing countries. Technical Report Series-World Health Organization, 938, 103.

Kumi-Kyereme, A., Awusabo-Asare, K., Biddlecom, A., \& Tanle, A. (2007). Influence of social connectedness, communication and monitoring on adolescent sexual activity in Ghana. African journal of reproductive health, 11(1), 133.

Lefkowitz, E. S., Boone, T. L., Sigman, M., \& Au, T. K. F. (2002). He said, she said: Gender differences in mother-adolescent conversations about sexuality. Journal of Research on Adolescence, 12(2), 217-242.

Lesch, E., \& Kruger, L. M. (2005). Mothers, daughters and sexual agency in one low-income South African community. Social Science \& Medicine, 61(5), 1072-1082.

Löfgren, J., Byamugisha, J., Tillgren, P., \& Rubenson, B. (2009). The perspectives of in-school youths in Kampala, Uganda, on the role of parents in HIV prevention. African Journal of AIDS Research, 8(2), 193-200.

Mathew, R. M., Shugaba, A. I., \& Ogala, W. N. (2006). Parents-adolescents Communication and HIV/AIDS in Jos North Local Government Area, Plateau State, Nigeria. Journal of Medical Sciences, 6(4), 537-545.

Markham, C. M., Lormand, D., Gloppen, K. M., Peskin, M. F., Flores, B., Low, B., \& House, L. D. (2010). Connectedness as a predictor of sexual and reproductive health outcomes for youth. Journal of Adolescent Health, 46(3), S23-S41.

Miller, K. S., Kotchick, B. A., Dorsey, S., Forehand, R., \& Ham, A. Y. (1998). Family communication about sex: What are parents saying and are their adolescents listening?. Family planning perspectives, 218-235.

Miller, K. S., Forehand, R., \& Kotchick, B. A. (1999). Adolescent sexual behavior in two ethnic minority samples: The role of family variables. Journal of Marriage and the Family, 85-98.

Musa, O. I., Akande, T. M., Salaudeen, A. G., \& Soladoye, O. M. (2008). Family communication on HIV/AIDS among secondary school students in a northern state of Nigeria. African Journal of Infectious Diseases, 2(1), 46-50.

Muyinda, H., Nakuya, J., Pool, R., \& Whitworth, J. (2003). Harnessing the senga institution of adolescent sex education for the control of HIV and STDs in rural Uganda. AIDS care, 15(2), 159-167.

Muyinda, H., Nakuya, J., AG Whitworth, J., \& Pool, R. (2004). Community sex education among adolescents in rural Uganda: utilizing indigenous institutions. AIDS care, 16(1), 69-79.

Mbugua, N. (2007). Factors inhibiting educated mothers in Kenya from giving meaningful sex-education to their daughters. Social Science \& Medicine, 64(5), 1079-1089.

Namisi FS, Flisher AJ, Overland S, Bastien S, Onya H, Kaaya S, Aaro LE. Sociodemographic variations in communication on sexuality and HIV/AIDS with parents, family members and teachers among in-school adolescents: a multi-site study in Tanzania and South Africa. Scand J Public Health 2009 June;37 Suppl 2:65-74.

Noar, S. M., Carlyle, K., \& Cole, C. (2006). Why communication is crucial: Meta-analysis of the relationship between safer sexual communication and condom use. Journal of health communication, 11(4), 365-390.

Ngom, P., Magadi, M. A., \& Owuor, T. (2003). Parental presence and adolescent reproductive health among the Nairobi urban poor. Journal of Adolescent Health, 33(5), 369-377.

Odimegwu, C. O., Solanke, L. B., \& Adedokun, A. (2002). Parental characteristics and adolescent sexual behaviour in Bida local government area of Niger State, Nigeria. African Journal of Reproductive Health, 95106.

Opara, P. I., Eke, G. K., \& Akani, N. A. (2010). Mothers perception of sexuality education for children. Nigerian journal of medicine, 19(2). 
Paruk, Z., Petersen, I., Bhana, A., Bell, C., \& McKay, M. (2005). Containment and contagion: How to strengthen families to support youth HIV prevention in South Africa. African Journal of AIDS Research, 4(1), 57-63.

Paruk, Z., Petersen, I., \& Bhana, A. (2009). Facilitating health-enabling social contexts for youth: qualitative evaluation of a family-based HIV-prevention pilot programme. African Journal of AIDS Research, 8(1), 6168.

Paul-Ebhohimhen, V. A., Poobalan, A., \& Van Teijlingen, E. R. (2008). A systematic review of school-based sexual health interventions to prevent STI/HIV in sub-Saharan Africa. BMC public health, 8(1), 1.

Peltzer, K. (2010). Early sexual debut and associated factors among in-school adolescents in eight African countries. Acta Paediatrica, 99(8), 1242-1247.

Poulsen, M. N., Miller, K. S., Lin, C., Fasula, A., Vandenhoudt, H., Wyckoff, S. C., ... \& Forehand, R. (2010). Factors associated with parent-child communication about HIV/AIDS in the United States and Kenya: a cross-cultural comparison. AIDS and Behavior, 14(5), 1083-1094.

Phetla, G., Busza, J., Hargreaves, J. R., Pronyk, P. M., Kim, J. C., Morison, L. A., ... \& Porter, J. D. (2008). "tHEY HavE opEnEd our MoutHs": incrEasing woMEn's skiLLs and Motivation for sExuaL coMMunication witH Young $\mathrm{pEopLE}$ in ruraL soutH africa. AIDS education and prevention: official publication of the International Society for AIDS Education, 20(6), 504.

Rosenthal, D. A., Feldman, S. S., \& Edwards, D. (1998). Mum's the word: Mothers' perspectives on communication about sexuality with adolescents. Journal of Adolescence, 21(6), 727-743.

Rosenthal, D. A., \& Feldman, S. S. (1999). The importance of importance: adolescents' perceptions of parental communication about sexuality. Journal of Adolescence, 22(6), 835-851.

Rwenge, M. (2000). Sexual risk behaviors among young people in Bamenda, Cameroon. International family planning perspectives, 118-130.

Tambashe, B. O., \& Shapiro, D. (1996). Family background and early life course transitions in Kinshasa. Journal of Marriage and the Family, 1029-1037.

Vandenhoudt, H., Miller, K. S., Ochura, J., Wyckoff, S. C., Obong'o, C. O., Otwoma, N. J., ... \& Buvé, A. (2010). Evaluation of a US evidence-based parenting intervention in rural Western Kenya: from parents matter! To families matter!. AIDS Education and Prevention, 22(4), 328.

Wamoyi, J., Fenwick, A., Urassa, M., Zaba, B., \& Stones, W. (2010). Parent-child communication about sexual and reproductive health in rural Tanzania: Implications for young people's sexual health interventions. Reproductive Health, 7(1), 1.

Wamoyi, J., Fenwick, A., Urassa, M., Zaba, B., \& Stones, W. (2011). Parental control and monitoring of young people's sexual behaviour in rural North-Western Tanzania: implications for sexual and reproductive health interventions. BMC Public Health, 11(1), 1.

Wamoyi, J., Fenwick, A., Urassa, M., Zaba, B., \& Stones, W. (2011). Socio-economic change and parent-child relationships: implications for parental control and HIV prevention among young people in rural North Western Tanzania. Culture, health \& sexuality, 13(06), 615-628.

Wight, D., Williamson, L., \& Henderson, M. (2006). Parental influences on young people's sexual behaviour: A longitudinal analysis. Journal of adolescence, 29(4), 473-494.

World Health Organization. (2007). Helping parents in developing countries improve adolescents' health. 


\section{Chapter}

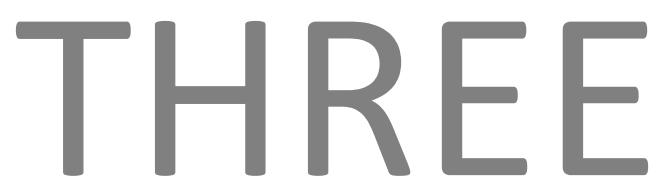

\section{Dynamics of parent-adolescent communication on sexual health and HIV/AIDS in Tanzania}

This chapter has been published as Kajula, L. J., Sheon, N., De Vries, H., Kaaya, S. F., \& Aarø, L. E. (2014). Dynamics of parent-adolescent communication on sexual health and HIV/AIDS in Tanzania. AIDS and Behavior, 18(1), 69-74. 


\section{ABSTRACT}

Communication between parents and their adolescent children has been identified as one of the potential protective factors for adolescent sexual health. Qualitative exploration of sexual health communication with adolescents aged $12-15(\mathrm{~N}=114)$ and a subgroup of the parents ( $N=20$ ) was carried out. Four major themes emerged: reasons for parent-adolescent communications, or lack thereof; the focus of parental messages; the moral of the message; and the barriers to communication between parents and adolescents. Findings revealed similarities and discrepancies in views and perceptions between parents and adolescents. Adolescents and parents suggested that some sexual health communication was happening. Parents were reportedly likely to use fear to ensure that their children do not engage in risky sexual activities, while adolescents reported that conversations with their parents were mostly ambiguous and filled with warnings about the dangers of HIV/AIDS. Several communication barriers were reported by parents and adolescents. Parents of adolescents would benefit from HIV/AIDS specific communication skills. 


\section{INTRODUCTION}

Epidemiological and behavioural studies across the developing world show that adolescents are highly affected by HIV/AIDS, STIs, and unplanned pregnancies. In Tanzania, almost $11 \%$ of adolescents have sex by age 15 . About $5.7 \%$ of Tanzanians aged $15-49$ years are living with HIV; among those aged $15-19$ years, $1.3 \%$ of females and $1 \%$ of males are HIV infected (UNAIDS, 2008; TACAIDS, NBS \& Macro International Inc., 200304; 2005; Kazaura \& Masatu, 2009).

In eastern and central Africa, educating adolescents about sexuality has traditionally been the responsibility of same-sex members of the extended family, such as aunts, uncles, and grandparents (Dilorio, Pluhar \& Belcher, 2003; Miller, Forehand \& Kotchick, 1999). The HIV/AIDS epidemic has prompted some parents to take a more active role in the sexual socialization of their adolescent children in order to protect them (Fuglesang, 1997; Balmer et al., 1997; Muyinda, Nakuya, Pool \& Whitworth, 2003); however, research in Ghana and eastern Africa suggests that adolescents infrequently obtain sexual health information from their parents (Namisi, 2005; Luwanga, 2004; Botchway, 2004; Kajula, 2005).

Although little research has been done on the topic, studies suggest an association between frequent, straightforward parent-adolescent communications about sexual health and protective practices such as delaying sexual initiation, condom use, and reducing the number of sex partners (Markham et al., 2010; Wight, Williamson \& Henderson, 2006). Up to this point, findings related to the role of parents as sexual health educators have been mixed, with some studies showing little or no effect (Kawai et al., 2008) and others suggesting that when parents communicate positively and affirmatively, adolescents are more likely to delay sex, use condoms, and reduce concurrent partnerships (Burleson, Albrecht, Goldsmith \& Sarason, 1994; Shoop \& Davidson, 1994).

This study describes parents' and adolescents' perspectives on communications about sexual health and HIV/AIDS in urban Tanzania, focusing on the similarities and differences between both groups as well as the implications for health practice and research.

\section{METHODS}

\section{Study design}

The study used a cross-sectional design involving 24 in-depth interviews (IDIs) and 12 same-sex focus-group discussions (FGDs). The 12 FGDs averaged 8 participants, with a total of 114 adolescents participating in the study. We also conducted IDIs with parents/guardians of 20 of the 114 adolescents. Data collection and analysis were con- 
ducted using an iterative approach, such that the interview guides evolved to fully explore emerging themes (Denzin \& Lincoln, 2000).

\section{Study implementation}

Adolescents were recruited using criteria-based sampling from 7 randomly selected schools in the Dar es Salaam region. Inclusion criteria were: being registered at one of the schools, being aged 12-15 years, adolescent giving assent, and parent giving passive consent for their adolescent to participate. Parents and adolescents were interviewed separately to identify convergent as well as divergent perspectives regarding sexual health communications.

IDI and FGD guides were developed to explore the following domains:

1. The nature of parent-adolescent sexual health communications

2. Communications about HIV/AIDS

3. Cultural norms associated with parent-adolescent sexual health communication

4. Parents' efforts to obtain HIV/AIDS information

IDIs and FGDs lasting 45-90 minutes were conducted in Swahili by trained research assistants.

\section{Data management and analysis}

All FGDs and IDIs were audio-recorded and transcribed in Swahili before being translated into English. The research team checked the validity of the English translations to ensure Swahili nuances were captured. Transcripts were analyzed using QSR NVivo software (QSR International, London). A codebook was created using a priori themes from the interview guides and was supplemented with themes that emerged during data analysis. Eight members of the research team were assigned a subset of the transcripts to code using the codebook. Validation checks ensured consistency in the application of codes. Themes that did not fit well into existing codes were noted and considered for recoding. Coding discrepancies were resolved through discussions among the analysts.

\section{Protection of human subjects}

The Regional Norwegian Ethical Committee (for western Norway) and the Muhimbili University of Health and Allied Sciences Institutional Review Board in Tanzania approved the study. Obtaining communal consent involved correspondence and multiple meetings with municipal education stakeholders. After written permission was given by the 
municipal education officer, head teachers, and chairperson of the school-parent committee at each of the 7 schools, adolescents aged 12-15 years were recruited for the study. Tanzanian adolescents younger than 18 years are not legally able to participate in research without parental consent, and we recognized that there were potentially negative consequences to actively seeking parental consent for a sexual health study. Some adolescents who are at risk or from abusive backgrounds could be denied participation as a result of a parent's or guardian's fear of exposure. Also, conservative parents might deny their children permission to participate based on moral or religious objections. Following discussion among our research team members and other parties to the ethical review process, as well as a review of the literature, we decided that these outcomes could be reduced by obtaining passive parental consent, which would allow adolescents more autonomy during research participation (Mathews et al., 2005; Zuch, Mason-Jones, Mathews \& Henley, 2012; Esbensen et al., 1999). Nevertheless, it was understood that children must give their agreement to participate (Schenk \& Williamson, 2005), and consent should be obtained from the appropriate adults.

Students were given forms explaining their right to refuse participation and asking them to indicate whether or not they wanted to participate. We used a passive parental consent procedure whereby parents were informed by invitation letter about the nature of the study. The letter sought permission for their child's participation and informed them of their right to refuse; parents were also given contact information for the researchers. Non-responding parents were considered to have provided passive informed consent. Data was collected from all interested adolescent participants whose parents had not provided notification of refusal. Personal identifying information was not collected, and names of cities, people, and schools mentioned during interviews were redacted during transcription.

\section{RESULTS}

Four key themes emerged from the adolescent and parental data: (1) reasons for parent-adolescent communications, or lack thereof; (2) the focus of parental messages; (3) the moral of the message; and (4) the barriers to communication between parents and adolescents.

Reasons for parent-adolescent communications, or lack thereof. Some adolescents reported that their parents had already communicated with them about sexual health topics:

"My mother already told me, but it was a long time ago. She told me ... 'Please, my son, you should hate those things [sexual health topics]. They can influence you to have sex." (male, aged 12 years, IDI) 
"Mother tells me about HIV, bodily changes, and cleanliness." (female, aged 13 years, IDI)

This same girl's mother reported that, while it is inappropriate to discuss sexual health with one's offspring, she felt compelled to communicate about HIV/AIDS:

"You know us in [name of town omitted]; you are not supposed to tell a child straight. In that, you are supposed to use grandmother, which is our tradition. I mean, like in my case, I was not told a thing [about sexual health]. Eeh, but in AIDS I've gotten scared and communicated." (female parent, IDI)

Nevertheless, most adolescent participants reported that, for various reasons, they had not had sexual health discussions with their parents. Some suggested that their parents might be too busy:

"I have not talked to my father or mother about HIV/AIDS or condoms because they do not have time. Like, my mother and father go to work even on Saturday." (male, aged 13 years, IDI)

Some adolescents said their parents think they are too young for this type of discussion:

"Because parents have no time to talk with their children, because they see this as a very young age, we cannot have the adult talk. Maybe when we grow older, they may talk." (male, aged 15 years, FGD)

"Maybe if you finish school, or you are married." (male, aged 14 years, FGD)

A lack of discussions with parents may lead some adolescents to gather information from peers:

"We get knowledge from our friends who are taught by their parents." (male, aged 12 years, IDI)

The focus of parental messages: Parents and adolescents both indicated that most communications consisted primarily of warnings and threats that having sex would result in HIV infection and death:

"I tell her, 'Do not do that [have sex]' ... I have told her that it is dangerous; do not do [that] for even a single day." (male parent, IDI)

"I asked him, 'Father, what is HIV/AIDS?' He started saying that if you have sex, you can get infected with HIV and you'll get AIDS." (male, aged 15 years, IDI)

The guardian of a 15-year-old girl said she scared the adolescent in order to prevent adverse outcomes of having sex:

"We shout a lot that if you make love, you will get AIDS disease, STIS. That thing, we try a lot to tell them. Now you have become a grown-up; if you walk with a man, then you will get AIDS disease, you will get pregnant, mostly you will get 
AIDS disease. I was scaring her, I mean telling her the truth. And after you get the AIDS disease, you should know you die. It does not have medicine. Therefore, you should be settled." (female guardian, IDI)

A mother reported threatening her daughter with physical inspection for evidence of virginity. The daughter had never initiated sexual health talks with her parents, despite the mother's reported encouragement to ask her anything:

"I tell her, 'You! I'll test you with a finger like my grandmother was testing me.'" (female parent, IDI)

None of the respondents reported having discussions about condom use or family planning.

The moral of the message: Adolescents reported that parents told them to use "good behaviour" to avoid HIV. This was explained as respect for elders, not being stubborn, and not being involved in "groups":

"I mean, the way I was taught is like I told you at the beginning: 'Do not go to discos, and then do not be friendly with that friend whose brain is ...' I mean, 'She stays a stubborn child, she does not enter into class; you should not follow her, or you may even get AIDS." (female, aged 13 years, IDI)

In the following narrative, there is no explanation given for not engaging in sexual relationships at a young age:

"My parent tells me that it's bad having sexual relationship with a woman, and when my parent found out that I had one, she shouted at me so much. And till now I don't have sexual relationships with women." (male, aged 15 years, IDI)

Some adolescents worry that asking questions about sexual health may raise parental suspicions:

"Now I ask myself, 'This is my mother, now where do I start?' Because my mother ... It's usual for her to start to ask me, now for me to start to ask mama ... I see she will think, 'Mmh! This one has maybe already started bad behaviour.' She may think of me badly." (female, aged 14 years, IDI)

Barriers to communication: Parents expressed concern about their children's vulnerability to HIV infection, but their own lack of sufficient sexual health knowledge is a possible barrier to communication with their adolescent offspring. In addition, some parents reported that their children receive adequate information about HIV and sexual health at school:

"My child told me that they are taught HIV issues. For a child who has a brain, I think it is enough." (female parent, IDI) 
"Let me say, I don't know what syllabus it is. I really don't know how they call it, but when he comes, he says, 'Mum, today we have been taught how a boy grows up, a girl grows up, and how they reproduce." (female parent, IDI)

To overcome the perceived lack of sexual health knowledge among parents, one father suggested that authorities should educate them:

"My opinion on the issue I see, especially to those who are in the district and wards should help us, they should educate us. I say this because I see there are some of our fellow parents who are very cruel. He/she is far from his/her child, then he/she fails to educate the child. I mean, the authorities should educate us, the parents, so that we know how to educate those children." (male parent, IDI)

\section{DISCUSSION}

Although some parents communicated with their adolescent children about sexual mores and the risks of contracting HIV/AIDS, parents and adolescents agreed that discussions about pregnancy, family planning, and STI prevention methods such as condom use had not occurred. This finding is similar to those from other studies in subSaharan Africa (Masatu, Kvale \& Klepp, 2003; Kinsman et al., 2001; Biddlecom, Awusabo-Asare \& Bankole, 2009; Wamoyi et al., 2010). Yet studies in Ghana and Tanzania (Adu-Mireku, 2003; Mmbaga, Leonard \& Leyne, 2012) have shown that communications about HIV/AIDS between adolescents and parents or other family members significantly increased the likelihood of delayed sexual debut and condom use at last sexual intercourse.

\section{Parents and adolescents both reported that messages about HIV/AIDS}

were primarily based on fear. Parents are naturally inclined to be concerned about their children becoming infected with HIV/AIDS, especially because there is no cure available, but communications that use scare tactics may induce anxiety and thereby discourage adolescents from asking relevant questions. Although fear-based appeals might be considered effective by parents, studies have shown mixed results (Das, 2001). Fear can lead to behavioral changes when there is a clear message about one's vulnerability to risk as well as feasible, convincing behaviour alternatives (Hoog, 2005). In some instances, a "mild" amount of fear has been considered effective, as long as the message and behaviour recommendations are good, recognizable, realistic, and convincing (Reiter, 2000). However, parents may not be convincing enough due to their inherent bias as well as their lack of factual information on HIV/AIDS. A meta-analysis of 98 studies (Witte \& Allen, 2000) confirmed the hypothesis that fear-based behaviour recommendations may induce resistance to and rejection of the message. According to a study con- 
ducted in eastern and southern Africa (Ford, Odallo \& Chorlton, 2003), the creation of a supportive social environment is an important HIV/AIDS communications strategy. Feararousing messages should include skills-building components for better sexual health decision -making (e.g., delaying onset of sex, using condoms, reducing concurrency).

Our findings show that focusing on morality and "good" behaviour during parentchild sexual health communications may interfere with parents' willingness to engage in a clear discussion of sexual health risks. While local moral values have been acknowledged as relevant in adolescent socialization (Dilger, 2003; Ahlberg, 1994), our findings suggest that parents rarely explained what good behaviour is, and instead stated which bad behaviors to avoid. Adolescents were not provided with explanations of how going to a disco or having friends who skip classes might adversely affect their sexual health, leaving the concept of good behaviour open to varying interpretations by adolescents. Clearer delineation of acceptable and unacceptable behaviour during discussions about sex initiation and sexual health are needed to enable young people to make educated decisions regarding sexual norms and practices (Silverman, Perakyla \& Bor, 1992; Lesch \& Kruger, 2005). Following their elders' suggestions without questions may be misleading and detrimental to adolescents' sexual health decision making. For example, some tribes in Tanzania believe female genital mutilation will protect children from engaging in early sex. This custom has long-term effects on the health of adolescents and does not equip them with protective mechanisms.

Critics of parental approaches to adolescent sexual-risk reduction argue that most parents are ill-informed and may convey inaccurate information (Jaccard, Dittus \& Litardo, 1999). Despite parents' expressions of concern regarding the risk of HIV/AIDS infection, our findings support the critics and suggest that most parents did not seek accurate information that could help them improve communications with their children. Furthermore, our findings suggest that most parents do not hold bidirectional conversations with their adolescent offspring and instead issue threats and warnings that may stifle further talk about sexual health and risk taking. Lack of expertise on matters pertaining to young people, as well as recognition of their autonomy, may cause parents to abandon their role as authorities in adolescent children's lives (Baumrind, 1972). Parental education programs that provide training on HIV/AIDS-specific communications skills (Miller \& Vandenhoudt, 2007; Vavrus, 2006) suggests, however, that it is feasible to foster parental self-efficacy in communications with adolescents.

Similarities and differences in views between both groups are informative and baffling at the same time. Parents and adolescents both reported that parents were likely to use fear in trying to ensure that their children do not engage in risky sexual activities. Yet several dissimilarities were also found. First, adolescent narratives suggested that parents might communicate with them about sexual health when they get older, implying that their young age was a barrier, but parent narratives mentioned possible cultural hindrances, implying that parent-child communications would not increase with age. Second, adolescents reported being confused by the logic of fear-based messages that 
having sex causes HIV: If their parents are having sex, does it mean they are at risk for HIV, too? Third, some parents claimed that they made sure their children felt free to ask questions regarding sexual health, but the parents' mode of talking about HIV/AIDS might have sent a message that such questions would result in reprisals and accusations of having initiated sexual acts. Parents' rhetorical approach (i.e., absolute, fear-based, cause-and-effect logic) could be considered overbearing by adolescents and lacking in credibility.

\section{LIMITATIONS}

Because the interviews were conducted in Swahili, which does not have a direct translation for certain English words, it is possible that some exact meanings were missed. Also, because this study was based not on observations of parent-adolescent communications but on perceived experiences of communication, some of the narratives might have been affected by recall and self-report bias, especially if the communications happened a long time ago. A combination of approaches that included observations, such as a study that videotaped discussions between Latina mothers and their daughters (Romo, Nandeem \& Kouyoumdjian, 2010), would have reduced potential recall and selfreport biases.

\section{CONCLUSIONS}

Action is needed on several fronts to reduce the impact of HIV/AIDS in the adolescent population of sub-Saharan Africa. Parents may benefit from learning sexual health information as well as better approaches in communicating such information to their adolescent offspring. Reciprocally, adolescents may be more willing to engage in dialogue with their parents if fear of reprisals can be reduced. Interventions aimed at parents, therefore, should discuss the unintentional consequences of fear-based approaches and outline more effective strategies. Parents should be encouraged to explore diverse arrangements for sexual health communications that are suitable for their family situations, such as seeking expert help when necessary. Programs targeting HIV/AIDS prevention should include alternative strategies for parents (such as reading sexual health books and building communication skills) and increased sexual abstinence and condom use for adolescents. Further research is needed to assess best methods to increase self-efficacy among parents and their children when discussing safe sexual behaviours, in order to guide future interventions and to reinforce sexual health messages communicated through school curricula. 


\section{REFERENCES}

Adu-Mireku, S. (2003). Family communication about HIV/AIDS and sexual behaviour among senior secondary school students in Accra, Ghana. African Health Sciences, 3(1), 7-14.

Ahlberg, B. M. (1994). Is there a distinct African sexuality? A critical response to Caldwell. Africa, 64(02), 220242.

Balmer, D. H., Gikundi, E., Billingsley, M. C., Kihuho, F. G., Kimani, M., Wang'Ondu, J., \& Njoroge, H. (1997). Adolescent knowledge, values, and coping strategies: implications for health in sub-Saharan Africa. Journal of Adolescent Health, 21(1), 33-38.

Baumrind D. Some thoughts on childrearing. In U. Bronfenbrenner (Ed.), Readings in the development of human behavior. 2nd ed. (270-281). New York: Dryden Press. 1972.

Biddlecom, A., Awusabo-Asare, K., \& Bankole, A. (2009). Role of parents in adolescent sexual activity and contraceptive use in four African countries. International perspectives on sexual and reproductive health, $72-81$.

Botchway, A. T. (2004). Parent and adolescent males' communication about sexuality in the context of HIV/AIDS-A study in the Eastern Region of Ghana. Unpublished Master's thesis. University of Bergen, Bergen, Norway.

Burleson, B. R., Albrecht, T. L., \& Sarason, I. G. (1994). Communication of social support: Messages, interactions, relationships, and community. Sage Publications, Inc.

Das, E. H. H. J. (2002). How fear appeals work: motivational biases in the processing of fear-arousing health communications.

Denzin, N. K., \& Lincoln, Y. (2000). Qualitative research. Thousand Oaks ua, 413-427.

Dilger, H. (2003). Sexuality, AIDS, and the lures of modernity: reflexivity and morality among young people in rural Tanzania. Medical anthropology, 22(1), 23-52.

Dilorio, C., Pluhar, E., \& Belcher, L. (2003). Parent-child communication about sexuality: A review of the literature from 1980-2002. Journal of HIV/AIDS Prevention \& Education for Adolescents \& Children, 5(3-4), 7 32.

Esbensen, F. A., Miller, M. H., Taylor, T., He, N., \& Freng, A. (1999). Differential attrition rates and active parental consent. Evaluation Review, 23(3), 316-335.

Ford, N., Odallo, D., \& Chorlton, R. (2003). Communication from a Human Rights Perspective: Responding to the HIV/AIDS Pandemic in Eastern and Southern Africa A Working Paper for use in HIV and AIDS Programmes. Journal of health communication, 8(6), 599-612.

Fuglesang, M. (1997). Lessons for life-Past and present modes of sexuality education in Tanzanian society. Social Science \& Medicine, 44(8), 1245-1254.

de Hoog, N. (2005). Fear-arousing communications and persuasion.

Jaccard, J., Dittus, P. J., \& Litardo, H. A. (1999). Parent-adolescent communication about sex and birth control: implications for parent based interventions to reduce unintended adolescent pregnancy. ADVANCES IN POPULATION, 3, 189-226.

Kajula, L. J. (2005). Cross-generation communication on sexuality in times of HIV/AIDS as perceived by adolescent girls and their parents in Dar es Salaam, Tanzania. University of Bergen, Norway.

Kawai, K., Kaaya, S. F., Kajula, L., Mbwambo, J., Kilonzo, G. P., \& Fawzi, W. W. (2008). Parents' and teachers' communication about HIV and sex in relation to the timing of sexual initiation among young adolescents in Tanzania. Scandinavian Journal of Public Health, 36(8), 879-888.

Masatu, M. C. (2009). Sexual practices among unmarried adolescents in Tanzania. BMC Public Health, 9(1), 373.

Kinsman, J., Nakiyingi, J., Kamali, A., Carpenter, L., Quigley, M., Pool, R., \& Whitworth, J. (2001). Evaluation of a comprehensive school-based AIDS education programme in rural Masaka, Uganda. Health Education Research, 16(1), 85-100.

Lesch, E., \& Kruger, L. M. (2005). Mothers, daughters and sexual agency in one low-income South African community. Social Science \& Medicine, 61(5), 1072-1082. 
Luwaga, L. C. Parent-adolescent communication on sexuality in the context of HIV/AIDS in Uganda: An exploratory study (MPhil dissertation, Faculty of Psychology, University of Bergen, Bergen-Norway 2004).

Mathews, C., Guttmacher, S. J., Flisher, A. J., Mtshizana, Y., Hani, A., \& Zwarenstein, M. (2005). Written parental consent in school-based HIV/AIDS prevention research. American journal of public health, 95(7), 1266-1269.

Markham, C. M., Lormand, D., Gloppen, K. M., Peskin, M. F., Flores, B., Low, B., \& House, L. D. (2010). Connectedness as a predictor of sexual and reproductive health outcomes for youth. Journal of Adolescent Health, 46(3), S23-S41.

Masatu, M. C., KvÅle, G., \& Klepp, K. I. (2003). Frequency and perceived credibility of reported sources of reproductive health information among primary school adolescents in Arusha, Tanzania. Scandinavian journal of public health, 31(3),

Miller, K. S., Forehand, R., \& Kotchick, B. A. (1999). Adolescent sexual behavior in two ethnic minority samples: The role of family variables. Journal of Marriage and the Family, 85-98.

Miller, K. S., \& Vandenhoudt, H. (2007, December). Youth prevention activities in western Kenya: the Families Matter program. In Interagency Youth Working Group meeting, Washington, DC.

Muyinda, H., Nakuya, J., Pool, R., \& Whitworth, J. (2003). Harnessing the senga institution of adolescent sex education for the control of HIV and STDs in rural Uganda. AIDS care, 15(2), 159-167.

Mmbaga, E. J., Leonard, F., \& Leyna, G. H. (2012). Incidence and predictors of adolescent's early sexual debut after three decades of HIV interventions in Tanzania: a time to debut analysis. PLoS One, 7(7), e41700.

Namisi FS. Communicating on Sexuality within Kenyan Family Setting in the Context of HIV/AIDS: Perceptions of Parents and 14-17 Year Old Adolescents [MPhil Dissertation]. University of Bergen, Norway; 2005.

Reiter, R. (2000). Scary warnings and rational precautions. A study into fear arousal and its contribution to precautionary motivation. Maastricht: Unigraphic.

Romo, L. F., Nadeem, E., \& Kouyoumdjian, C. (2010). Latino parent-adolescent communication about sexuality: an interdisciplinary literature review. Latina/o sexualities: Probing powers, passions, practices, and policies, 62-74.

Silverman, D., Perakyla, A., \& Bor, R. (1992). Discussing safer sex in HIV counselling: assessing three communication formats. AIDS care, 4(1), 69-82.

Shoop, D. M., \& Davidson, P. M. (1994). AIDS and adolescents: the relation of parent and partner communication to adolescent condom use. Journal of adolescence, 17(2), 137.

Schenk, K., \& Williamson, J. (2005). Ethical approaches to gathering information from children and adolescents in international settings: guidelines and resources.

Tanzania Commission for AIDS (TACAIDS), National Bureau of Statistics (NBS), Macro International Inc. Tanzania HIV/AIDS Indicator Survey 2003-04; 2005.

UNAIDS. The global aids epidemic. Geneva: World Health Organization and UNAIDS. Report 2008.

Vavrus, F. (2006). Girls' schooling in Tanzania: the key to HIV/AIDS prevention?. AIDS care, 18(8), 863-871.

Wamoyi, J., Fenwick, A., Urassa, M., Zaba, B., \& Stones, W. (2010). Parent-child communication about sexual and reproductive health in rural Tanzania: Implications for young people's sexual health interventions. Reproductive Health, 7(1), 1.

Wamoyi, J., Fenwick, A., Urassa, M., Zaba, B., \& Stones, W. (2010). Parent-child communication about sexual and reproductive health in rural Tanzania: Implications for young people's sexual health interventions. Reproductive Health, 7(1), 1.

Wight, D., Williamson, L., \& Henderson, M. (2006). Parental influences on young people's sexual behaviour: A longitudinal analysis. Journal of adolescence, 29(4), 473-494.

Witte, K., \& Allen, M. (2000). A meta-analysis of fear appeals: Implications for effective public health campaigns. Health education \& behavior, 27(5), 591-615.

Zuch, M., Mason-Jones, A. J., Mathews, C., \& Henley, L. (2012). Changes to the law on consent in South Africa: implications for school-based adolescent sexual and reproductive health research. BMC international health and human rights, 12(1), 1. 


\section{Chapter}

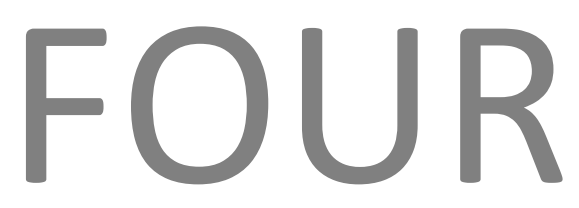

\section{Parenting practices and styles associated with adolescent sexual health in Dar es Salaam, \\ Tanzania}

This chapter has been published as Kajula, L. J., Darling, N., Kaaya, S. F., \& De Vries, H.

(2016). Parenting practices and styles associated with adolescent sexual health in Dar es Salaam, Tanzania. AIDS care, 1-6. 


\section{ABSTRACT}

Parenting styles and practices are suggested to be important predictors of adolescent sexual health, mostly in Europe and North America. Limited research has been conducted on these processes in sub-Saharan Africa, which has different patterns of adolescent sexual behaviour and family traditions. This study qualitatively explored parenting practices and styles associated with adolescent sexual health in Tanzania, with 12 adolescents and 12 parents of adolescents. The themes we identified from the data included parental monitoring, preventive and punitive behaviours. Parents were reported to use mostly punitive behaviours to correct or prohibit sexual behaviour; parents also set clear rules about appropriate sexual behaviour (e.g., modesty and abstinence). Parents were also reported to closely monitor their adolescent children's friendships and sexual behaviour to minimize possibility of their children engaging in sex. However, some parents also engaged in positive preventive practices aimed at protecting their adolescent children. 


\section{INTRODUCTION}

Parents are important socializing agents in adolescent sexual health (Markham et al., 2010) and may be particularly important in monitoring social contexts marked by high sexual risk that their adolescent children are engaged in (Fehringer et al., 2013). Most research on parents' efforts to socialize their adolescents in the area of sexual health has been carried out in North America or Europe. This paper presents exploratory qualitative findings, describing themes emerging from interviews about parents' sexual socialization efforts in Dar Salam, Tanzania. The overall qualities of parent-child relationships are strong determinants of adolescent sexual decision- making (Ngom, Magadi \& Owuor, 2003; Lesch \& Kruger, 2005; Biddlecom, Awusabo-Asare, \& Bankole, 2009). The strength of parent-child connectedness is enhanced by parenting practices, which refer to very specific rules of parents concerning a particular behaviour (Darling \& Steinberg, 1993).

Further, the important role of parenting styles in adolescent sexual socialization has been previously reported. Parenting styles refer to the general climate within the family, including communication to children of the required behaviors (Darling \& Steinberg, 1993). Despite cultural and ethnic variations in parenting styles and outcomes for youth, research suggests more benefits of authoritative style of parenting while neglectful or disengaged parents are reported to have more negative effects across different cultural groups (Steinberg et al., 1994).

In Tanzania, $9 \%$ of girls and $10 \%$ of boys have had sex by 15 years of age (Kazaura \& Masatu, 2009). Early sexual debut is associated with adolescent pregnancy and increased risk of sexually transmitted infections (STIS) including HIV (Kaaya, Leshabari \& Mbwambo, 1998; Kahn et al., 2002). Yet, little is known about sexual health socialization of adolescents by parents and research is needed to assess current parenting practices and styles.

\section{METHODS}

\section{Protocol and sample}

Twelve parents (six mothers, six fathers) and 12 adolescents (six boys, six girls) were recruited to participate in interviews exploring parent-adolescent relationships and sexual socialization. Parents were not all paired with their children, some parents' children participated in a survey that we carried out but they did not participate in the indepth interviews. Adolescents were recruited using criteria-based sampling from six randomly selected schools in the Dar es Salaam region. All adolescent participants were between 12 and 14 years old. To be eligible, adolescents needed to be registered at one of the selected schools, give assent, and have passive consent for their participation 
from a parent. Potential participants were nominated by teachers, who acted as gatekeepers. Selected parents responded to invitations sent through their children. Trained research assistants conducted interviews using an in-depth iterative approach, whereby interview guides were continuously updated to explore and capture emerging themes (Denzin and Lincoln, 2000).

Adolescent interviews were conducted in school during break time and lasted 30-60 minutes, while parents could choose to be interviewed at home or in school.

The interview protocol used the parenting style construct (Baumrind, 1991) and explored the following domains:

1. Parenting behaviour/statements regarding adolescent sexual health

2. Parental behaviour in tracking adolescent movement or peers

3. Parental rules and regulations regarding adolescent sexual health

4. Parental recommendations on parenting adolescents

All interviews were audio-recorded and transcribed in Swahili before being translated into English. Transcripts were analyzed using QSR NVivo software (QSR, 2002). A codebook was created using a priori themes (Denzin and Lincoln, 2000) from the interview guides and was supplemented with themes that emerged during data analysis (Denzin and Lincoln, 2000). Validation checks ensured consistency in the application of codes. Analysis utilized content analysis and comparative analysis methods.

\section{Protection of human subjects}

The Regional Norwegian Ethical Committee (for western Norway) and the Muhimbili University of Health and Allied Sciences Institutional Review Board in Tanzania approved the study. Adolescents aged 12-14 years were recruited for the study (Kajula et al., 2014) after attaining the required permissions from the municipal education officer and head teachers. Tanzanian adolescents younger than 18 years are not legally able to participate in research without parental consent; however we recognized that there were potentially negative consequences to actively seeking parental consent for a sexual health study. Some adolescents who are possibly at risk or from abusive backgrounds could be denied participation as a result of a parent's or guardian's fear of exposure. Discussion among our research team as well as a review of the literature concluded that these outcomes could be reduced by obtaining passive parental consent, therefore allowing adolescents more autonomy during research participation (Esbensen et al., 1999; Mathews et al., 2005; Zuch, Mason- Jones, Mathews \& Henley, 2012;). Nevertheless, children must give their agreement to participate (Schenk \& Williamson, 2005) even when passive consent from parents is used. Personal identifying information was not collected, while names of cities, people, and schools mentioned during interviews were redacted during transcription. 


\section{RESULTS}

Both parents and adolescents suggested parents' primary goal in sexual socialization to be preventing sexual behaviour. Three major parenting practices emerged as themes: Parental preventive strategies, parental punitive practices and parental monitoring of adolescent behaviour and peers.

\section{Parental Preventive Strategies}

Both parents and adolescents reported a variety of parenting preventive practices ranging from the direct - keeping adolescents busy - to the distal - reducing adolescents' economic motivation for engaging in transactional sex.

Adolescents interpreted some rules seemingly unrelated to sexual behaviour as being primarily motivated by parents' desire to keep them away from peers and social contexts that increased their likelihood of engaging in sexual behaviours. One strategy parents used to prevent their adolescent offspring from engaging in sex was to warn them directly engaging with the opposite sex, as reported by this 12 year old girl:

"My mother forbids me from playing with boys because they have bad behaviours. She didn't tell me what behaviours."

Parents warning their adolescent children about the opposite sex seem to apply for girls and boys, as when this mother said:

"I have already told my son that there are girls whom he will meet at school ... and when a girl knows how much money you have she will do anything for you to date her."

In addition to preventing adolescents from associating with the opposite sex, parents also report trying to influence how their children present themselves. This father said:

"Some children have bad behaviour, but the environment I raised my children in... I don't want them to put on trousers. I don't like my daughters to put on trousers, they wear only decent clothes and they cannot talk nonsense when I am around. I also don't like my daughters to be in peer groups of children who have not been raised well by their parents. Some children put on miniskirts."

This father seemed to hope that by setting rules for how his daughters dress, they would uphold their family values. Not all parents engage in protective or preventive practices, however. For example, this 14-year-old boy said "There are not any rules that are made (at home)."

Several parents were forthcoming about the danger that exposure to inappropriate behaviour may have on their adolescents' desire to engage in risky behaviour. This father said: 
"Poor upbringing is for children to see bad actions, for example a child might see in their streets or at home adults doing things openly such as fighting, having sex openly in alleys or even inside (when parents share a room with children) the child is told to close his/her eyes, not to watch. That might make the child have that condition of wanting to try."

Attempts to discourage adolescents' motivation to engage in risk behaviors include a father who quite explicitly suggested economic security reduces the risk of sexual behaviour:

"When our children go to school in the morning, even if we don't have any money we will borrow or steal if necessary but he must leave with some money (for food). We don't want them to beg at school because begging at school is what causes many things. A person may give you (the adolescent) one hundred shillings today, two hundred tomorrow and it reaches a point they will tell you strange things like having sex or using marijuana. And if they (adolescents) think this is the person who helps me so I can't say no, then that act of using you (the adolescent) begins."

In concluding the section, parents seem to have different rules for their daughters and sons concerning the way they dress and associate with the opposite sex.

\section{Parental monitoring of sexual behaviour and friends}

Several participants implied that parents carefully monitored adolescents' behaviour and peers in order to enact strategies to prevent sexual behaviour. The perceived dangers of peers and efforts to keep adolescents out of sexually risky contexts can be seen in this excerpt from a mother's interview:

"Those influences (peer) are always bad. Because I can control my children, I can say "this thing is bad, so and so (a friend) is not good." But as a parent, sometimes I'm not there, and I don't know who they are with and what influence those people may give them."

This mother recognized that although she has no direct control about her child's behaviour, she tries to minimize their risk by discouraging involvement with "problematic" peers.

Another mother supports this view:

"I normally talk to her so she's on the safer side, I don't want her to engage in what I should say are matters that are older than her age. I tell her if she has any problem, she should tell me. There is another girl who started promiscuous behaviour in standard five and six, so I told her (daughter) that when you stay with your fellows, you must be in the right frame of mind." 
Parental monitoring as explained by a father:

"When I follow up my boy, I can check his things, his clothes and I may find sometimes that he has condoms. But I know he is careful on these things. I don't complain to him a lot since I see he is safe and understands himself."

Although monitoring appears to have reassured the father, he does not seem to use it to change the son's behaviour.

Furthermore, monitoring can also allow parents to increase their protective behaviours:

"I also took two of my children to check their health status. When I discovered that one of them had TB, I decided to check her/him for HIV. S/he didn't have it and I was tempted to test the other one as well"

In another elaboration of control of behaviour associated with sex, a brother was doing the monitoring:

"First, my brother is a Muslim, he doesn't like me to go for Taarab (a type of sexualized dance normally attended by adults). If my mother goes, that's when I go. My brother doesn't want me to step my feet there. I usually go with my mother, and if I mingle with friends and my mother decides to go back home, I dance until sunset that's when I go home." Female adolescent, 14 years old

In the above excerpt, while the brother tried to keep his sister from a sexual risky setting, the mother showed a lack of control and poor monitoring by leaving the daughter behind, unsupervised.

As with preventive and punitive behaviours, differences are seen in parents' and adolescents' discussions of monitoring as exemplified by the reaction of the father who found condoms in his son's pockets.

\section{Parental punitive behaviour}

Parents were reported to use punishment in three different ways: threats of punishment to prevent sex from occurring; punitive actions in response to sexual behaviors to reduce future occurrence of sex and also as a reinforcement of social norms.

Adolescents and their parents mentioned punishment for rule violations frequently. This 12-year-old girl elaborated:

"I have thought God forbid me from such issues as having sex. I should be a good child and my parents won't hate me. If one day I do it, I won't stay. My parents will chase me away until I know the bad things I did."

Punishment is not only used as a threat to enforce sexual norms, it is also used to prevent sexual victimization, as this 12-year-old girl described: 
"My male cousin told me (name withheld), let's do this game. I had no idea about it, so I accepted. Then we were found and my mother asked me, "What are you doing?" and I said I don't know. Then she told me "Why do you do something you don't know?" Since that day I was told not to go out without permission, so I never go out again (without permission). When I go out I'm beaten, until this day. I was three years old."

While parents may have the intention of "punishing to protect", these efforts can backfire. This can be seen clearly in this 14-year-old girl's description of being raped:

"I said "You've already raped me, eh," and he said, "I've already raped you, what's your problem? What is remaining is you go to your home." I said "No! I can't go home. You've already destroyed everything like this and I don't agree!" After I dressed, I decided to go home and I found my mother; they were already looking for me. It was night, around ten o'clock. When I greeted them, they started shouting at me."

Because she feared being beaten, ostracized or thrown out of her home, this girl never told her parents about the rape. She explained further:

"If I had sex and got pregnant everything will be destroyed. My parents will ask me "Where did you get this pregnancy?" They will insult me and chase me away. My father chased away my sister who got pregnant, but later forgave her and asked her to come home."

Importantly, the girl did not expect there to be any difference in her parents' punishment if the sexual behaviour was voluntary or if she was the victim of rape as was the case.

Not all parents behaved punitively however:

"He (father) usually talks to me as he says that, beating a child doesn't mean that you teach him/her, he says that talking to a child makes him/her to listen."

Adolescent male, 14

A father expressed similar sentiments:

"First let us have affection with our children, if you love them and you have something to explain to them, they will understand you, and you will be close to them. We should not be very harsh to our children, if you become so, even if you tell him/her something, they will agree just out of fear, he/she might listen to you but with worry."

Similarly, another mother said, "I tell her if she has any problem, she should tell me."

These parents clearly believe that being less punitive and warmer will facilitate communication and enable their children to better use them as a source of support. In concluding the section, parents appear to be more restrictive to girls' compared to boys' violations. 


\section{DISCUSSION}

Research has consistently shown a relationship between dimensions of parenting and a range of adolescent outcomes (Peterson, 2005). Parental role in the sexual health outcomes of sub-Saharan African adolescents has been studied as part of understanding proximal influences of adolescent sexual behaviour (Ngom, Magadi \& Owuor, 2003; Lesch \& Kruger, 2005). According to Bersamin et al., (2008) intervention efforts to improve adolescent sexual health need to recognize parents as primary socializing agents. The major themes in our study included parental preventive strategies, parental monitoring of sexual behaviour and friends, and parental punitive behaviours.

The practice of monitoring, which is suggested to bridge prevention and punishment (Patterson, 1976) has been defined as supervision and tracking of activities and peer relationships as well as surveillance of behaviour (Stattin \& Kerr, 2000; DiClemente et al., 2001). Researchers in Ghana report that youth with high levels of parental monitoring were less likely to have had sex in the prior 12 months (Adu-Mireku, 2003). However, since the sample of adolescents in our study consisted of younger adolescents (1214), parents may have had the attitude to protect them from engaging in early sex and its associated risks. A parental protective behaviour that was striking in our study was parents ensuring food security for their adolescent children. Food insecurity has been suggested to drive those on the margin of poverty in some Sub Saharan African countries into engaging in sexual behaviours that could put them at risk of diverse health consequences (Adler \& Ostrove, 1999; Kalichman et al., 2006; Weiser et al., 2007; Wamoyi et al., 2010). Most parents appeared to use an authoritarian style of parenting, characterized as "Shaping, controlling and evaluation of behaviour and attitudes of the child in accordance with a set standard of conduct; the parent values obedience as a virtue and favors punitive, forceful measures to curb self-will" (Baumrind, 1966. p. 261). However, punishing adolescents, threatening and making affection contingent on compliance is likely to make adolescents less forthcoming to parents (Darling, Cumsille, Caldwell, \& Dowdy, 2006; Kajula et al., 2014). Fear of punishment could put girls at even more at risk should they get pregnant, limiting their choices and increasing their vulnerability. Parents may hope that by using restrictions and punitive strategies they are protecting their adolescent children from engaging in early sex. However, Failure to report a rape exemplifies how some actions parents engage in to protect their adolescents may result in implied lack of social support and may inhibit access to preventive health services, including post-exposure prophylaxis to prevent HIV.

\section{LIMITATIONS}

These interviews come from a limited number of participants and obviously do not represent the full range of parent sexual health socialization efforts experienced by 


\section{Chapter four}

Tanzanian adolescents. Further, the sampling methods may have caused bias since the teachers who acted as gatekeepers may have picked only a certain type of adolescent, such as those who were more eloquent than others. Also, interviews were conducted in Swahili, which has no direct English translations for some words, therefore possibly losing some exact meanings.

\section{CONCLUSIONS}

Interventions to confront sexual health challenges facing the adolescent population of Tanzania needs to include personal to proximal issues such as the context in which adolescents live. A clearer understanding of current parenting practices and styles is an important starting place in any intervention that tries to include the family in prevention efforts. 


\section{REFERENCES}

Adler, N. E., \& Ostrove, J. M. (1999). Socioeconomic status and health: what we know and what we don't. Annals of the New York academy of Sciences, 896(1), 3-15.

Adu-Mireku, S. (2003). Family communication about HIV/AIDS and sexual behaviour among senior secondary school students in Accra, Ghana. African Health Sciences, 3(1), 7-14.

Baumrind, D. (1966). Effects of authoritative parental control on child behavior. Child development, 887-907.

Baumrind, D. (1991). The influence of parenting style on adolescent competence and substance use. The Journal of Early Adolescence, 11(1), 56-95.

Bersamin, M., Todd, M., Fisher, D. A., Hill, D. L., Grube, J. W., \& Walker, S. (2008). Parenting practices and adolescent sexual behavior: A longitudinal study. Journal of Marriage and Family, 70(1), 97-112.

Biddlecom, A., Awusabo-Asare, K., \& Bankole, A. (2009). Role of parents in adolescent sexual activity and contraceptive use in four African countries. International perspectives on sexual and reproductive health, 72-81.

Darling, N., \& Steinberg, L. (1993). Parenting style as context: An integrative model. Psychological bulletin, $113(3), 487$.

Darling, N., Cumsille, P., Caldwell, L. L., \& Dowdy, B. (2006). Predictors of adolescents' disclosure to parents and perceived parental knowledge: Between-and within-person differences. Journal of Youth and Adolescence, 35(4), 659-670.

Denzin, N. K., \& Lincoln, Y. (2000). Qualitative research. Thousand Oaks ua, 413-427.

DiClemente, R. J., Wingood, G. M., Crosby, R., Sionean, C., Cobb, B. K., Harrington, K., ... \& Oh, M. K. (2001). Parental monitoring: Association with adolescents' risk behaviors. Pediatrics, 107(6), 1363-1368.

Esbensen, F. A., Miller, M. H., Taylor, T., He, N., \& Freng, A. (1999). Differential attrition rates and active parental consent. Evaluation Review, 23(3), 316-335.

Fehringer, J. A., Babalola, S., Kennedy, C. E., Kajula, L. J., Mbwambo, J. K., \& Kerrigan, D. (2013). Community perspectives on parental influence on engagement in multiple concurrent sexual partnerships among youth in Tanzania: Implications for HIV prevention programming. AIDS care, 25(2), 207-214.

Kaaya, S. F., Leshabari, M. T., \& Mbwambo, J. K. (1998). Risk behaviors and vulnerability to HIV infection among Tanzanian youth. Journal of Health and Population in Developing Countries, 1(2), 51-60.

Kahn, J. A., Rosenthal, S. L., Succop, P. A., Ho, G. Y., \& Burk, R. D. (2002). Mediators of the association between age of first sexual intercourse and subsequent human papillomavirus infection. Pediatrics, 109(1), e5-e5.

Kajula, L. J., Sheon, N., De Vries, H., Kaaya, S. F., \& Aarø, L. E. (2014). Dynamics of parent-adolescent communication on sexual health and HIV/AIDS in Tanzania. AIDS and Behavior, 18(1), 69-74.

Kalichman, S. C., Simbayi, L. C., Kagee, A., Toefy, Y., Jooste, S., Cain, D., \& Cherry, C. (2006). Associations of poverty, substance use, and HIV transmission risk behaviors in three South African communities. Social Science \& Medicine, 62(7), 1641-1649.

Lesch, E., \& Kruger, L. M. (2005). Mothers, daughters and sexual agency in one low-income South African community. Social Science \& Medicine, 61(5), 1072-1082.

Markham, C. M., Lormand, D., Gloppen, K. M., Peskin, M. F., Flores, B., Low, B., \& House, L. D. (2010). Connectedness as a predictor of sexual and reproductive health outcomes for youth. Journal of Adolescent Health, 46(3), S23-S41.

Mathews, C., Guttmacher, S. J., Flisher, A. J., Mtshizana, Y., Hani, A., \& Zwarenstein, M. (2005). Written parental consent in school-based HIV/AIDS prevention research. American journal of public health, 95(7), 1266-1269.

Ngom, P., Magadi, M. A., \& Owuor, T. (2003). Parental presence and adolescent reproductive health among the Nairobi urban poor. Journal of Adolescent Health, 33(5), 369-377.

Patterson, G. R., \& Gullion, M. E. (1968). Living with children: New methods for parents and teachers.

Stattin, H., \& Kerr, M. (2000). Parental monitoring: A reinterpretation. Child development, 71(4), 1072-1085. 


\section{Chapter four}

Steinberg, L., Lamborn, S. D., Darling, N., Mounts, N. S., \& Dornbusch, S. M. (1994). Over-time changes in adjustment and competence among adolescents from authoritative, authoritarian, indulgent, and neglectful families. Child development, 65(3), 754-770.

Wamoyi, J., Fenwick, A., Urassa, M., Zaba, B., \& Stones, W. (2010). Parent-child communication about sexual and reproductive health in rural Tanzania: Implications for young people's sexual health interventions. Reproductive Health, 7(1), 1.

Weiser, S. D., Leiter, K., Bangsberg, D. R., Butler, L. M., Percy-de Korte, F., Hlanze, Z., ... \& Heisler, M. (2007). Food insufficiency is associated with high-risk sexual behavior among women in Botswana and Swaziland. PLoS Med, 4(10), e260.

Zuch, M., Mason-Jones, A. J., Mathews, C., \& Henley, L. (2012). Changes to the law on consent in South Africa: implications for school-based adolescent sexual and reproductive health research. BMC international health and human rights, 12(1) 


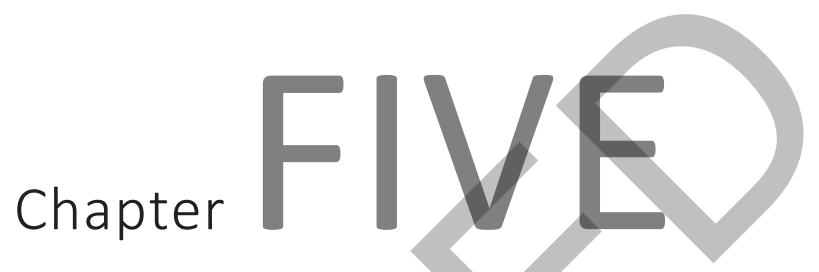

Factors Associated with Adolescent Sexual Health Communication with Parents and Peers in Dar es Salaam, Tanzania

This chapter is in the process of submission for publication as Kajula, L. J., Kaaya, S.F., Eggers, S. M., de Vries., $\mathrm{H}$.

Factors Associated with Adolescent Sexual Health Communication with Parents and Peers in Dar es Salaam, Tanzania. 
This chapter is embargoed at request

Chapter

Sexual Health Communication Among Adolescents, Peers and Parents in Dar es Salaam Tanzania: A Cluster Randomized Controlled Trial

This chapter is in the process of submission for publication as Kajula, L. J., Mmbaga, E.J., Kaaya, S.F., Eggers, S. M., Aarø L.E., \& De Vries., H.

Sexual Health Communication Among Adolescents, Peers and Parents in Dar es Salaam Tanzania: A Cluster Randomized Controlled Trial. 
General discussion 

This dissertation aimed to gain increased insight into adolescent sexual health communication with peers and parents and the associated parenting practices in Dar es Salaam, Tanzania. This insight should inform efforts to improve adolescent sexual health in Tanzania. The dissertation comprises of papers that use quantitative and qualitative methods that complement each other in a quest to broaden the understanding of adolescent sexual health communication with parents and peers. Due to the sensitivity surrounding sexual health, multiple approaches are suggested especially when dealing with adolescents in a context where sexual behaviour involves much secrecy (Plummer et al., 2004).

This dissertation has two main parts. The first is an exploratory and a prevalence study that focuses on the prevalence and nature of parent- adolescent sexual health communication and the parenting practices utilised. This part includes four chapters starting from chapter two, three, four and five. Chapter two focuses on a review of adolescent sexual health communication in sub-Saharan Africa, chapter three on the nature of parent-adolescent sexual health communication and the fourth on parenting practices and styles associated with adolescent sexual health. Chapter five examines factors associated with adolescent sexual health communication with parents and peers. The second part is an outcome analysis for an evaluation of an intervention that was conducted in primary schools that aimed to improve adolescent sexual health in Dar es Salaam, Tanzania. One chapter (chapter six) focuses on the effects of the intervention on sexual health communication with peers and parents.

In this concluding chapter, the main findings of the five studies presented in this dissertation are discussed. Also, limitations and suggestions for future research are provided. In conclusion, practical implications of the findings of the studies are discussed.

\section{PARENT-ADOLESCENT SEXUAL HEALTH COMMUNICATION}

The first question that this thesis focused on was i) "What is the nature of parentadolescent sexual health communication in Tanzania?" From results presented in chapter two, three and five, it appears that most parents seemed to be "talking to" rather than communicating with adolescents. Findings suggest that parents used mostly vague fear-filled messages to dissuade their children from engaging in sex (Kajula et al., 2014; Kajula, 2005). Also, chapter five revealed that parent-adolescent sexual health communication is associated with higher levels of condom use self-efficacy, condom use action planning and intentions. Similar findings were found for higher levels of action planning and the intention to delay sexual debut. However, longitudinal studies are needed to confirm whether high levels of parent-adolescent sexual health communication can also predict these cognitions for adolescents since the current cross-sectional piece of the study as described in chapter five does not allow for such conclusions. 
The nature of parent - adolescent sexual health communication includes several barriers to communication such as cultural and personal discomfort such as lack of proper knowledge and skills on the part of parents. This is supported by findings that suggest that parents either lacked specific knowledge regarding sexual health as well as communication skills (Kirby \& Miller, 2002; Kajula, 2005; Guilamo -Ramos, Jaccard, Dittus \& Bouris, 2006). Sexual health communication between parents and their adolescent children can be improved by programs that focus on communication skills as shown by Schuster et al., (2008). Cultural norms and taboos surrounding parent-child sexual health communication are also mentioned as being one of the major reasons for parents to engage less in sexual health communication with their adolescent children. Studies conducted in South Africa suggest that children talking about sexuality to their parents may be considered disrespectful (Wood, Lambert \& Jewkes, 2007; JeareyGraham \& Macleod, 2015). Empirical research from East Africa suggests that sexuality information was traditionally passed down to adolescents by close relatives such as aunts, uncles and grandparents and not own parents (Fuglesang, 1997; Wamoyi et al., 2010). From the review of studies that we conducted on chapter two, several issues emerged including paucity of studies on parenting practices associated with sexual health communication or socio-cognitive variables (Bastien, Kajula \& Muhwezi, 2011). The need to include understanding the role of parents in adolescent sexual health was also considered due to evidence from the review of as well as the studies from the west that found positive associations in engaging parents (Babalola, Oleko, Tambashe \& Vondrasek, 2005; Short \& Rosenthal, 2008; Schuster et al., 2008; Magadi \& Agwanda, 2009). Gaps in previous studies about the effect of urbanisation on adolescent sexual health were also elaborated by the review on chapter two (Bastien, Kajula \& Muhwezi, 2011). Understanding social change as a result of urbanisation is paramount since traditional forms of sexual health communication with adolescents have limited success with the current challenges (Parker, Easton \& Klein, 2000). Urban-based adolescents live far from their extended families and parents or other caretakers who live with the adolescents do constant monitoring (Kajula et al., 2016). Consequently, traditional education about sexuality has become difficult to realise via close relatives. Furthermore, previous sexuality information focused more on marital life and less on sexual health (Fuglesang, 1997). The parental practice of monitoring, defined as tracking of activities and friends as well as surveillance of behaviour (Stattin and Kerr, 2000), is suggested to be a key predictor of adolescent sexual health (Steinberg, Fletcher \& Darling, 1994; Kumi-Kyereme et al., 2007). Engaging parents with the goal of improving adolescent sexual health in any intervention that includes a broader level than the individual has also been suggested to be important (Bastien, Kajula \& Muhwezi, 2011; Kajula et al., 2014).

Parents in this study, however, are reported to communicate with their adolescent children after they suspect that the adolescents are already engaging in intimate relationships (Kajula et al., 2016). This has also been observed by other studies (Bankole et 
al., 2007; Sommer, Likindikoki \& Kaaya, 2015). Early adolescence is suggested to be an immensely important stage for understanding and intervening to reduce negative outcomes of early sexual initiation (Simbayi et al., 2005). Consequently, an important conclusion and recommendation to be considered in adolescent sexual health interventions is for parents to constructively communicate to younger adolescents so as to delay sexual initiation.

\section{PARENTING PRACTICES ASSOCIATED WITH SEXUAL HEALTH COMMUNICATION IN TANZANIA}

The second question posed was "What are the parenting practices associated with sexual health communication Tanzania?" Results presented in chapter four suggest that the most prominent parenting practices by parents in our study appear to be harm reduction, punishment and monitoring of both sexual behaviour and adolescents' friends. These practices in our study are closely associated with the authoritarian style of parenting with its predominance of strictness and demand for obedience without questioning. Authoritarian parenting involves making high demands and giving directives, while not being responsive and is linked with poor adolescent outcomes (Baumrind, 1991). It is therefore not surprising that adolescents in our study found it difficult to communicate with parents about sexual health. Adolescents and parents in our study reported parental monitoring of adolescents' sexual behaviour and of their friends. The parental practice of monitoring is suggested to be highly protective of adolescent sexual risk taking (Huebner \& Howell, 2003; Romer et al., 1994). However, it is also important for parents to help adolescents achieve the developmental challenge of establishing autonomy and responsibility for their sexual health. Currently the parenting discussion has moved from mere monitoring to include adolescent disclosure, with the communication coming most from adolescents who disclose issues of concern to parents (Darling, Cumsille, Caldwell \& Dowdy, 2006). Understanding factors that determine adolescent disclosure may improve adolescent sexual health since it is a reliable way for parents to gain information about their children (Statin \& Kerr, 2000; Huebner \& Howell, 2003). In addition to parental monitoring, a supportive and safe environment is important. WHO (2000), suggested that adolescents who live in a social environment that provide meaningful relationships, encourages self-expression while providing structure and boundaries, are also less likely to initiate sex at a young age. The importance of parental influence on adolescent sexual decision-making has also been documented in a review study conducted in developing countries (Mmari \& Blum, 2009).

A key conclusion is that parents should be encouraged to minimise the use of harsh parenting practices that limit sexual health communication with their adolescent children. The parenting practice of monitoring however is important and should be encouraged. 


\section{PEER SEXUAL HEALTH COMMUNICATION}

The third question asked was "What is the nature of peer sexual health communicated in Tanzania?" Responses to this question are summarised in chapter five and six. Peer sexual health communication appeared to be happening more often than parentadolescent sexual health communication. Findings suggest that adolescents engaged in more sexual health communication with their peers than parents. Limited parent- adolescent sexual health communication and harsh parenting practices are reported by a majority of adolescents in our sample (Kajula et al., 2014; Kajula et al., 2016). While peer relationships gain more importance in adolescence which in turn increases the adolescent's social network, it does not replace the parents' important place in adolescents' lives (Lashbrook, 2000). Other studies also suggest that adolescent behaviour may be shaped by peer norms within their networks (Barrington et al., 2009). The influence of friends on adolescent sexual behaviour is also supported by WHO (2004), which suggests that having friends who are sexually active is a risk factor for sexual debut. Other studies on youth sexual behaviour in Tanzania, have also found shared norms on condom use and HIV risk perceptions within close networks (Yamanis, Fisher, Moody \& Kajula, 2015; Kohler, Behrman \& Watkins, 2007). Social influence studies from Tanzania show that young men tend to engage in concurrency to prove their sexual prowess to peers (Rweyemamu \& Fuglesang, 2008; Yamanis et al., 2010). Peer influence has also been revealed to be important in reported sexual behaviours (Mmari \& Blum, 2009; Sommer, Likindikoki \& Kaaya, 2015). Behaviour change studies that make a distinction between peer selection and influence such as those studying the smoking behaviour of adolescents, acknowledge that smokers select smoking friends and non-smoking friends select non-smoking friends (Mercken, Candel, Willems \& de Vries, 2007). Additionally, Henry et al., (2007) also demonstrated peer influence on condom use. While peer influence may be positive or negative, understanding peer selection and influence is therefore of utmost importance. With this in mind, perhaps the recommendation for parents would be to encourage their adolescent children to engage with peers that have healthy sexual behaviours.

\section{EFFECTIVE PROMOTION FOR DELAYED \& SAFER SEX}

The final question was "How can we effectively promote delayed and safer sex?" Proximal factors such as motivation to change behaviour may have contributed to a delay in sexual debut and safer sex choices as presented in chapters five and six. Additionally we found promising effects on sexual behaviour and action planning to delay sex and condom use (Kajula et al., in print). With regards to delayed sex, empirical studies have shown that early intervention is key (Mmbaga, Leonard \& Leyna, 2012; Aarø et al., 2014). Early sexual debut means the adolescent is confronted with issues that could be 
beyond their ability to cope, particularly when female. This includes having riskier sexual partners, encountering gender norms and power issues especially when partners are older or physically more powerful, therefore minimising the adolescent's ability for safer sex negotiation (Tengia-Kessy et al., 1998; Mwakagile et al. 2001;Rickert, Sanghvi \& Wiemann, 2002).

Further, in working with adolescents for enhancement of safer sexual behaviours especially in sub-Saharan Africa, it is imperative to consider other factors that can reduce adolescents' sexual health risks (Parker, Easton \& Klein, 2000). These factors include sexual assertiveness, negotiating for condom use etc. Unfortunately, for most adolescents in sub-Saharan Africa, the topic of condoms either symbolises promiscuity or lack of trust and adolescents may prefer to keep quiet than bring up the topic (MacPhail \& Campbell, 2001). Skill building to improve adolescent sexual health should consider action planning to delay sex or to use condoms. Action planning has been suggested to be important in enhancing the likelihood that a healthy behaviour will occur (Eggers et al., 2014). In conclusion, adolescents need skills that will enable them to affirm healthier sexual behaviour including delaying sexual debut and using protective mechanisms when they decide to engage in sex.

\section{LIMITATIONS AND SUGGESTIONS FOR FUTURE RESEARCH}

A number of limitations are associated with this study. First is the fact that our study did not include other influential family members, though important in the African context and may have offered important insights. We only interviewed parents and a handful of guardians in the qualitative interviews, while previous research and even few parents in our sample suggested that aunts, uncles and grandparents should be the ones communicating with adolescents about sexuality (Fuglesang, 1997). Interviewing other family members may have given us insights into whether cross-generational sexual health communication has occurred and the modalities that made it possible. Second, most behavioural estimates from the study were based on self-reports that may be liable to desirability bias. We explicitly limited the possibility linking participants to their responses by providing learners with a unique identification on envelopes which held their questionnaires and asking the learners themselves to tape the envelopes. The interviewers also ensured that there was enough space between the learners when filling the questionnaires so that others could not see the responses. However, we cannot be completely certain that the learners felt comfortable enough to give honest responses without fear of being judged in a certain way. An addition of observational data could provide information with less bias. This is a consideration for future research, which will also add interesting findings. Third, the limited age-range of the study sample may limit the generalisability of the findings from the study to older adolescents as the age range of the adolescents involved ranged from 12 to 14 . Including older adolescents 
would have enabled us to explore the differences in sexual health communication and parenting practices with different age groups of adolescents. Also, peer influence has been suggested to increase with age, therefore including a wider age-range would have enriched our understanding of peer and influence and potential differences in these influences per age group (Steinberg \& Monahan, 2007). Another important limitation is that for the two quantitative studies that involved multiple testing, the possibility of getting a type 1 error and therefore the possibility of making wrong conclusions increases. The fifth limitation is for the two qualitative studies. Based on the nature of qualitative studies, it is almost impossible to make general conclusions (Ulin, Robinson \& Tolley, 2005). However, these studies enabled us to explore issues to gain understanding of trends in the nature of parent-adolescent sexual health communication and the associated practices.

\section{PRACTICAL IMPLICATIONS}

Although the HIV epidemic in Tanzania has been receding as evidenced by recent declines in prevalence rates (THIMS, 2011-12), there remains some concerns especially for early adolescence. Studies show that rates of HIV infection spike at an alarming rate during early adolescence and this is an important factor for sexual health work with adolescents below the age of 15 years (THIMS, 2011-12).

Findings in this dissertation show that there was more silence than parentadolescent sexual health communication. Further, when sexual health communication has occurred, it was fear-filled and vague. Some of the factors that are suggested to be causes for poor communication include cultural constraints, lack of skills or a belief that these adolescents are too young and therefore parents want to wait until they are older. However, considering the risks associated with early sexual debut, waiting could mean adolescents may already have engaged in risky sex. Encouraging parents to engage in sexual health communication with younger adolescents would improve adolescent adoption of protective behaviours earlier.

Lack of skills in communicating about sexual health among parents is also reported in this study. Therefore efforts to improve parent sexual health communication skills for the provision of appropriate sexual health information will go far in improving adolescent sexual health. Studies have shown that parents will talk to their children if given appropriate support (Bastien, Kajula \& Muhwezi, 2011). Programs working to reduce the effects of early and unsafe sex for adolescents need to work with parents to build required skills for communication. This will make parents as potential allies for improving adolescent sexual health. However, more research is needed to clarify the type of skills and knowledge that will have the utmost improvement in parent-adolescent sexual health communication. 
Parenting practices that encourage connectedness are reported to increase adolescent disclosure (Darling, Cumsille, Caldwell \& Dowdy, 2006). Parenting practices that involve emotional support, high standards, clear, bidirectional communication as well as appropriate autonomy granting and that are connected with the authoritative style of parenting are commended (Baumrind, 1991a; Darling, Cumsille, Caldwell \& Dowdy, 2006). Our findings suggest that parents used harsh parenting practices that may not foster connectedness and discourage adolescents to disclose or to initiate any sexual health communication with parents. By encouraging parents to adopt less harsh practices and engage in balancing warmth and control as utilised in the authoritative style of parenting, adolescent sexual health interventions may improve adolescent disclosure and parent-adolescent communication.

Since our study demonstrated that adolescents communicated more with peers than parents, strategies are needed to encourage adolescents to develop more positive norms and select peers with healthy sexual behaviours so that the influence from them will be health enhancing. Interventions working with adolescents need to focus on building skills for adolescents to gain attitudes that will point them in the direction of healthy choices. Good examples are two longitudinal school-based randomised controlled trials that were carried out by our team in Dar es Salaam, which included the use of peer educators. The peer educators were taught more intensively on peer-to-peer communication on issues related to sexuality and sexual health as well as skills to facilitate sexual health communication with teachers and parents (Kawai et al., 2008; Aaro et al., 2014). Programs that show positive effects in delaying sexual debut [Kawai et al., 2008] should be examined further so that they can adopted by other schools in the country.

Further, negotiation skills are an important resource for adolescents. These would increase the ability of adolescents to protect themselves by standing up for health enhancing choices even when it goes against what their partners want. Programs aiming to improve adolescent sexual health, should consider building skills for safer sex negotiation (Rickert, Sanghvi \& Wiemann, 2002).

National efforts for adolescent sexual health programs in Tanzania currently include an improved curriculum that includes HIV/AIDS and the provision of youth friendly clinics. However, since the curriculum does not include condom demonstration, linkages between schools and youth friendly clinics may have widespread benefits for adolescents as shown in our trial (Aaro et al., 2014; Mmbaga et al., in print). Further, linkages between schools and youth friendly clinics will enhance adolescents' self-efficacy in utilising the services. 


\section{FINAL CONCLUSIONS}

From the studies reported in this dissertation, several conclusions on parenting practices and sexual health communication with parents and peers can be reached. First, parents may improve their parenting practices by utilising more positive techniques by increasing connectedness and therefore enhance sexual health disclosure with their adolescent children. Adolescents may be more willing to engage in sexual health dialogue with their parents if fear of ridicule and punishment from parents is reduced. Second, while it is agreed that adolescents are susceptible to peer influence, improving parent-adolescent connectedness and adolescent disclosure would enable parents to guide their adolescent children to peers with more healthy sexual behaviours. Third, intervention programs that aim to improve adolescent sexual health should challenge dominant norms against condom use and also include skills on action planning for adolescent condom use. Finally, while the Tanzanian government has a policy on corporal punishment in schools, it is not so clear about corporal punishment and the use of harsh parenting practices at home. The health of the adolescent population in Tanzania would improve by enforcing policy changes that discourage parental use of harsh practices especially the use of corporal punishment. 


\section{REFERENCES}

Aad, G., Abat, E., Abdallah, J., Abdelalim, A. A., Abdesselam, A., Abdinov, O., ... \& Acharya, B. S. (2008). The ATLAS experiment at the CERN large hadron collider. Journal of Instrumentation, 3(8).

Aarø, L. E., Mathews, C., Kaaya, S., Katahoire, A. R., Onya, H., Abraham, C., ... \& De Vries, H. (2014). Promoting sexual and reproductive health among adolescents in southern and eastern Africa (PREPARE): project design and conceptual framework. BMC Public Health, 14(1), 1.

Babalola, S., Tambashe, B. O., \& Vondrasek, C. (2005). Parental factors and sexual risk- $\quad$ taking among young people in Cote d'Ivoire. African journal of reproductive health, 49-65.

Bankole, A., Biddlecom, A., Guiella, G., Singh, S., \& Zulu, E. (2007). Sexual behavior, knowledge and information sources of very young adolescents in four sub-Saharan African countries. African journal of reproductive health,11(3), 28.

Barrington, M. J., Watts, S. A., Gledhill, S. R., Thomas, R. D., Said, S. A., Snyder, G. L., ... \& Jamrozik, K. (2009). Preliminary results of the Australasian Regional Anaesthesia Collaboration: a prospective audit of more than 7000 peripheral nerve and plexus blocks for neurologic and other complications. Regional anesthesia and pain medicine, 34(6), 534-541.

Bastien, S., Kajula, L. J., \& Muhwezi, W. W. (2011). A review of studies of parent-child communication about sexuality and HIV/AIDS in sub-Saharan Africa. Reproductive health, 8(1), 1.

Baumrind, D. (1991). The influence of parenting style on adolescent competence and substance use. The Journal of Early Adolescence, 11(1), 56-95.

Baumrind, D. (1991). Effective parenting during the early adolescent transition. Family transitions, 2, 111-163.

Darling, N., Cumsille, P., Caldwell, L. L., \& Dowdy, B. (2006). Predictors of adolescents' disclosure to parents and perceived parental knowledge: Between-and within-person differences. Journal of Youth and Adolescence, 35(4), 659-670.

Eggers, S. M., Aarø, L. E., Bos, A. E., Mathews, C., \& de Vries, H. (2014). Predicting condom use in South Africa: a test of two integrative models. AIDS and Behavior, 18(1), 135-145.

Fuglesang, M. (1997). Lessons for life-Past and present modes of sexuality education in Tanzanian society. Social Science \& Medicine, 44(8), 1245-1254.

Guilamo-Ramos, V., Jaccard, J., Dittus, P., \& Bouris, A. M. (2006). Parental expertise, trustworthiness, and accessibility: Parent-adolescent communication and adolescent risk behavior. Journal of Marriage and Family, 68(5), 1229-1246.

Henry, D. B., Schoeny, M. E., Deptula, D. P., \& Slavick, J. T. (2007). Peer selection and socialization effects on adolescent intercourse without a condom and attitudes about the costs of sex. Child development, 78(3), 825-838.

Huebner, A. J., \& Howell, L. W. (2003). Examining the relationship between adolescent sexual risk-taking and perceptions of monitoring, communication, and parenting styles. Journal of adolescent health, 33(2), 71-78.

Jearey-Graham, N., \& Macleod, C. (2015). A discourse of disconnect: young people from the Eastern Cape talk about the failure of adult communications to provide habitable sexual subject positions. Perspectives in Education, 33(2), 11-29.

Kajula, L. J., Darling, N., Kaaya, S. F., \& De Vries, H. (2016). Parenting practices and styles associated with adolescent sexual health in Dar es Salaam, Tanzania. AIDS care, 1-6.

Kajula, L. J. (2005). Cross-generation communication on sexuality in times of HIV/AIDS as perceived by adolescent girls and their parents in Dar es Salaam, Tanzania. University of Bergen, Norway.

Kawai, K., Kaaya, S. F., Kajula, L., Mbwambo, J., Kilonzo, G. P., \& Fawzi, W. W. (2008). Parents' and teachers' communication about HIV and sex in relation to the timing of sexual initiation among young adolescents in Tanzania. Scandinavian Journal of Public Health, 36(8), 879-888.

Kirby, D., \& Miller, B. C. (2002). Interventions designed to promote parent-teen communication about sexuality. New directions for child and adolescent development, 2002(97), 93-110.

Kohler, H. P., Behrman, J. R., \& Watkins, S. C. (2007). Social networks and HIV/AIDS risk perceptions. Demography, $44(1)$. 
Kumi-Kyereme, A., Awusabo-Asare, K., Biddlecom, A., \& Tanle, A. (2007). Influence of social connectedness, communication and monitoring on adolescent sexual activity in Ghana. African journal of reproductive health, 11(1), 133.

Lashbrook, J. T. (2000). Fitting in: Exploring the emotional dimension of adolescent peer pressure. Adolescence, 35(140), 747.

Leow, A., Ajilore, O., Zhan, L., Arienzo, D., GadElkarim, J., Zhang, A., ... \& Thompson, P. (2013). Impaired interhemispheric integration in bipolar disorder revealed with brain network analyses. Biological psychiatry, 73(2), 183-193.

MacPhail, C., \& Campbell, C. (2001). 'I think condoms are good but, aai, I hate those things':: condom use among adolescents and young people in a Southern African township. Social science \& medicine, 52(11), 1613-1627.

Magadi, M. A., \& Agwanda, A. O. (2009). Determinants of transitions to first sexual intercourse, marriage and pregnancy among female adolescents: evidence from South Nyanza, Kenya. Journal of biosocial science, 41(03), 409-427.

Mmari, K., \& Blum, R. W. (2009). Risk and protective factors that affect adolescent reproductive health in developing countries: a structured literature review. Global public health, 4(4), 350-366.

Mmbaga, E. J., Leonard, F., \& Leyna, G. H. (2012). Incidence and predictors of adolescent's early sexual debut after three decades of HIV interventions in Tanzania: a time to debut analysis. PLoS One, 7(7), e41700.

Mercken, L., Candel, M., Willems, P., \& De Vries, H. (2007). Disentangling social selection and social influence effects on adolescent smoking: the importance of reciprocity in friendships. Addiction, 102(9), 14831492.

Mwakagile, D., Mmari, E., Makwaya, C., Mbwana, J., Biberfeld, G., Mhalu, F., \& Sandström, E. (2001). Sexual behaviour among youths at high risk for HIV-1 infection in Dar es Salaam, Tanzania. Sexually Transmitted Infections, 77(4), 255-259.

Parker, R., Easton, D., \& Klein, C. (2000). Structural Barriers and Facilitators in HIV Prevention: A Review of International Research. AIDS, 14. S22-S32. http://dx. doi. org/10.1097/00002030-200006001-00004.

Plummer, M. L., Ross, D. A., Wight, D., Changalucha, J., Mshana, G., Wamoyi, J., ... \& Hayes, R. J. (2004). "A bit more truthful": the validity of adolescent sexual behaviour data collected in rural northern Tanzania using five methods. Sexually transmitted infections, 80(suppl 2), ii49-ii56.

Rickert, V. I., Sanghvi, R., \& Wiemann, C. M. (2002). Is lack of sexual assertiveness among adolescent and young adult women a cause for concern? Perspectives on sexual and reproductive health, 178-183.

Romer, D., Black, M., Ricardo, I., Feigelman, S., Kaljee, L., Galbraith, J., ... \& Stanton, B. (1994). Social influences on the sexual behavior of youth at risk for HIV exposure. American Journal of Public Health, 84(6), $977-$ 985.

Rweyemamu, D., \& Fuglesang, M. (2008). Multiple and concurrent sexual partnerships among youth in Tanzania. Research study commissioned by Femina HIP.

Schuster, M. A., Corona, R., Elliott, M. N., Kanouse, D. E., Eastman, K. L., Zhou, A. J., \& Klein, D. J. (2008). Evaluation of Talking Parents, Healthy Teens, a new worksite based parenting programme to promote parent-adolescent communication about sexual health: randomised controlled trial. bmj, 337, a308.

Short, M. B., \& Rosenthal, S. L. (2008). Psychosocial development and puberty. Annals of the New York Academy of Sciences, 1135(1), 36-42.

Sommer, M., Likindikoki, S., \& Kaaya, S. (2015). "Bend a fish when the fish is not yet dry": adolescent boys' perceptions of sexual risk in Tanzania. Archives of sexual behavior, 44(3), 583-595.

Stattin, H., \& Kerr, M. (2000). Parental monitoring: A reinterpretation. Child development, 71(4), 1072-1085.

Simbayi, L. C., Kalichman, S. C., Jooste, S., Cherry, C., Mfecane, S., \& Cain, D. (2005). Risk factors for HIV-AIDS among youth in Cape Town, South Africa. AIDS and Behavior, 9(1), 53-61.

Steinberg, L., \& Monahan, K. C. (2007). Age differences in resistance to peer influence. Developmental psychology, 43(6), 1531.

Steinberg, L., Fletcher, A., \& Darling, N. (1994). Parental monitoring and peer influences on adolescent substance use. Pediatrics, 93(6), 1060-1064. 
Tanzania, H. I. V. "AIDS and malaria indicator survey 2011-12." Dar es Salaam: Tanzania Commission for AIDS (2013).

Tengia-Kessy, A., Msamanga, G. I., \& Moshiro, C. S. (1998). Assessment of behavioural risk factors associated with HIV infection among youth in Moshi rural district, Tanzania. East African medical journal, 75(9), 528532.

Ulin, P. R., Robinson, E. T., \& Tolley, E. E. (2005). Qualitative methods in public health. San Francisco, CA: JosseyBass.

Wamoyi, J., Fenwick, A., Urassa, M., Zaba, B., \& Stones, W. (2010). Parent-child communication about sexual and reproductive health in rural Tanzania: Implications for young people's sexual health interventions. Reproductive Health, 7(1), 1.

Wood, K., Lambert, H., \& Jewkes, R. (2007). "Showing roughness in a beautiful way": talk about love, coercion, and rape in South African youth sexual culture. Medical anthropology quarterly, 21(3), 277-300.

World Health Organization. (2000). The world health report 2000: health systems: improving performance. World Health Organization.

World Health Organization (WHO)"Risk and protective factors affecting adolescent reproductive health in developing countries." 2004.

Yamanis, T. J., Maman, S., Mbwambo, J. K., Earp, J. A. E., \& Kajula, L. J. (2010). Social venues that protect against and promote HIV risk for young men in Dar es Salaam, Tanzania. Social Science \& Medicine, 71(9), 1601-1609.

Yamanis, T. J., Fisher, J. C., Moody, J. W., \& Kajula, L. J. (2015). Young men's social network characteristics and associations with sexual partnership concurrency in Tanzania. AIDS and Behavior, 1-12. 

Summary 

Parent - adolescent relationship remains one of the most influential for adolescent sexual health outcomes. Studies indicate that parent-child connectedness and resulting communication is associated with reduced adolescent risky behaviors. Effectiveness of preventive programs targeting adolescents has been suggested to improve when they include important contextual stakeholders such as parents and peers.

Findings reported in this dissertation focus on two main goals. The first is to describe parenting practices associated with adolescent sexual health while the second is aimed at improving understanding of parent and peer sexual health communication with adolescents. Concerns of parent-adolescent sexual health communication in Tanzania and the associated parenting practices are described in detail. Results from chapters 2-6 suggest that the parent-adolescent sexual health communication reported in this study were mostly uni-directional rather than bi-directional. Parents are reported to mostly use fear-filled messages to dissuade their children from engaging in sex. These messages were also suggested to be vague. Also, parents were suggested to communicate after they suspect that their adolescent offspring are already engaging in intimate relationships. Further, results presented in this thesis suggest that the most prominent parenting practices by parents are prevention, punishment and monitoring of both sexual behaviour and adolescents' close friends. There was also predominance of strictness and a demand for obedience indicative of the authoritarian style of parenting. Furthermore, peer sexual health communication was reported to be happening more frequently than sexual health communication with parents.

Several conclusions on parenting practices and sexual health communication with parents and peers can be drawn from findings reported in this thesis. First, adolescent sexual health interventions need to take into consideration parenting practices to improve parent-adolescent connectedness and communication. Second, for parents to improve their parenting practices, they need to be enabled in adopting more positive techniques with less of harsh parenting which will enhance adolescent disclosure and improve communication. This requires targeted sexual health communication interventions addressing parent adolescent connectedness and alternative means of disciplining. Third, Adolescents may be more willing to engage in sexual health dialogue with their parents if fear of ridicule and punishment from parents is reduced.

Consequently, an important recommendation to be considered in adolescent sexual health interventions is for parents to hold constructive sexual health communication with their younger adolescent offspring so as to delay sexual initiation and engage in safer sex when they start intimate relationships. 

Valorisation addendum 



\section{RELEVANCE}

Parenting of adolescents is challenging for most parents. Sexual socialisation in a context that considers parent-adolescent sexual health communication taboo is an additional challenge for parents [Fuglesang, 1997]. Adolescents in sub-Saharan Africa, including Tanzania are faced with a multitude of risks associated with early sexual debut including unplanned pregnancies, STIs and HIV specifically [Kazaura \& Masatu, 2009; Mmbaga, Leonard \& Leyna, 2012]. In ensuring that their adolescent children do not engage in sexual activities that could increase the risks associated with early sexual debut, parents in this study were reported to use harsh parenting practices and fearbased messages in communication. Parents have set strict rules at home with the aim of limiting the possibility of their adolescent children to engage in sexual activities. Parents in our study were reported to use spanking and threats to ensure adolescents follow the set rules. While we acknowledge cultural variations in parenting and that some parents may be in favour of punitiveness as a way of protecting their adolescent children from engaging in sexual behaviours, these practices could have a negative effect to adolescent sexual health. Studies have shown that spanking, rejection and fear inducement are associated with low warmth and could further alienate adolescents instead of improving connectedness and information sharing [Darling, Cumsille, Caldwell \& Dowdy, 2006; Kajula et al., 2016]. A number of studies on family processes and adolescent sexual behaviour have indicated that parent-child connectedness is associated with reduced adolescent sexual risky behaviours [Miller et al., 2001; Jaccard, Dittus \& Gordon, 1996].

Our findings show that parents do communicate with their adolescent children. However, the nature of the communication is uni-directional, ambiguous and fear inducing. Also, the punitive strategies that were reportedly used by parents seemed to further alienate their adolescent children and reduce sexual health communication. Therefore, working with parents and their adolescent children to improve connectedness, enhance sexual health communication and encourage adolescent disclosure is recommended in order to contribute to a delay of sexual debut and encourage safer sexual practices when it happens.

\section{TARGET GROUPS}

Results presented in this dissertation suggest a potential direction in confronting sexual health challenges facing the adolescent population of Tanzania. These efforts would include moving from personal to proximal issues especially the context in which adolescents live.

First are the adolescents themselves. Research from Tanzania has shown a high spike in HIV infection for adolescents after age 15. It is therefore imperative to work 
with younger adolescents and improve their action planning to delay sex and improve condom use. From the intervention that has been presented in this thesis, action planning for delayed sex seems to be having a positive effect. Using information from our findings, interventions could be planned with adolescents to increase action planning for delaying sex. Further, while knowledge for HIV/AIDS is quite high for the Tanzanian population including adolescents, sexual protective measures are used at almost 40\% [THIMS, 2011-12]. Therefore adolescents need to increase action planning for condom use. This will be a positive direction to reducing early pregnancy, HIV and other STIs when adolescents start having sex. Adolescents would also benefit from learning negotiating skills to enable them to negotiate delaying sex, condom use as well as being able to counter negative peer influence.

Secondly for parents, positive parenting approaches that could lead to better adolescent sexual health outcomes could be useful. Interventions aimed at parents including discussions on the unintentional negative consequences of authoritarian parenting styles and punitive practices could improve parent-adolescent connectedness, which will in turn improve adolescent disclosure. Parents would also be at an added advantage to learn skills in authoritative parenting using a mixture of warmth and control. Communication skills are also important for parents to improve how and what they communicate to their adolescent children regarding sexual health.

Third, for the level of policy makers, two things are to be considered. This is the level where policies are made, leading to budgeting for health programs. Results of this study might be of interest for the Ministry of Health, Gender, Community Development, Elderly and Children of Tanzania, Tanzania (MoHCDGEC), Commission for AIDS (TACAIDS) and National AIDS Control Program (NACP) amongst others. All these organisations and others that work to improve youth sexual health are urged to include parents in sexual health programs for adolescents. Another issue of emphasis for this level is to increase and improve youth friendly services. These services are of added importance since the current school curriculum in Tanzania does not allow condom demonstrations, however engaging youth friendly clinics for the same provides needed services for adolescents.

\section{ACTIVITY AND PRODUCTS}

Findings presented in this study have documented improved action planning for delayed sex and condom use for adolescents. It is therefore recommended to increase implementation of similar activities in other primary schools. The manuals that were produced should be increased in number and the teachers that were trained during the intervention could be engaged to train other teachers. In addition, parent sessions should be adapted from other programs that have reported positive results in Tanzania to improve adolescent sexual health such as the MEMA KWA VIJANA project [Wamoyi et al., 2010]. 


\section{INNOVATION}

Focusing on action planning will be a new direction since most programs in Tanzania are still keen on improving knowledge. However, since knowledge seems not to be an issue for most Tanzanian adolescents [THIMS, 2011-12], action planning and skill building will mean that adolescents are better prepared to confront challenges in delaying sex, condom use and negative peer influence. The combination of improving sociocognitive factors for adolescents and improving parenting practices will also be an improvement for Tanzania, since most programs focus on adolescents only.

\section{SCHEDULE AND IMPLEMENTATION}

Due to the encouraging findings from our study, implementation to more schools is recommended. An important first step would be to work with municipalities and the ministry of education so that training manuals from the PREPARE project can be adopted. Our team already has experience in working with the Kinondoni municipal in Dar es Salaam, therefore adding other municipalities will the logical step.

The second step would be to liaise with the Tanzania Committee for AIDS (TACAIDS), National AIDS Control Programme (NACP) and the Ministry of Health, Community Development, Gender, the Elderly and Children (MoHCDGEC) to discuss the possibility of increasing the number of manuals. Due to budgetary constraints, the municipalities are underfunded and therefore cannot afford to increase the number of manuals without further support.

To ensure that the program is carried out as required, monitoring and evaluation should be carried out. Monitoring will also ensure that any challenges in implementation are met before they progress to a worse state. 

Curriculum Vitae 



\section{PERSONAL INFORMATION}

Name: (including title) Ms. Lusajo Kajula Nationality: Tanzanian

Email address: sajokm@gmail.com

\section{PRIMARY AFFILIATION}

Department of Psychiatry, Muhimbili University of Health and Allied Sciences (MUHAS)

\section{EMPLOYMENT HISTORY}

Nov 2002 - Mar 2006: Tutorial Assistant, Department Psychiatry \& Mental Health, Muhimbili University College of Health Sciences (MUCHS)

March 2006 to date: Assistant Lecturer, Department Psychiatry \& Mental Health, Muhimbili University of Health and Allied Sciences

\section{EDUCATION AND QUALIFICATIONS}

\begin{tabular}{llll}
\hline Institution and location & Degree & Date & Field \\
\hline Aligarh University, India & BA (Honours) & $1994-1997$ & Psychology \\
University of Bergen, Norway & MPhil & $2002-2005$ & Health Promotion \\
University of Maastricht, & PhD & $2011-$ Ongoing & Health Promotion \\
Netherlands & & & \\
\hline
\end{tabular}

\section{CURRENT FUNDING}

NIH 1R01MH098690-01 Kajula, L \& Maman, S (PI) 2012 to 2017. Intervention trial for networks of young men: a cluster-randomized intervention trial to evaluate the efficacy of an intervention that combines microfinance with health promotion for networks of young men (15-24 years) who socialize in what are called camps in Dar es Salaam, Tanzania.

Role: Local PI

\section{PROFESSIONAL INVOLVEMENT}

2008 - Member: Mental Health Association of Tanzania (MEHATA) 
2009 - Member: Tanzania Psychological Association (TAPA)

2012 - Affiliate member: Psychological Society of South Africa (PsySSA)

2014 - Member: Pan African Psychological Union (PAPU)

\section{SUPERVISION AND MENTORING}

Deborah Salehe (MSc Supervisor) Final year, Master's program Saldin Kimangale (MSc Supervisor) Final year, Master's program

Lisbeth Mhando (MSc Supervisor) Clinical Psychologist, Arusha, Tanzania

Liness Ndelwa (MSc Supervisor) Clinical Psychologist, Mbeya refferal Hospital, Mbeya, Tanzania

Sarah (MSc Supervisor) Lecturer, Tumaini University, Iringa, Tanzania

Masunga Iseselo (MSc supervisor) Assistant Lecturer, MUHAS, Dar es Salaam, Tanzania

Isaac Lema (MSc supervisor) Assistant Lecturer \& Clinical Psychologist, MUHAS, Tanzania

\section{ADDITIONAL INFORMATION}

My knowledge and expertise include the development, implementation and testing of interventions that aim to tackle different challenges including HIV related stigma, risky sexual behaviour among adolescents and youth, Intimate Partner Violence (IPV), Violence against Children (VAW) as well as parenting and family interactions. Since 2002, I have been involved in a number of international collaborations that addressed adolescent and youth sexual behavior in Sub-Saharan Africa. 


\section{List of publications}

\section{FOR THIS THESIS}

1. Bastien, S., Kajula, L. J., \& Muhwezi, W. W. (2011). A review of studies of parentchild communication about sexuality and HIV/AIDS in sub-Saharan Africa. Reproductive health, 8(1), 25.

2. Kajula, L. J., Sheon, N., De Vries, H., Kaaya, S. F., \& Aarø, L. E. (2014). Dynamics of parent-adolescent communication on sexual health and HIV/AIDS in Tanzania. AIDS and Behavior, 18(1), 69-74.

3. Kajula, L. J., Darling, N., Kaaya, S. F., \& De Vries, H. (2016). Parenting practices and styles associated with adolescent sexual health in Dar es Salaam, Tanzania. AIDS care, 28(11), 1467-1472.

4. Kajula, L. J., Eggers, S. M., Kaaya, S. F., \& De Vries, H. Factors Associated with Adolescent Sexual Health Communication with Parents and Peers in Dar es Salaam, Tanzania. (To be submitted).

5. Kajula, L. J., Mmbaga, E. J., Eggers, S. M., Kaaya, S. F., Aarø, L. E., \& De Vries, H. Sexual Health Communication Among Adolescents, Peers and Parents in Dar es Salaam Tanzania: A Cluster Randomized Controlled Trial. (To be submitted).

\section{OVERALL}

1. Mulawa, M. I., Reyes, H. L. M., Foshee, V. A., Halpern, C. T., Martin, S. L., Kajula, L. J., \& Maman, S. (2017). Associations between peer network gender norms and the perpetration of intimate partner violence among urban Tanzanian men: a multilevel analysis. Prevention science, 1-10.

2. Mulawa, M. I., Kajula, L. J., \& Maman, S. (2017). Peer network influence on intimate partner violence perpetration among urban Tanzanian men. Culture, Health \& Sexuality, 1-15. 
3. Yamanis, T. J., Dervisevic, E., Mulawa, M., Conserve, D. F., Barrington, C., Kajula, L. J., \& Maman, S. (2017). Social network influence on HIV testing among urban men in Tanzania. AIDS and Behavior, 21(4), 1171-1182.

4. Hill, L. M., Maman, S., Kilonzo, M. N., \& Kajula, L. J. (2017). Anxiety and depression strongly associated with sexual risk behaviors among networks of young men in Dar es Salaam, Tanzania. AIDS care, 29(2), 252-258.

5. Mmbaga, E. J., Kajula, L., Aarø, L. E., Kilonzo, M., Wubs, A. G., Eggers, S. M., ... \& Kaaya, S. (2017). Effect of the PREPARE intervention on sexual initiation and condom use among adolescents aged 12-14: a cluster randomised controlled trial in Dar es Salaam, Tanzania. BMC public health,17(1), 322.

6. Jennings, L., Conserve, D. F., Kajula, L., Iwelunmor, J., \& Maman, S. (2017). Perceived Cost Advantages and Disadvantages of Purchasing HIV Self-Testing Kits among Urban Tanzanian Men: An Inductive Content Analysis.Annals of Global Health, 83(1), 66-67.

7. Conserve, D., Kajula, L., Yamanis, T., \& Maman, S. (2016, December). Formative Research to Develop Human Immunodeficiency Virus (HIV) Self-Testing Intervention Among Networks of Men in Dar es Salaam, Tanzania: A Mixed Methods Approach. In Open Forum Infectious Diseases (Vol. 3, No. suppl_1). Oxford University Press.

8. Kajula L., Kaaya SF, Darling N \& De Vries H. (2016). Parenting practices and styles associated with adolescent sexual health in Dar es Salaam, Tanzania. AIDS Care.

9. Iseselo M, Kajula L \& Yahya-Malima K. (2016). The psychosocial problems of families caring for relatives with mental illnesses and their coping strategies: a qualitative urban based study in Dar es Salaam, Tanzania. BMC Psychiatry.

10. Kajula L, Balvans P, Kilonzo M, Mwikoko G et al., (2016) Vijana Vijiweni II: a clusterrandomized trial to evaluate the efficacy of a microfinance and peer health leadership intervention for HIV and intimate partner violence prevention among social networks of young men in Dar es Salaam. BMC Public Health.

11. Mulawa M, Yamanis T, Balvans P, Kajula L, \& Maman S. (2016). Comparing Perceptions with Actual Reports of Close Friend's HIV Testing Behavior Among Urban Tanzanian Men. AIDS and Behavior, 2016.

12. Mulawa M, Yamanis T, Hill L, Balvanz P, Kajula L, \& Maman S. (2016). Evidence of social network influence on multiple HIV risk behaviors and normative beliefs among young Tanzanian men. Social Science Medicine.

13. Maman S, Kajula L, Balvans P, Kilonzo M, Mulawa M \& Yamanis T. (2015). Leveraging strong social ties among young men in Dar es Salaam: a pilot intervention of microfinance and peer leadership for HIV and gender-based violence prevention. Global Public Health. 
14. Yamanis T, Fisher J, Mood J \& Kajula L. (2015). Young Men's Social Network Characteristics and Associations with Sexual Partnership Concurrency in Tanzania. AIDS and Behavior.

15. Mulawa M, Reyes HL, Foshee V, Halperin C, Kajula L \& Maman S. (2015). Networklevel factors associated with IPV perpetration among young urban Tanzanian men. Journal of the International AIDS Society.

16. Namisi, F., Aarø, L. E., Kaaya, S., Kajula, L. J., Kilonzo, G. P., Onya, H., ... \& Mathews, C. (2015). Adolescents' communication with parents, other adult family members and teachers on sexuality: effects of school-based interventions in South Africa and Tanzania. AIDS and Behavior, 19(12), 2162-2176.

17. Kajula, L., Sheon, N., De Vries, H., Kaaya, S. F., \& Aaro, L. E (2014). Dynamics of Parent-adolescent Sexual Health and HIV/AIDS in Tanzania. AIDS and Behavior.

18. Jessica A. Fehringer, Stella Babalola, Caitlin E. Kennedy, Lusajo J. Kajula, Jessie K. Mbwambo \& Deanna Kerrigan (2012): Community perspectives on parental influence on engagement in multiple concurrent sexual partnerships among youth in Tanzania: Implications for HIV prevention programming, AIDS Care: Psychological and Sociomedical Aspects of AIDS/HIV.

19. Thespina J. Yamanis, Irene A. Doherty, Sharon S. Weir, James M. Bowling, Lusajo J. Kajula, Jessie K. Mbwambo \& Suzanne Maman. From Coitus to Concurrency: Sexual Partnership Characteristics and Risk Behaviors of 15-19 Year Old Men Recruited from Urban Venues in Tanzania. AIDS Behav 2012.

20. Bastien, S., Kajula, L., \& Muhwezi, W. (2011). A review of studies of parent-child communication about sexuality and HIV/AIDS in sub-Saharan Africa. Reproductive Health Journal.

21. Yamanis, T. J., Maman, S., Mbwambo, J. K., Earp, J. A. E., \& Kajula, L. J. (2010). Social isk for young men in Dar es Salaam, Tanzania. Svenues that protect against and promote HIV rocial Science \& Medicine, 71(9), 1601-1609.

22. Kawai, K., Kaaya, S. F., Kajula, L., Mbwambo, J., Kilonzo, G. P., \& Fawzi, W. F. (2008). Parents' and teachers' communication about HIV and sex in relation to the timing of sexual initiation among young adolescents in Tanzania. Scandinavian Journal of Public Health, 36(8), 879-888.

23. Nyblade, L., MacQuarrie, K., Kwesigabo, G., Jain, A., Kajula, L., Philip, F., Tibesigwa, W. H., \& Mbwambo, J. (2008). "Moving forward: Tackling stigma in a Tanzanian community," Horizons Final Report. Washington, DC: Population Council. 


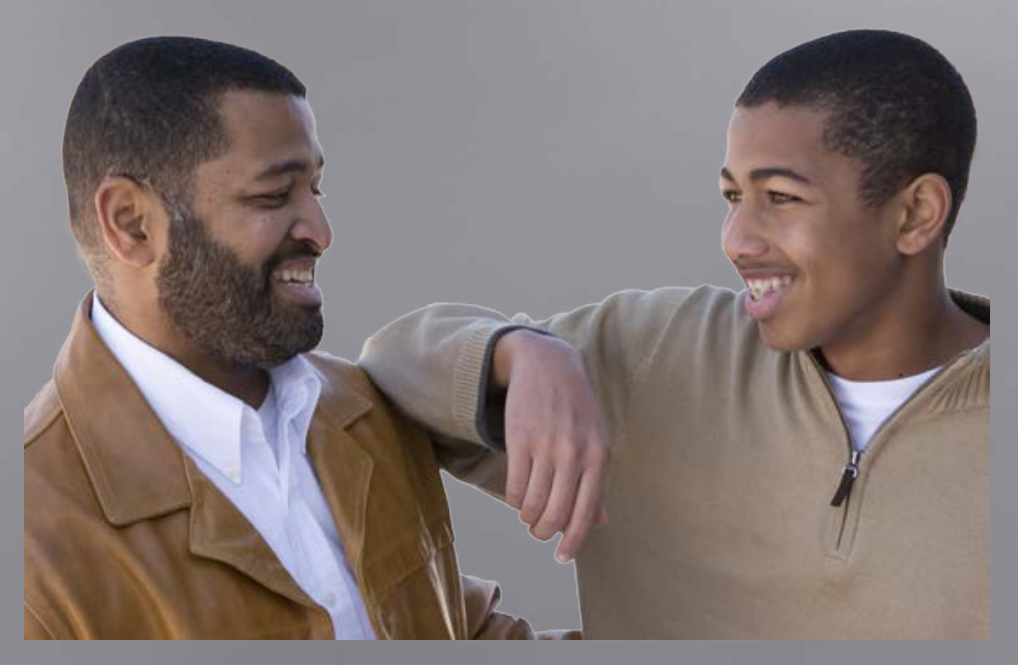

